\title{
FINAL SCIENTIFIC TECHNICAL REPORT
}

Project Title: Advanced Nanostructured Molecular Sieves for Energy Efficient Industrial Separations

Date of Report: December $31^{\text {st }}, 2011$

Recipient Organization: Rive Technology, Inc., One Canal Park, $4^{\text {th }}$ floor, Cambridge, MA, 02141-2234

Award Number: DE-EE0003470

Project Period: Aug. $1^{\text {st }}, 2010$ to Dec. $31^{\text {st }}, 2011$

Contacts: Kunhao (Eric) Li, Principal Investigator, Eric.Li@rivetechnology.com

Tel.: 732-329-4448; FAX: 732-329-4464

Michael Beaver, Research Engineer, Michael.Beaver@rivetechnology.com

Tel.: 732-329-4478; FAX: 732-329-4464

Drew McGillivary, Business Contact, drew@rivetechnology.com

Tel.: 617-528-2806

Project Team: Gibson Asuquo, 303-275-4910, gibson.asuquo@go.doe.gov

Kristen McDaniel, 720-356-1285, kristen.mcdaniel@go.doe.gov

Dickson Ozokwelu, 202-586-8501, dickson.ozokwelu@hq.doe.gov

Tina Kouch, 303-275-6045, christina.kouch@go.doe.gov

Project Objective: The objective of this project is to explore the application of the company's proprietary mesoporous zeolite technology to large-scale, energy-intensive separations in the chemical industry, specifically propane and propylene separation. Rive Technology proposes to achieve these objectives by producing zeolitic materials with different degrees of mesoporosity and testing these materials in a bench-scale unit to generate kinetic and equilibrium separation data. Upon completion of the project, Rive will have demonstrated applicability of the technology in the process with sufficient experimental results and modeling data to interest partners in working with us to translate the technology into commercial use. 
Document Availability: Reports are available free via the U.S. Department of Energy (DOE) Information Bridge: Web Site http://www.osti.gov/bridge

Reports are available to DOE employees, DOE contractors, Energy Technology Data Exchange (ETDE) representatives and Informational Nuclear Information System (INIS) representatives from the following source:

Office of Scientific and Technical Information

P.O. Box 62

Oak Ridge, TN 37831

Tel: (865) $576-8401$

Fax: (865) 576-5728

E-mail: reports@osti.gov

Web Site: http://www.osti.gov/contact.html

Acknowledgment: This report is based upon work supported by the U. S. Department of Energy under Award No. DE-EE0003470

Disclaimer: Any findings, opinions, and conclusions or recommendations expressed in this report are those of the author(s) and do not necessarily reflect the views of the Department of Energy. 


\section{Table of Contents}

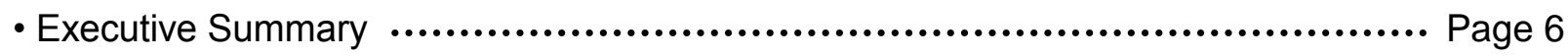

•Introduction ................................................................................. Page 7

- Materials Preparation and Characterization …........................................... Page 11

-Pulse Test Unit and Adsorbent Testing ................................................... Page 22

• Energy Saving Calculation

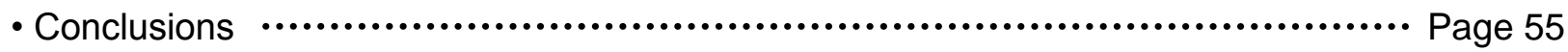

- Patents/Publications ..................................................................... Page 56

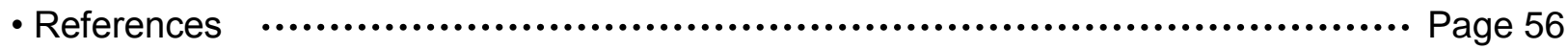

-Appendix

\section{List of Figures and Tables}

Figure 1 TEM micrographs showing a zeolite before (left) and after (right) the incorporation of mesopores n....................................................... Page 8

Figure 2 Catalytic performance of catalysts based on a meosoporous zeolite (RiveCat) and a conventional zeolite ................................................. Page 9

Figure 3 Cumulative and pore size distribution of rived and unrived $Y$ zeolite (top) and pore volume dependence on citric acid amount (bottom) …................... Page 12

Figure $4 \quad X R D$ powder diffraction patterns of unrived and rived Na-Y (CBV100) samples at

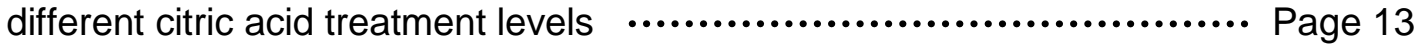

Figure 5 Effect of $\mathrm{pH}$ on crystallinity of $\mathrm{NaY}, \mathrm{NaX}$ and $\mathrm{NaA}$ zeolites …............ Page 13

Figure $6 \quad X R D$ powder pattern of unrived and rived $X$ samples at different levels of citric acid

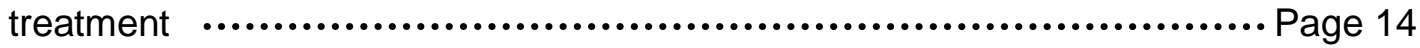

Figure 7 Argon adsorption isotherms and the corresponding DFT cumulative and differential pore size distribution of an unrived $5 \mathrm{~A}$ zeolite (blue)) and rived $4 \mathrm{~A}$ zeolites by the normal riving procedure (red) and the modified procedure (green) …...... Page 15

Figure 8 TEM images of an unrived NaA zeolite crystal. The picture on right is a digital

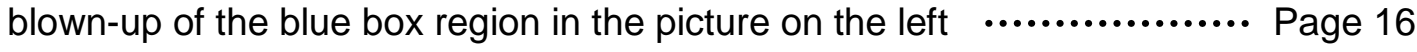


Figure 9 TEM images of a rived $\mathrm{Na}-\mathrm{A}$ sample by the normal procedure. The picture on right is a digital blown-up of the blue box region in the picture on the left...... . Page 17

Figure 10 TEM images of a rived Na-A sample by the modified procedure. The picture on right is a digital blown-up of the blue box region in the picture on the left..... . Page 17

Figure 11 Cumulative and differential pore size distribution of $\mathrm{NaY}$ rived with $\mathrm{NaOH}$ and $\mathrm{NH}_{4} \mathrm{OH}$ Page 18

Figure 12 Micropore and mesopore (20-80 $\mathrm{A}$ ) volumes of rived NaX showing that $\sim 10 \mathrm{~g}$ of $50 \%$ $\mathrm{NaOH}$ per $100 \mathrm{~g}$ of starting $\mathrm{NaX}$ zeolite is optimal. Similar effects were also found

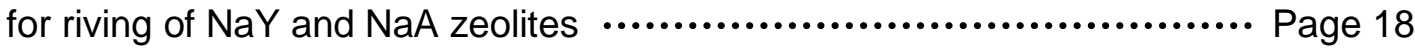

Figure 13 Current preparation process scheme for laboratory adsorbent particles .... Page 20

Figure 14 A schematic of the pulse test unit built and used in this project........... Page 22

Figure 15 Comparison of Pulse Test Experiments on Commercial NaX(left) and Rived NaX

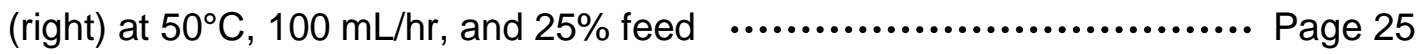

Figure 16 Comparison of pulse test results on Commercial NaX (left) and Rived NaX (right) at

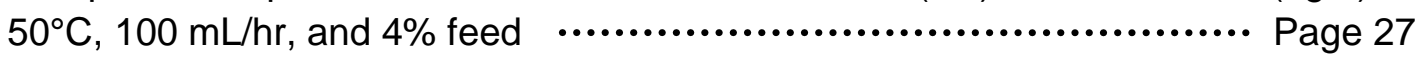

Figure 17 Arrhenius plot showing temperature dependence of $\mathrm{C}_{3} \mathrm{H}_{6}$ transport in Rived and Unrived NaX zeolites Page 30

Figure 18 Propylene adsorption isotherms on Commercial NaX (top), Rived NaX (middle), and In-house UnRived NaX (bottom) zeolites Page 33

Figure 19 Propane adsorption isotherms on Commercial NaX (top), Rived NaX (middle), and In-house Unrived NaX (bottom)zeolites - Page 34

Figure 20 Pulse test results on UnRived NaY zeolite (left) and Rived NaY zeolite (right) at $50^{\circ} \mathrm{C}, 100 \mathrm{~mL} / \mathrm{hr}$, and $25 \%$ feed concentration . Page 36

Figure 21 Pulse test tesults on UnRived NaY zeolite (left) and Rived NaY zeolite (right) at

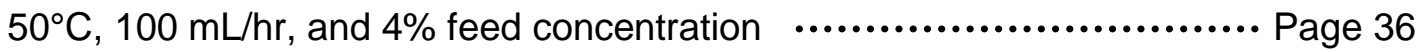

Figure 22 Arrhenius plot showing temperature dependence of $\mathrm{C}_{3} \mathrm{H}_{6}$ and $\mathrm{C}_{3} \mathrm{H}_{8}$ transport in Rived and Unrived NaY zeolites Page 39

Figure 23 Propylene adsorption isotherms on Rived NaY (top) and Unrived NaY (bottom) ....

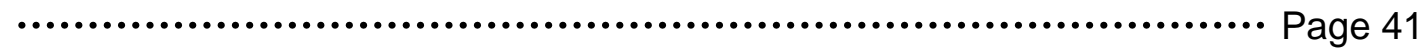

Figure 24 Propane adsorption isotherms on Rived NaY (top) and Unrived NaY (bottom) .....

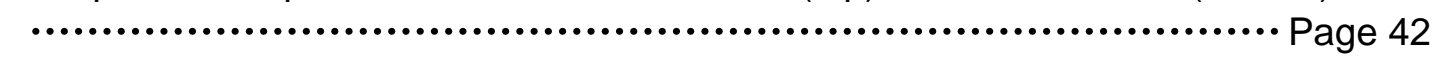

Figure 25 Schematic of True Moving Bed adsorption system and corresponding liquid

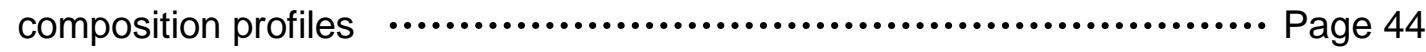


Figure 26 Schematic of Simulated Moving Bed adsorption system …............... Page 45

Figure 27 Schematic of a hypothetical integrated 4-bed SMB unit for processing 6000 BPSD $\mathrm{C}_{3}$ stream

Figure 28 Region of complete separation in the $\left(\mathrm{m}_{2}, \mathrm{~m}_{3}\right)$ plane, $\mathrm{K}_{A}=1.5, \mathrm{y}_{\mathrm{A}}{ }^{\mathrm{F}}=0.175, \mathrm{~K}_{\mathrm{B}}=0.2$,

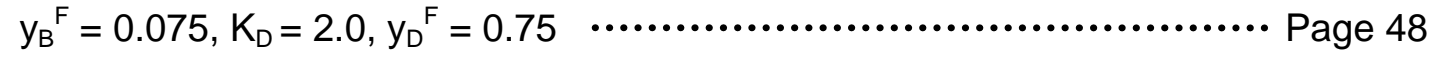

Table 1 Micropore and mesopore volumes of rived and unrived $\mathrm{NaX}$............... Page 14

Table 2 Properties of the unrived and rived $\mathrm{Na}-\mathrm{A}$ zeolite samples compared to unrived and

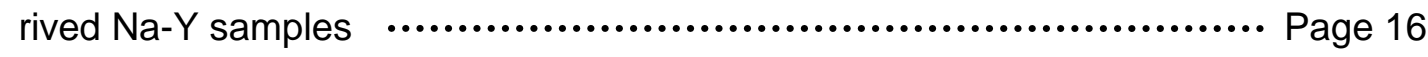

Table 3 Properties of unrived and rived A zeolites …............................. Page 19

Table 4 Properties of the zeolites and the adsorbent particles prepared from the corresponding zeolites ................................................. Page 20

Table 5 Packed column properties for different adsorbents ….................... Page 23

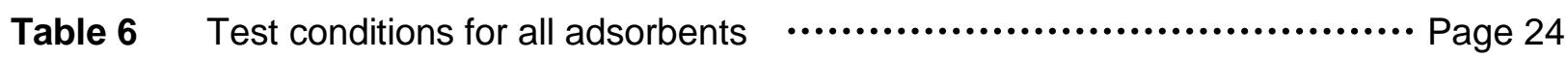

Table 7 Tabulated pulse test results for Commercial NaX (top), In-house Unrived $\mathrm{NaX}$ (middle), and Rived $\mathrm{NaX}$ (bottom)

Table 8 Tabulated pulse test results for In-house Unrived NaY (top) and Rived NaY (bottom) adsorbents ….............................................................. Page 37

Table 9 Calculations for a hypothetical SMB process: Subscripts $F=F e e d, R=$ Raffinate, $D$

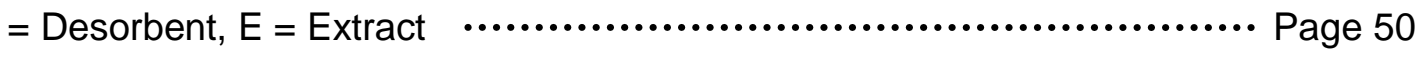

Table 10 Comparison of energy savings of SMB process using hexane (top), pentane (middle), and iso-pentane (bottom) as desorbent. Last column are corresponding

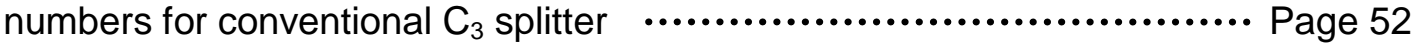




\section{Executive Summary:}

Due to the very small relative volatility difference between propane and propylene, current propane/propylene separation by distillation requires very tall distillation towers (150-250 theoretical plates) and large reflux ratios (up to 15), which is considered to be the most energy consuming large-scale separation process. Adsorptive separation processes are widely considered to be more energy-efficient alternatives to distillation. However, slow diffusion kinetics/mass transport rate through the adsorbent bed often limits the performance of such processes, so further improvements are possible if intra-particle mass transfer rates can be improved.

Rive Technology, Inc. is developing and commercializing its proprietary mesoporous zeolite technology for catalysis and separation. With well-controlled intracrystalline mesoposity, diffusion kinetics through such mesoporous zeolite based catalysts is much improved relative to conventional zeolites, leading to significantly better product selectivity. This "proof-of-principle" project (DE-EE0003470) is intended to demonstrate that Rive mesoporous zeolite technology can be extended and applied in adsorptive propane/propylene separation and lead to significant energy saving compared to the current distillation process.

In this project, the mesoporous zeolite $Y$ synthesis technology was successfully extended to $X$ and $A$ zeolites that are more relevant to adsorbent applications. Mesoporosity was introduced to zeolite $\mathrm{X}$ and $\mathrm{A}$ for the first time while maintaining adequate adsorption capacity. Zeolite adsorbents were tested for liquid phase separation performance using a pulse flow test unit and the test results show that the separation selectivity of the mesoporous zeolite adsorbent is much closer to optimal for a Simulated Moving Bed (SMB) separation process and the enhanced mesoporosity lead to $>100 \%$ increase of overall mass transport rate for propane and propylene. These improvements will significantly improve the performance of an adsorptive separation unit for propane/propylene separation compared with traditional zeolite adsorbents. The enhanced transport will allow for more efficient utilization of a given adsorbent inventory by reducing process cycle time, allowing a faster production rate with a fixed amount of adsorbent or smaller adsorbent inventory at a fixed production rate. Smaller adsorbent inventory would also lead to significant savings in the capital cost due to smaller footprint of the equipments.

Energy consumption calculation, based on the pulse test results for rived $\mathrm{NaX}$ zeolite adsorbent, of a hypothetical moderate-scale SMB propane/propylene separation plant that processes 6000 BPSD refinery grade propylene (70\% propylene) will consume about $60-80 \%$ less energy (both re-boiler and condenser duties) compared to a C3 splitter that process the same amount of feed. This energy saving also translates to a reduction of 30,000-35,000 tons of $\mathrm{CO}_{2}$ emission per year at this moderate processing rate. The enhancement of mass transport achievable by introduction of controlled mesoporosity to the zeolite also opens the door for the technology to be applied to several other adsorption separation processes such as the separation of xylene isomers by SMB, small- and large scale production of $\mathrm{O}_{2} / \mathrm{N}_{2}$ from air by pressure swing adsorption, the separation of $\mathrm{CO}_{2}$ from natural gas at natural gas wellheads, and the purification of ultra-high purity $\mathrm{H}_{2}$ from the off gas produced by steam-methane-reforming. 


\section{Introduction:}

Propane and propylene separation is currently achieved by distillation process. This process (C3 split) is often cited as the most energy-consuming separation operation.[1] About half of the propylene produced in the US ( 41 billion pounds/year) comes from C3 splitters in petroleum refineries (the other half as co-product from ethylene plants, i.e. steam crackers). The main source of propylene within oil refineries is from fluid catalytic cracking units (FCCU) for production of gasoline. "Refinery Grade Propylene" typically contains $\sim 70 \%$ propylene (balance being propane and trace impurities). Due to the very small relative volatility between propane and propylene (b.p. -43 and $-48{ }^{\circ} \mathrm{C}$ at 1 atm, respectively), separation of the two by distillation requires very large towers and high reflux ratios. Chemical Grade Propylene (92-94\% purity) and Polymer Grade Propylene (>99.3\% purity) are the main products from the C3 splitters, the latter being preferred due to its higher market demand and economic value. In the front-end energy consumption calculation carried out by Adsorptech (Appendix), a hypothetical refinery C3 splitter producing 40 million pounds of Polymer Grade Propylene per year would require 2790 BTU/lb propylene in reboiler duty and 2774 BTU/lb propylene in condenser duty.

This situation has spurred advanced research in more energy efficient separation methods over the last several decades-especially alternatives to distillation-much of it through DOE/OITindustry collaborations or other government funding. These aslternatives include gas phase pressure swing adsorption (PSA),[2, 3] vacuum swing adsorption (VSA),[4, 5] kinetic adsorption separation,[6] and simulated moving bed (SMB) adsorption.[7] The traditional PSA and VSA systems have been found to suffer from large mass transfer resistances leading to long step cycles in the VSA case, and poor propylene recoveries $(<30 \%)$ in the PSA and kinetic separation cases.[8] The SMB process has attracted attention for this separation as it has been successfully applied to a number of large petrochemical separation processes such as $p$-xylene separation from its isomers, $n$-paraffins from branched and cyclic hydrocarbons, olefins from paraffins, glucose-fructose separation in the sugar processing industry, and several new applications in the pharmaceutical and fine chemical industries.[8]

Assuming the adsorptive separation technology under this development (specifically the SMB process utilizing the mesoporous zeolite based adsorbents) can fully satisfy the requirements for product purity (99.5\% propylene) and productivity (40 million lbs propylene per year), the front-end energy consumption calculation (Appendix) showed that the energy consumption would be reduced to $666 \mathrm{BTU} / \mathrm{lb}$ propylene in reboiler duty and $656 \mathrm{BTU} / \mathrm{lb}$ propylene in condenser duty, roughly $75 \%$ reduction.

Zeolites are microporous crystalline aluminosilicates having pores of molecular dimensions, typically $<12 \AA$ (thus the name "molecular sieves"). Due to their unique porous properties (uniform and regular pore sizes, high surface areas, strong acidities and high thermal/hydrothermal stability), they are widely used in ion-exchange, adsorption, separation and catalytic applications. However, the micropores can impose diffusion limitations due to the restricted access and slow mass transport to and from active sites located within the micropores. This phenomenon represents the major drawback in most industrial applications of zeolites, especially in catalytic reactions such as fluid catalytic cracking. In adsorptive 
separation processes, the narrow size of the micropores could also limit the diffusion of the molecules that need to be separated, reducing the flow and increasing the energy needed to maintain good production. A typical solution to this problem is to optimize the size (and shape) of the zeolite crystals and the adsorbent particles to reduce diffusion path length. However, there is a practical limitation on how small the crystals (and more importantly the adsorbent particles) can be because of increasing difficulty in manufacturing of small zeolite crystals and increasing pressure drop in adsorption towers with decreasing adsorbent particle size.

Intracrystalline mesoporosity introduced by the "riving" process will greatly reduce the diffusion limitation while the crystal size remains unchanged.

Rive Technology, Inc. is developing and commercializing the proprietary mesoporous zeolite technology in catalysis and separation.[9-13] The technology, called "riving", introduces additional, controlled mesoporosity (pore size $>2 \mathrm{~nm}$ ) into zeolite crystals through a simple, surfactant-assisted method of nanoengineering, thus improving mass transport inside the small crystals where reactions (or separation) take place. The transmission electron micrographs (TEM) of a typical zeolite before and after the incorporation of the mesopores (Figure 1), clearly shows the more accessible structure of the modified version. In the micrograph on the left, the crystal lattice of the zeolite is observed as straight horizontal parallel lines. However, no porosity is observed (the magnification is too low to see the micropores). On the contrary, the micrograph on the right (corresponding to a mesoporous zeolite), both the crystal lattice and the additional mesoporosity are observed, indicating a much more accessible crystalline structure. In the inset of the micrograph of the mesoporous zeolite (taken at high magnification) the crystal lattice (going in diagonal) and the mesopore (as pale holes inside the structure) are clearly present.
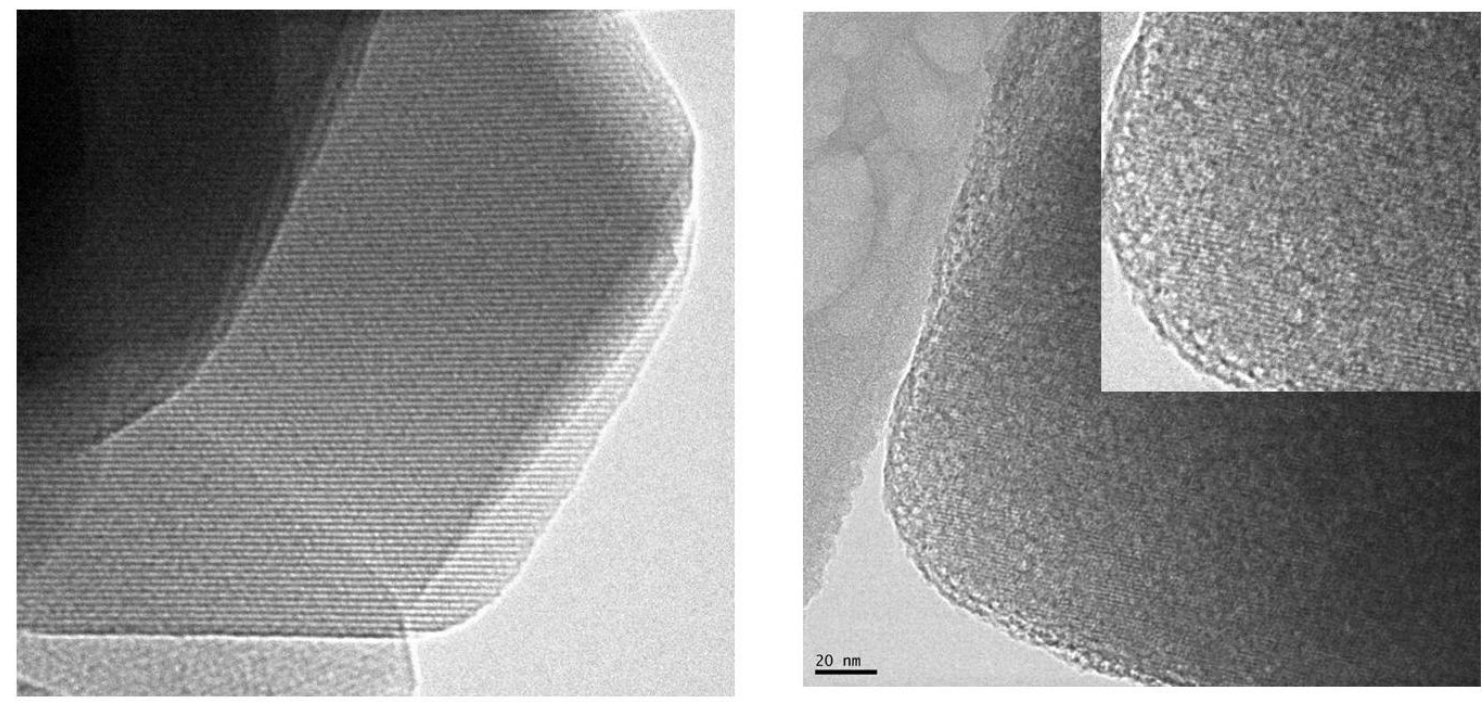

Figure 1. TEM micrographs showing a zeolite before (left) and after (right) the incorporation of mesopores 
The advantage of the intracrystalline mesoporosity of rived zeolites is evidenced by the improved catalytic performance of the FCC catalysts made from the mesoporous zeolite. Rive's recent development proved that the intracrystalline mesopores make the catalysts more capable of cracking large hydrocarbon molecules, and enable valuable primary cracked products, like gasoline and diesel molecules, to more readily escape the catalyst before they are over-cracked to less valuable light gases and coke (Figure 2).

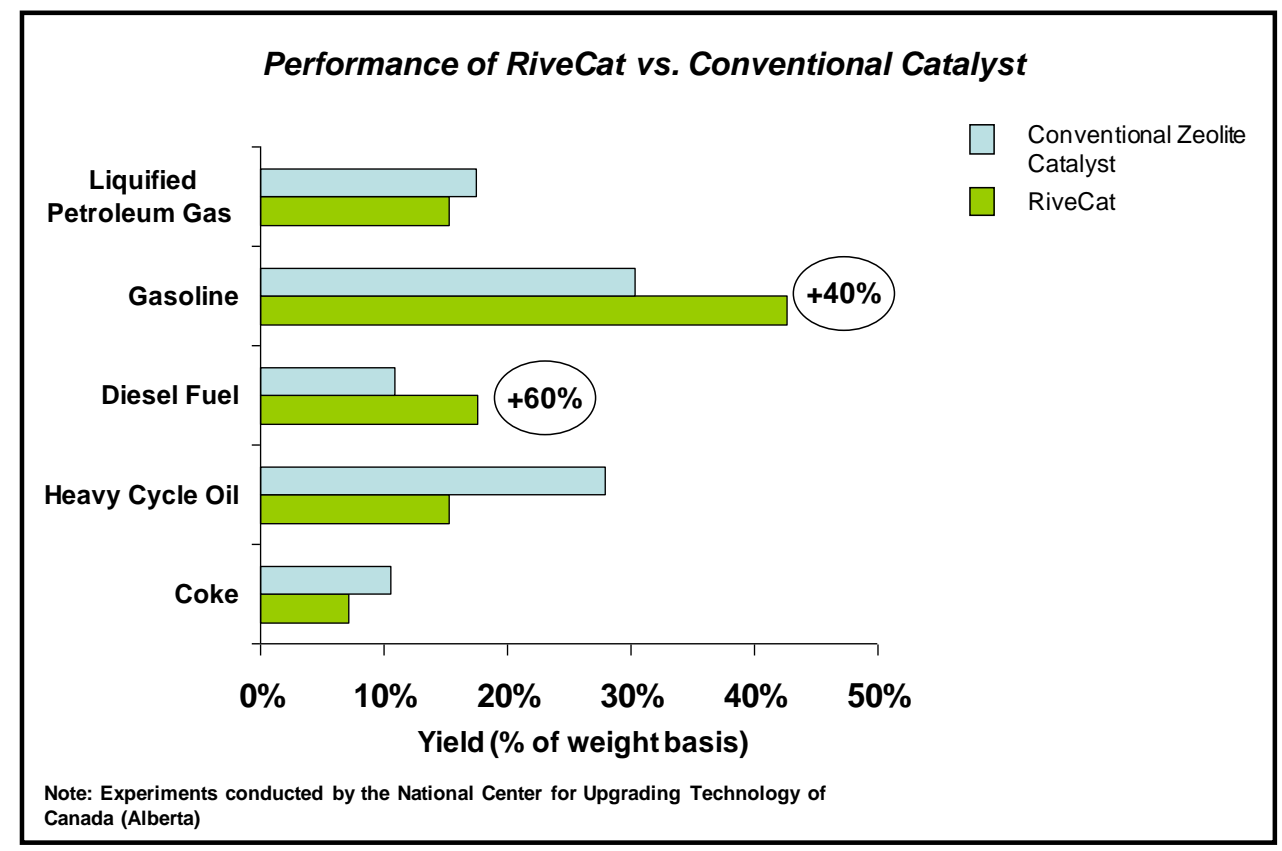

Figure 2. Catalytic performance of catalysts based on a meosoporous zeolite (RiveCat) and a conventional zeolite

In addition, Rive's proprietary technology has the following advantages:

- The amount of mesoporosity introduced can be tailored very precisely, and can therefore be optimized for a particular separation and process.

- Mesoporosity can be incorporated into a range of zeolitic materials, which will allow us to identify an optimal material for the separation of propane / propylene.

- The introduction of mesoporosity does not change the main macroscale physical chemical properties of the zeolite or the crystal size or shape. The properties of the zeolite are usually optimized for each separation process, so maintaining those properties is important.

- The technology is low cost and easily manufactured. Based on our experience in developing mesoporous zeolite catalysts for the refining industry, we expect to develop an adsorbent that is commercially cost competitive.

The objective of Rive Technology's project (DE-EE0003470) is to explore the application of the company's proprietary mesoporous zeolite technology to large-scale, energy-intensive 
separations in the chemical industry. The project will focus on the separation of propane from propylene utilizing zeolite-containing adsorbents with enhanced mesoporosity in a Simulated Moving Bed (SMB) process in comparison to the energy-intensive distillation process used today. 


\section{Materials Preparation and Characterization:}

\section{Riving of zeolites $\mathrm{Y}, \mathrm{X}$ and $\mathrm{A}$}

Rive Technology has developed and optimized over the past few years a chemical process, referred as "riving", to introduce controlled intracrystalline mesoporosity into Y (Faujasite) zeolite. Typically, the starting NaY zeolite (e.g. Zeolyst CBV100) is slurried into de-ionized water and was added mineral acid (nitric acid or sulfuric acid) to adjust the $\mathrm{pH}$ to $\sim 5.9$. Then $10 \%$ citric acid (or other aluminum chelating acid) at a certain dosage level (e.g. 4 miliequivalents (meq.)/g zeolite) is added over a period of 1 hour. Following filtration and rinsing with de-ionized water, the solid is re-slurried into de-ionized water and was added certain amount of cetyltrimethylammonium bromide or chloride solution (CTAB or CTAC), e.g. at $0.5 \mathrm{~g} \mathrm{CTAB/g}$ zeolite level. Then certain amount of concentrated $\mathrm{NH}_{4} \mathrm{OH}$ or $\mathrm{NaOH}$ solution is added to the reaction mixture. The $\mathrm{pH}$ of the mixture is typically about $10-11$. The mixture is then heated to $80{ }^{\circ} \mathrm{C}$ in an oven with or without stirring for an extended period of time (e.g. 24 hours) before it is filtered and washed with hot de-ionized water to remove the excess surfactant. The occluded surfactant templates are typically removed by careful calcination. A typical calcination of rived zeolite involves loading certain amount of dried surfactant-containing zeolite into a custommade calcination tube that has a gas inlet and outlet, flowing nitrogen through the sample at 6 $\mathrm{cc} / \mathrm{min}$, heating the sample in a muffle furnace from room temperature to $150{ }^{\circ} \mathrm{C}$ slowly at 5 ${ }^{\circ} \mathrm{C} /$ minute and holding for 1 hour, then heating up to $550{ }^{\circ} \mathrm{C}$ at $5{ }^{\circ} \mathrm{C} /$ minute and holding for 2 hours, switching the nitrogen to dry air at $6 \mathrm{cc} / \mathrm{min}$ and holding at $550{ }^{\circ} \mathrm{C}$ for another 2 hours, and cooling under dry air flow to room temperature.

The rived zeolites are typically characterized by X-ray diffraction (PANalytical Cubix Pro X-ray Diffractometer with a $1.8 \mathrm{~kW}$ Cu-target X-ray tube), $\mathrm{N}_{2}$ (and/or $\mathrm{Ar}$ ) gas adsorption/desorption (Quantachrome Quadrasorb-SI Surface Area/Pore Size analyzer), and X-ray fluorescence spectrometry (PANalytical Axios Wavelength Dispersive X-ray Fluorescence Spectrometer). Multi-point BET surface areas are calculated using $\mathrm{N}_{2}$ adsorption results that range at 0.005 to $0.03 \mathrm{P} / \mathrm{P}_{0}$. Pore size distribution is calculated from all adsorption results using NLDFT model. External surface areas (the total area of the true crystal external surface and the mesopore surface) are calculated from $\mathrm{N}_{2}$ adsoprtion results using t-plot analysis. The unit cell size of the remaining crystalline framework is calculated from the X-ray diffraction results following ASTM D3942. Relative apparent crystallinity of the rived zeolite is calculated from the X-ray diffraction results following ASTM D3942 and referred to the starting CBV100 (NaY).

Argon adsorption measurements show that most of the mesoporosity introduced during riving are in the $40 \AA$ range (Figure 3 top). With increasing amount of citric acid (meq/g), higher mesopore volumes can be introduced. Apparently, the mesopore size is controlled by the size of the surfactant used and the mesopore volume is controlled by the acid wash severity. The increase in mesopore volume is accompanied by a decrease in the micropore volume as shown in Figure 3 (bottom). The increase in mesopore volume is not proportional to the decrease in micropore volume. As a result, riving results in a net increase in the total pore volume (Figure 3 , top). 


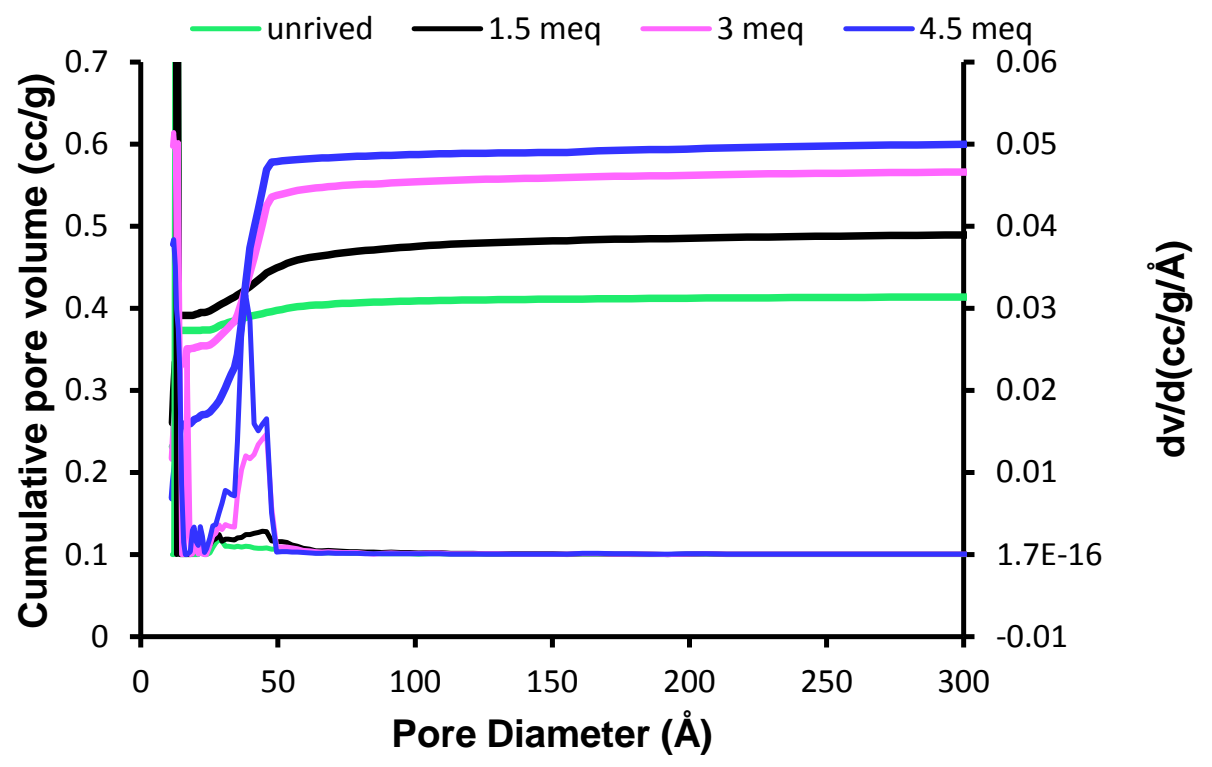

- 0-20 ̊ $\quad 20-300 \AA$

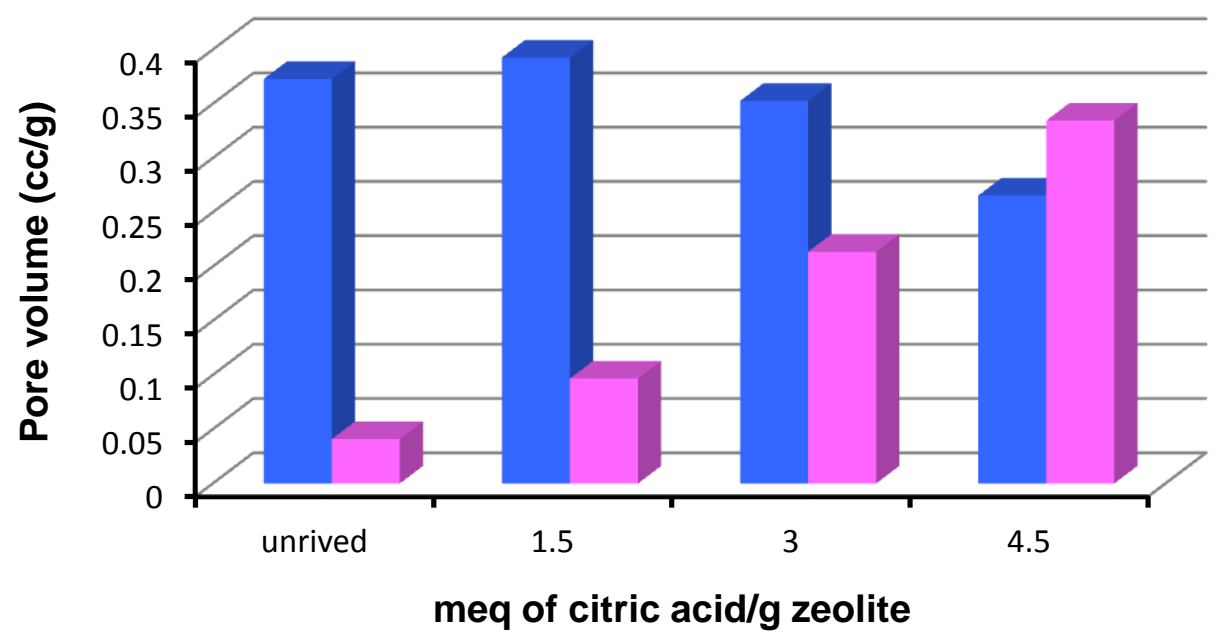

Figure 3. Cumulative and pore size distribution of rived and unrived $Y$ zeolite (top) and pore volume dependence on citric acid amount (bottom)

XRD powder patterns (Figure 4) confirm that rived $Y$ zeolite retains the faujasite structure with decreasing crystallinity. 


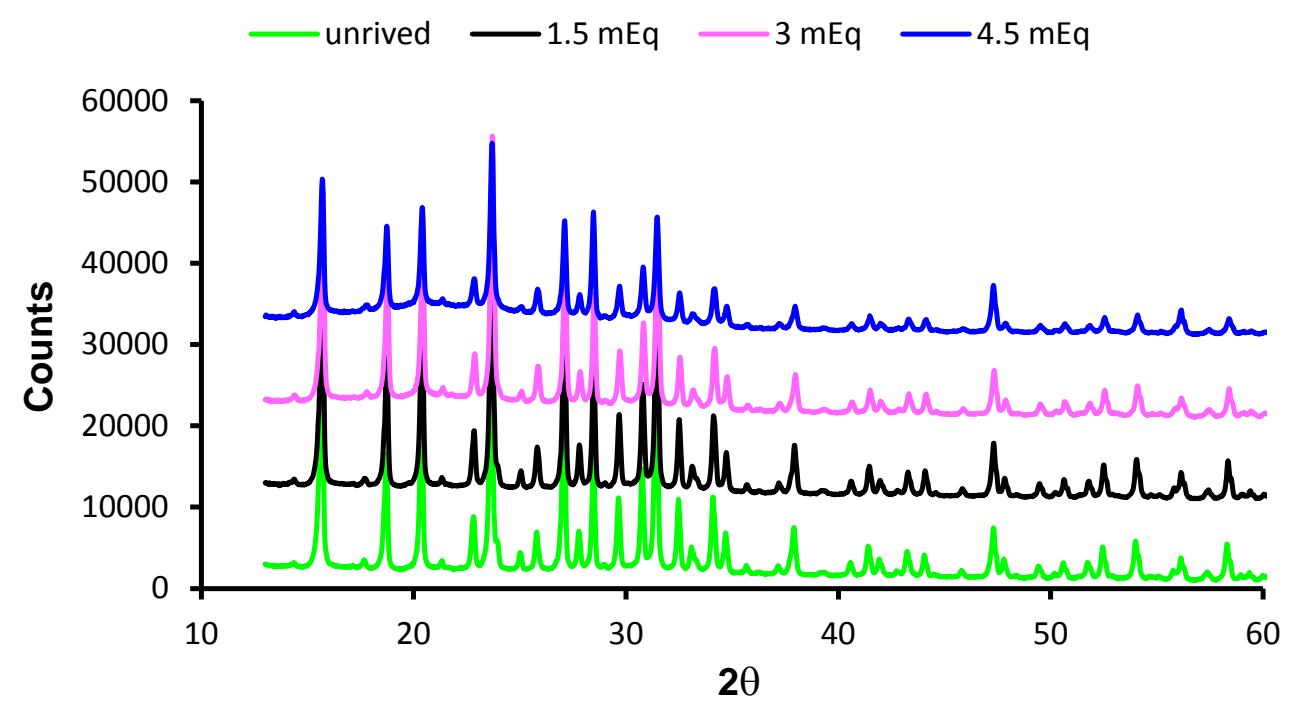

Figure 4. XRD powder diffraction patterns of unrived and rived Na-Y (CBV100) samples at different citric acid treatment levels

The silica to alumina molar ratios (SAR) of $Y, X$ and $A$ are $5,2.5$, and 2, respectively. Due to the difference in their chemical compositions, dealumination of $X$ and $A$ zeolites by acid (e.g. citric acid or nitric), which is typically accompanied by destruction to the zeolite crystalline structures, is expected to be much more facile and much less selective than dealumination of $Y$. This is manifested by the vast difference of their stability in nitric acid (Figure 5). While $Y$ zeolite retains $95 \%$ of the original crystallinity at $\mathrm{pH} 3, \mathrm{X}$ retains only $23 \%$ and $\mathrm{A}$ already becomes a gel at $\mathrm{pH}$ 4. Therefore, more careful control of the acid wash conditions is recognized to be the key to successful "riving" of $X$ and A zeolites.

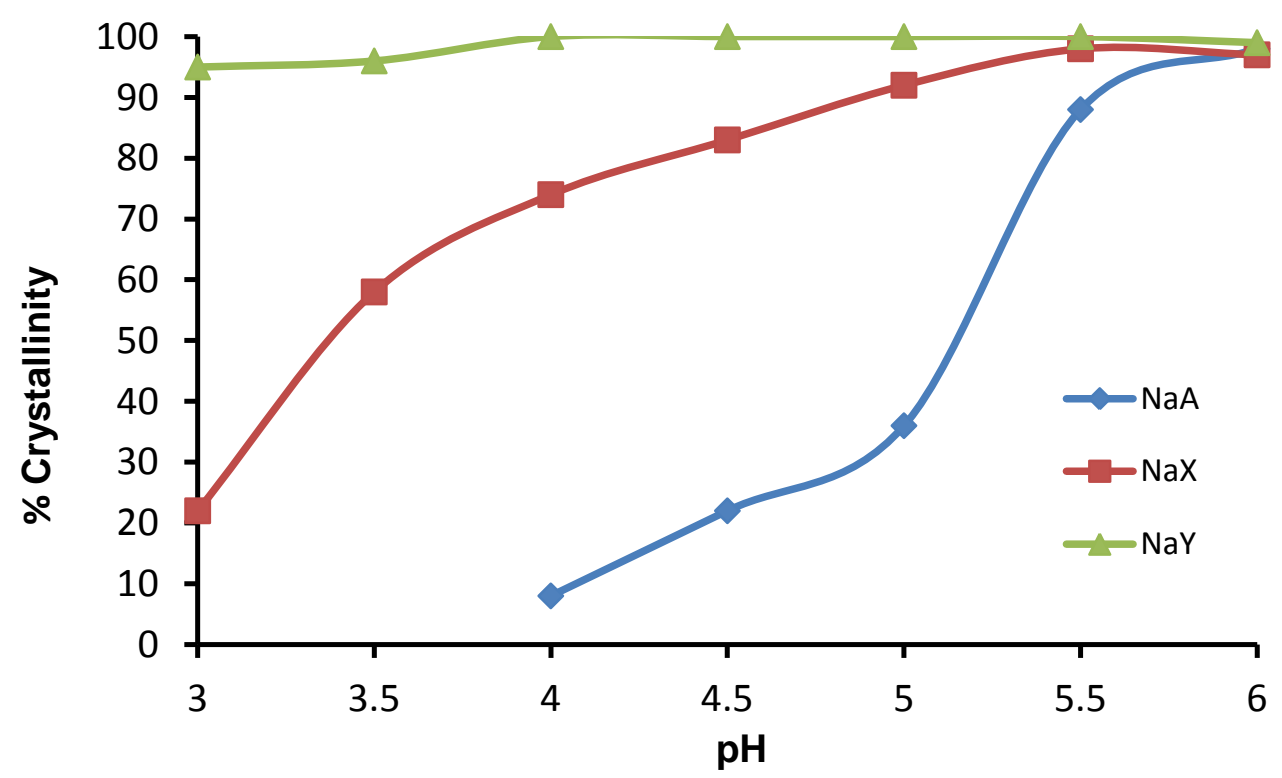

Figure 5. Effect of $\mathrm{pH}$ on crystallinity of $\mathrm{NaY}, \mathrm{NaX}$ and $\mathrm{NaA}$ zeolites 
Under very similar reaction conditions as for $\mathrm{NaY}, \mathrm{NaX}$ zeolite can be rived to different degrees by controlling the acid treatment severity (Table 1 ).

Table 1. Micropore and mesopore volumes of rived and unrived $\mathrm{NaX}$

\begin{tabular}{lccc}
\hline $\begin{array}{l}\text { Citric Acid } \\
\text { (meq/g zeolite) }\end{array}$ & $\begin{array}{c}\text { MicroPV (0-20 Å) } \\
\text { cc/g }\end{array}$ & $\begin{array}{c}\text { MesoPV (20-300Å) } \\
\text { cc/g }\end{array}$ & \% Crystallinity \\
\hline 0 (unrived) & 0.43 & 0.03 & 100 \\
3.0 & 0.38 & 0.11 & 89 \\
4.5 & 0.38 & 0.14 & 84 \\
6 & 0.31 & 0.18 & 68 \\
\hline
\end{tabular}

Rived Na- X zeolites retain faujasite structure (Figure 6). The relative crystallinity also follows the severity of the citric acid treatment (Table 1 ).

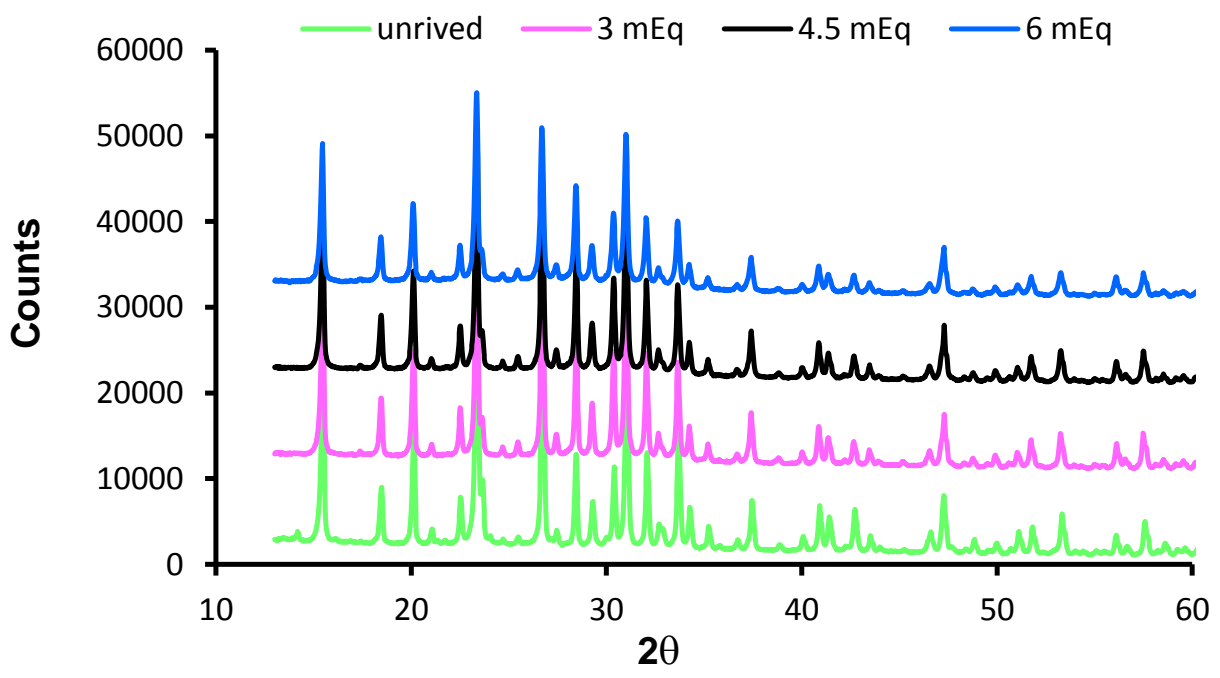

Figure 6. XRD powder pattern of unrived and rived $X$ samples at different levels of citric acid treatment

When "riving" of NaA zeolite was first attempted using the normal procedure that has been developed for $Y$ zeolite, very little mesoprorosity (20-80 $\AA$ ) was introduced as shown by Argon adsorption measurements (Figure 7). TEM analysis of the A zeolite sample revealed that the crystals were broken into very small pieces, suggesting that A zeolite was partially damaged during the process (Figure 8-10). TEM results also revealed that the large mesopores $(>140 \AA)$ observed in Ar adsorption measurement are probably the interparticle voids between the small broken pieces of the A zeolite crystals. XRD analysis showed that the sample still maintains significant crystallinity while Ar adsorption showed no micropore volume (Table 2). This difference suggests that $X$-ray diffraction comes from the undamaged $A$ zeolite crystals in the sample. It should be noted that $4 \mathrm{~A}$ zeolite will not adsorb $\operatorname{Ar}$ or $\mathrm{N}_{2}$ due to the small pore 
openings that restrict the diffusion of the probe $\left(\mathrm{N}_{2}\right.$ or $\left.\mathrm{Ar}\right)$ molecules into the micropores under the experimental conditions (low partial pressure and low temperatures) while a Ca-exchanged sample showed $\sim 0.28 \mathrm{cc} / \mathrm{g}$ micropore $(0-20 \AA)$ volume from $\mathrm{N}_{2}$ adsorption measurement.
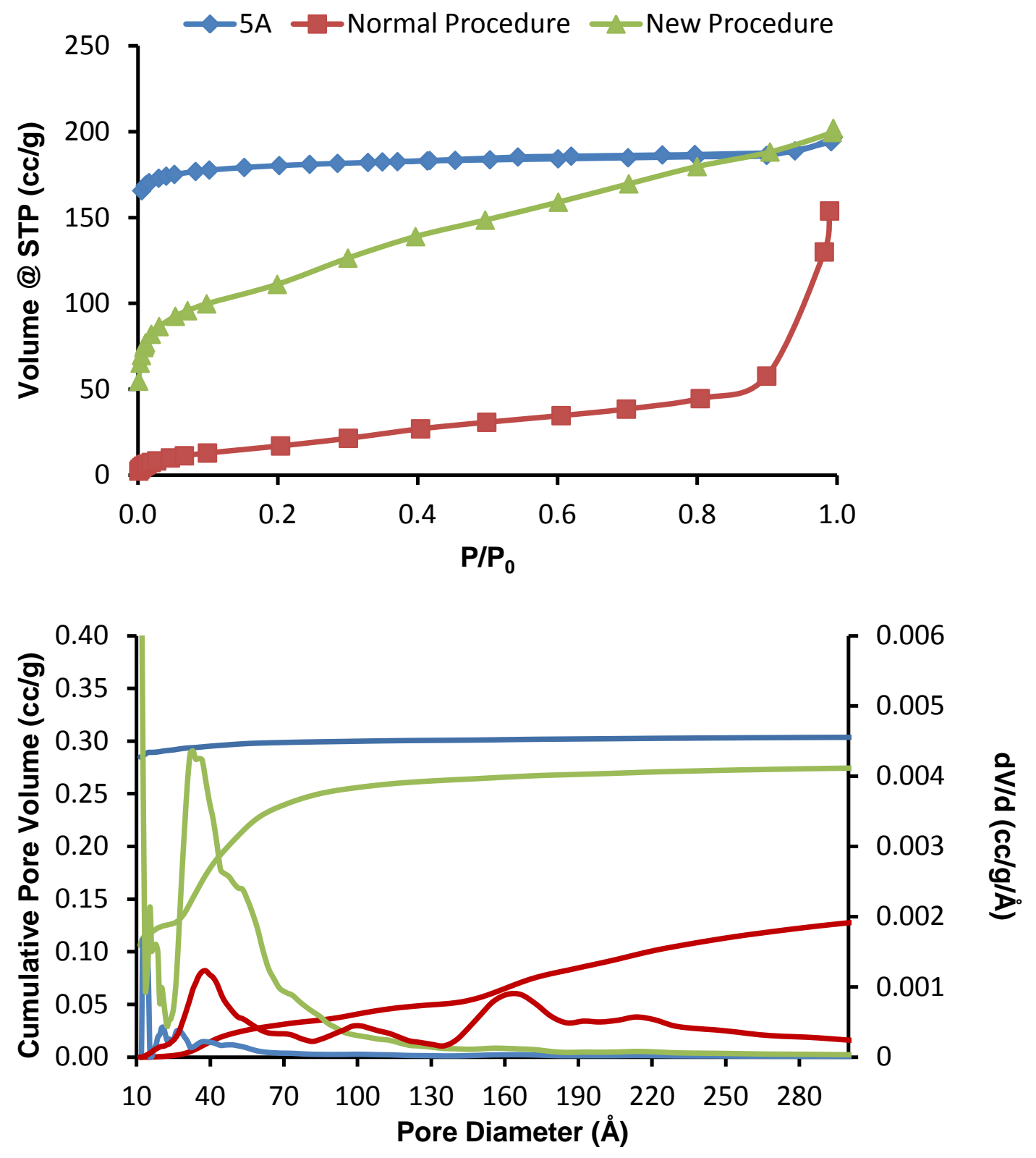

Figure 7. Argon adsorption isotherms and the corresponding DFT cumulative and differential pore size distribution of an unrived $5 \mathrm{~A}$ zeolite (blue)) and rived $4 \mathrm{~A}$ zeolites by the normal riving procedure (red) and the modified procedure (green)

The typical riving procedure was then modified (will disclose the details later due to proprietary reason). At the same acid wash severity (4 meq citric acid per gram of A zeolite), the sample treated by this new procedure showed significant mesoporosity within the $20-80 \AA$ size range (Table 2). X-ray diffraction showed that the sample retained $\sim 75 \%$ of the original crystallinity. 
Argon adsorption showed $0.12 \mathrm{cc} / \mathrm{g}$ microporosity, lower than the X-ray crystallinity predicts $(\sim 0.21 \mathrm{cc} / \mathrm{g})$, suggesting that the "riving" is not uniform. Some crystals may have been well "rived" while the others are not rived at all. The unrived A zeolite will not contribute to the micropore volume measured by Ar adsorption. This is substantiated by TEM analysis. It is very interesting that at a lower acid wash severity ( 2 meq citric acid per gram zeolite), the X-ray crystallinity match the micropore volume retention very well. It is possible in this case that the "riving" is more uniform and even at this small degree of "riving" ( $0.05 \mathrm{cc} / \mathrm{g}$ mesoporosity introduced) it seems that the material readily takes up $\operatorname{Ar}$ (untreated 4A zeolite does not take up Ar under the same experimental conditions and show zero micropore volume). The new "riving" process is currently under evaluation for patent application.

Table 2. Properties of the unrived and rived $\mathrm{Na}-\mathrm{A}$ zeolite samples compared to unrived and rived $\mathrm{Na}-\mathrm{Y}$ samples

\begin{tabular}{|c|c|c|c|c|c|c|}
\hline Zeolite & $\begin{array}{l}\text { \%Cryst. } \\
\text { (XRD) }\end{array}$ & $\begin{array}{l}\text { UCS } \\
\text { (A) }\end{array}$ & $\begin{array}{l}\text { Micro } \\
(0-20 \AA)\end{array}$ & $\begin{array}{l}\text { \%Cryst. } \\
\text { (MicroPV) }\end{array}$ & $\begin{array}{l}\text { Meso } \\
(20-80 \AA)\end{array}$ & $\begin{array}{c}\text { Meso } \\
(20-300 \AA)\end{array}$ \\
\hline $4 \mathrm{~A}(\mathrm{Na}-\mathrm{A})$ & 100 & 24.61 & 0 & & 0.04 & 0.05 \\
\hline $5 \mathrm{~A}(\mathrm{Ca}-\mathrm{A})$ & $N / A$ & $N / A$ & 0.28 & 100 & 0.01 & 0.01 \\
\hline $\begin{array}{l}\text { Rived } 4 \text { A- Normal Procedure } \\
\text { (at } 4 \text { meq/g zeolite) }\end{array}$ & 62 & 24.63 & 0 & 0 & 0.03 & 0.13 \\
\hline $\begin{array}{l}\text { Rived 4A-New Procedure } \\
\text { (at } 4 \text { mea/g zeolite) }\end{array}$ & 75 & 24.63 & 0.12 & 43 & 0.12 & 0.15 \\
\hline CBV100 (Na-Y) & 100 & 24.71 & 0.37 & 100 & 0.03 & 0.04 \\
\hline $\begin{array}{l}\text { Rived CBV100 (at } 4.5 \mathrm{meq} / \mathrm{g} \\
\text { zeolite) }\end{array}$ & 68 & 24.64 & 0.28 & 76 & 0.27 & 0.28 \\
\hline
\end{tabular}
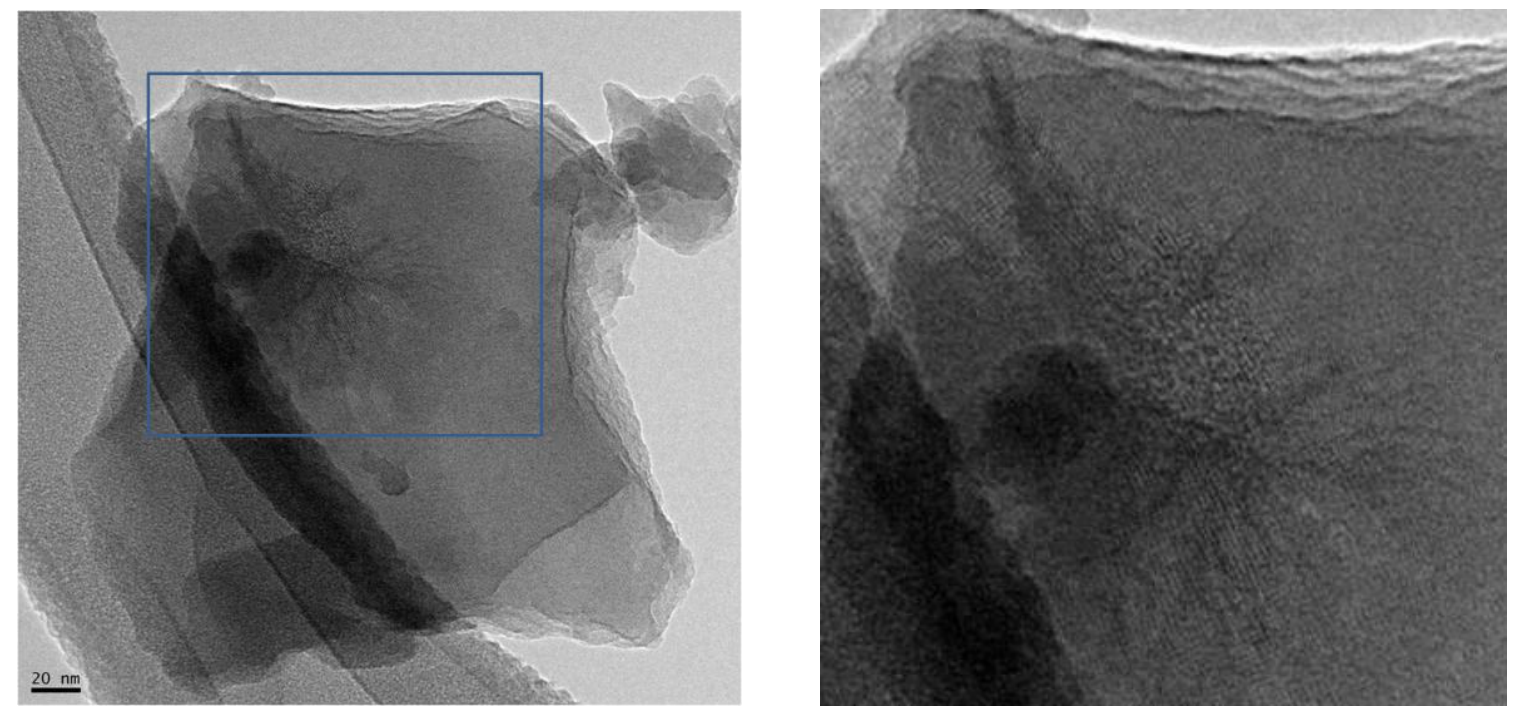

Figure 8. TEM images of an unrived NaA zeolite crystal. The picture on right is a digital blownup of the blue box region in the picture on the left 

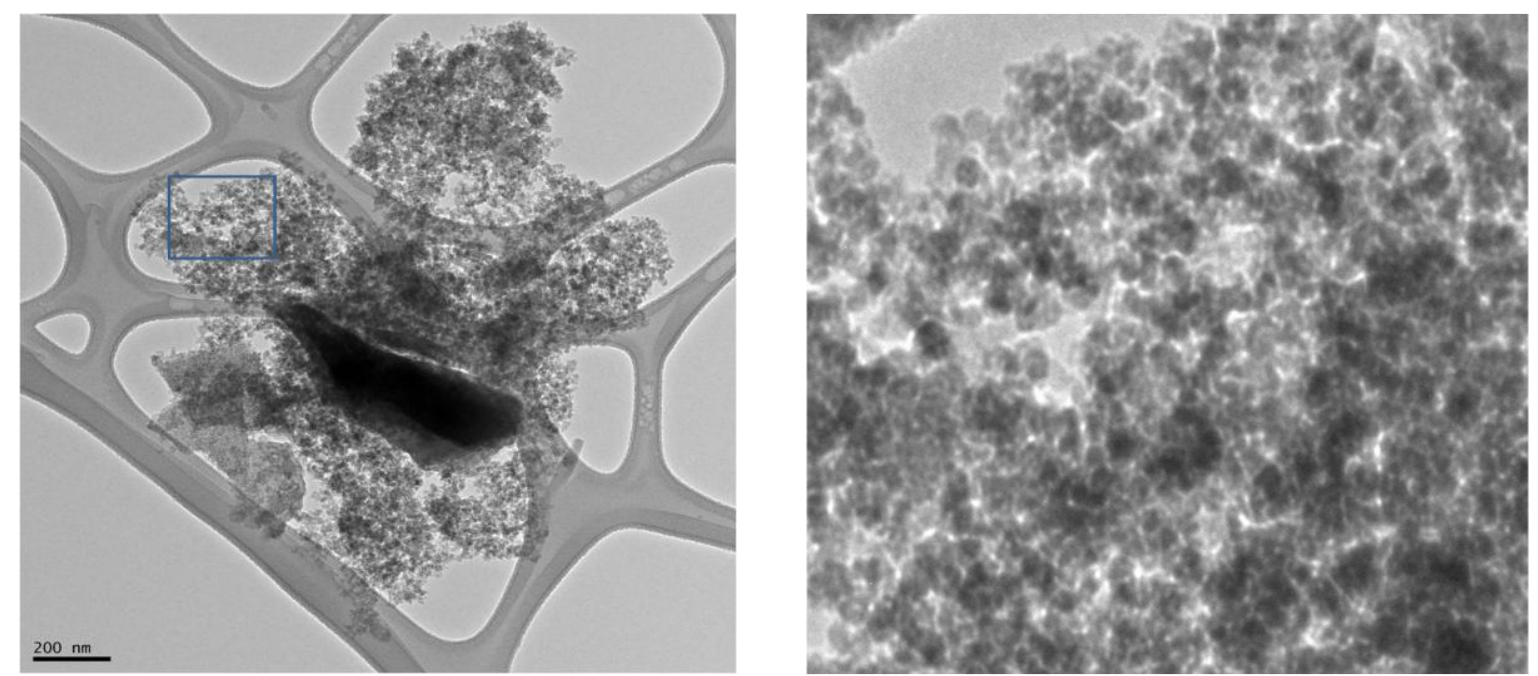

Figure 9. TEM images of a rived Na-A sample by the normal procedure. The picture on right is a digital blown-up of the blue box region in the picture on the left
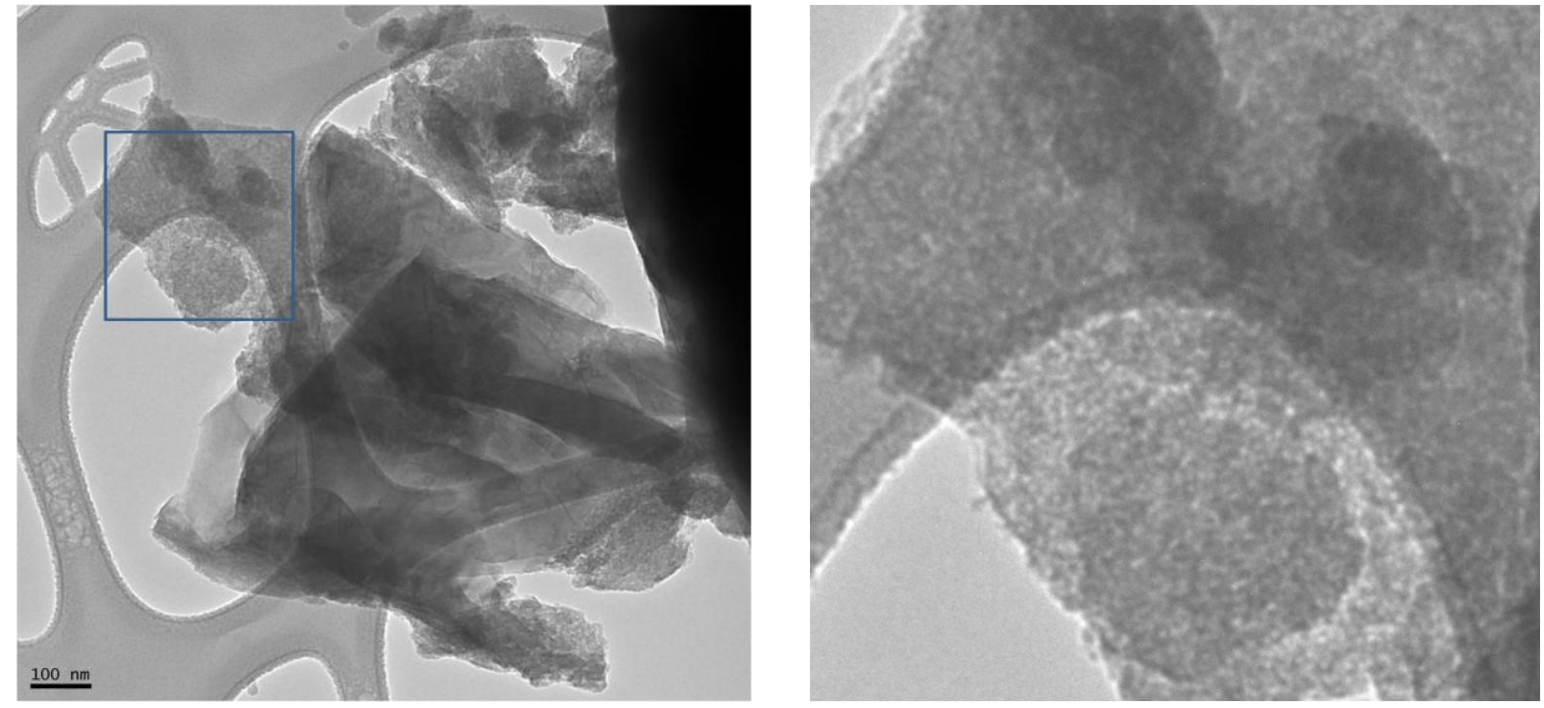

Figure 10. TEM images of a rived Na-A sample by the modified procedure. The picture on right is a digital blown-up of the blue box region in the picture on the left

To control the purity of cations in the rived zeolites and also to avoid the instability of $H Y, H X$ or $\mathrm{HA}$ that form during calcination (to remove surfactant template) of the NH4-Y, NH4-X, NH4-A zeolites, concentrated $\mathrm{NH} 4 \mathrm{OH}$ used in the riving processes described above is replaced by $50 \%$ $\mathrm{NaOH}$.

Figure 11 shows the cumulative and differential pore size distribution of $\mathrm{NaOH}$ and $\mathrm{NH}_{4} \mathrm{OH}$ rived $\mathrm{NaY}$ (both pre-treated with 4.5 miliequivalent/g of citric acid). $\mathrm{NaOH}$ riving gives similar (or slightly better) results than $\mathrm{NH}_{4} \mathrm{OH}$. In terms of pore size distribution, there is a slight uplift in

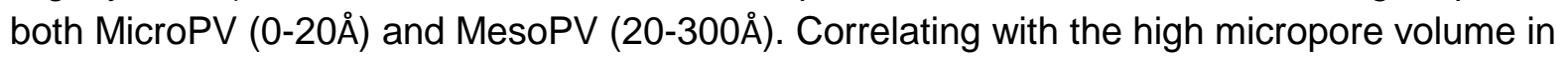
$\mathrm{NaOH}$ rived zeolite is the higher crystallinity of $78 \%$ compared to $57 \%$ for zeolite rived in $\mathrm{NH}_{4} \mathrm{OH}$. 


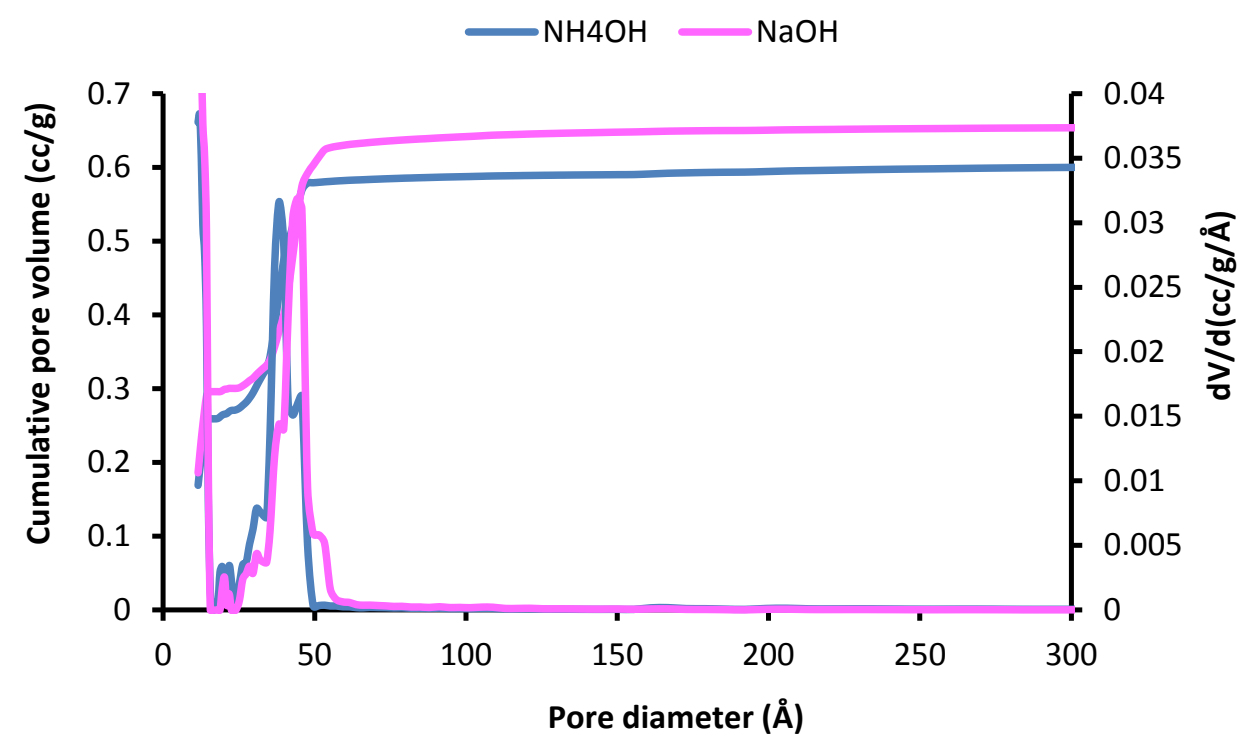

Figure 11. Cumulative and differential pore size distribution of $\mathrm{NaY}$ rived with $\mathrm{NaOH}$ and $\mathrm{NH}_{4} \mathrm{OH}$ For riving of $\mathrm{NaX}$ zeolite, it was found that the amount of $\mathrm{NaOH}$ used could also affect the mesoporosity introduced (Figure 12).

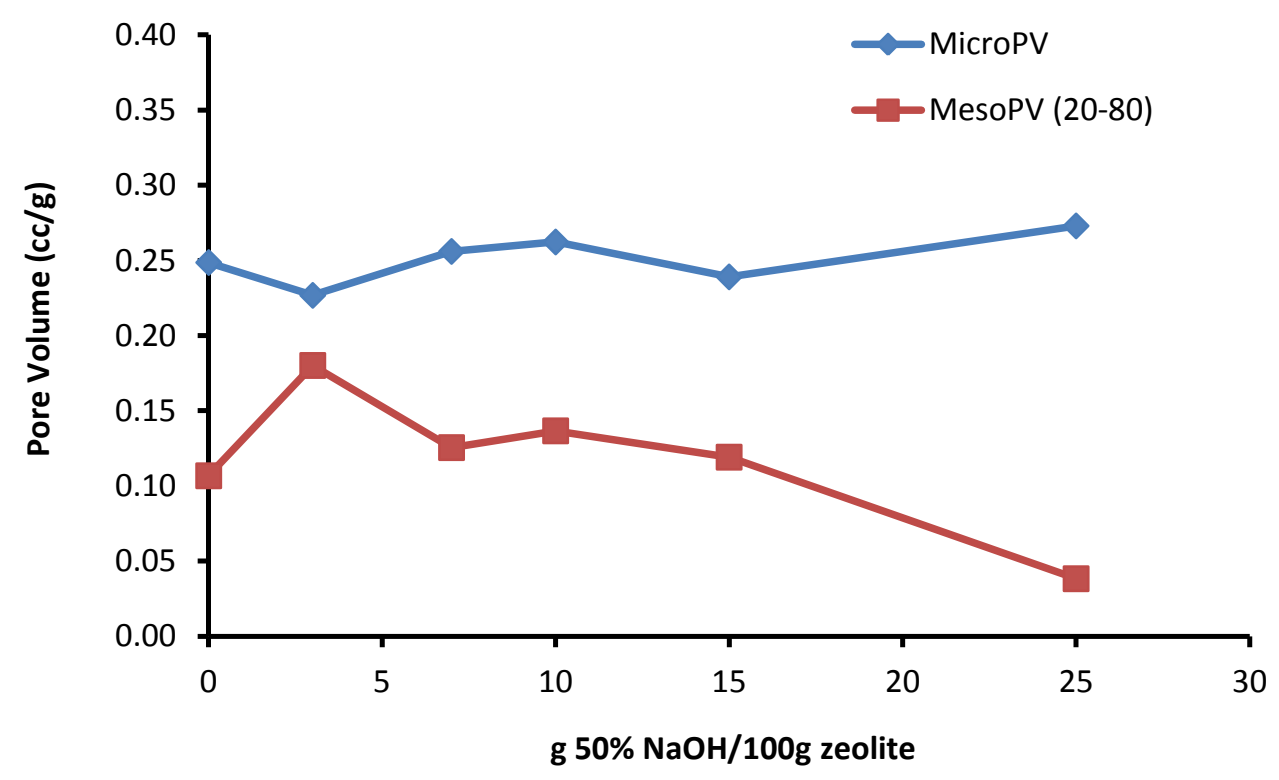

Figure 12. Micropore and mesopore (20-80 $\AA$ ) volumes of rived NaX showing that $\sim 10 \mathrm{~g}$ of $50 \%$ $\mathrm{NaOH}$ per $100 \mathrm{~g}$ of starting $\mathrm{NaX}$ zeolite is optimal. Similar effects were also found for riving of $\mathrm{NaY}$ and $\mathrm{NaA}$ zeolites

Replacing $\mathrm{NH}_{4} \mathrm{OH}$ with $\mathrm{NaOH}$ in riving of $\mathrm{NaA}$ in the new riving procedure described above show that the mesoporsity is controlled by the acid treatment severity, similar to riving of $\mathrm{NaX}$ and $\mathrm{NaY}$ (Table 3). No microposity is observed for the as-rived samples because $\mathrm{N}_{2}$ or $\mathrm{Ar}$ 
cannot diffuse through the small pore openings $(\sim 4 \AA)$. After ion exchange with $\mathrm{Ca}^{2+}$, the microporsity can be measured and show that they decrease with increasing acid treatment level. Removal of surfactant templates by calcinations does not affect the crystallinity of the samples.

Table 3. Properties of unrived and rived A zeolites

\begin{tabular}{|c|c|c|c|c|c|}
\hline & $\begin{array}{c}\text { Citric Acid } \\
\text { (meq/g zeolite) }\end{array}$ & $\begin{array}{c}\text { MicroPV, cc/g } \\
(0-20 \AA)\end{array}$ & $\begin{array}{c}\text { MesoPV, cc/g } \\
(20-135 \AA)\end{array}$ & $\begin{array}{c}\text { \%Cryst. } \\
\text { (vs. Na-A) }\end{array}$ & $\begin{array}{l}\text { UCS } \\
\text { (Å) }\end{array}$ \\
\hline $\mathrm{Na}-\mathrm{A}(4 \mathrm{~A})$ & 0 & 0 & 0.01 & 100 & 24.60 \\
\hline $\mathrm{Ca}-\mathrm{A}(5 \mathrm{~A})$ & 0 & 0.39 & 0.01 & 90 & 24.62 \\
\hline Rived-1 & 4 & 0 & 0.09 & 84 & 24.59 \\
\hline Rived-2 & 6 & 0 & 0.15 & 70 & 24.59 \\
\hline Rived-1 (Calc.) & $\mathrm{N} / \mathrm{A}$ & 0 & 0.08 & 85 & 24.56 \\
\hline Rived-2 (Calc.) & $N / A$ & 0 & 0.15 & 71 & 24.55 \\
\hline Rived-1 ( $\mathrm{Ca}^{2+}$ exch.) & $\mathrm{N} / \mathrm{A}$ & 0.26 & 0.11 & 64 & 24.61 \\
\hline Rived-2 ( $\mathrm{Ca}^{2+}$ exch.) & $N / A$ & 0.19 & 0.21 & 49 & 24.52 \\
\hline
\end{tabular}

In summary, Rive's proprietary technology in making mesoporous $Y$ zeolite is successfully exctended to make mesoporous $X$ and $A$ zeolites. The mesopore volume can be easily controlled by the amount of citric acid used in the pre-treatment step before surfactant and base treatment.

\section{Binding of zeolites to form adsorbent particles}

Zeolites, typically a few hundred nanometers to a few micrometers in size, cannot be used directly in adsorptive separation or testing because the pressure drop through the compacted bed would be too high.

Typically, the zeolite is mixed with some kind of "adhesive", e.g. clay, and compressed or extruded to form certain shape and size. For the pulse testing, particles of 20-60 mesh ( 250840 micron) are typically used. After experimenting with different formulations and particle forming processes, it is found that a mixture of $80 \mathrm{wt} \%$ hydrated zeolite and $20 \%$ hydrated Attagel 50 with additional 10-25 wt\% de-ionized water can be pressed using a hydraulic press at $\sim 12000-15000$ psi pressure to form reasonably strong pressed pellets, which can then be carefully calcined at $650{ }^{\circ} \mathrm{C}$ for 2 hours under flowing dry air to set the binder (Attagel 50). The pressed pellets then are crushed in a grinder and sieved to the desirable size range (20-60 mesh). The particles made by this process are of irregular shape and have reasonable bulk density and good mechanical strength to sustain the pulse testing. After calcinations, the particles are washed with dilute $\mathrm{NaOH}$ slolution to remove any possible proton sites formed 
during the calcinations step. Before testing, the adsorbents are typically activated at $250{ }^{\circ} \mathrm{C}$ under flowing nitrogen for 2 hours (Figure 13).

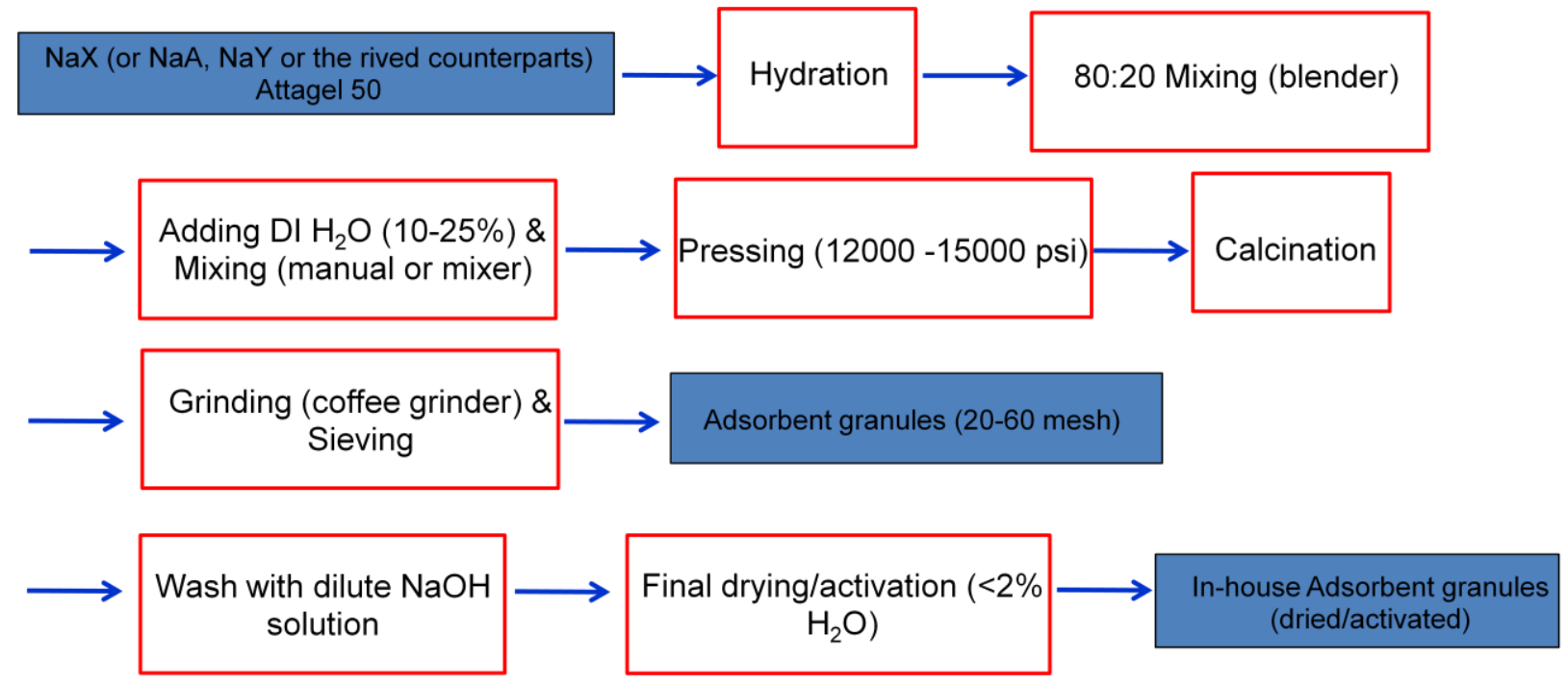

Figure 13. Current preparation process scheme for laboratory adsorbent particles

Table 4. Properties of the zeolites and the adsorbent particles prepared from the corresponding zeolites

\begin{tabular}{|c|c|c|c|c|c|c|c|c|c|}
\hline & $\%$ Crystal & $\begin{array}{l}\text { UCS } \\
(\AA)\end{array}$ & $\begin{array}{c}\text { MicroPV } \\
(0-20 \AA, \mathrm{cc} / \mathrm{g})\end{array}$ & $\begin{array}{c}\text { MesoPV } \\
(20-300 \AA, \mathrm{cc} / \mathrm{g})\end{array}$ & $\begin{array}{c}\text { BET } \\
\left(\mathrm{m}^{2} / \mathrm{g}\right)\end{array}$ & $\begin{array}{c}\text { ESA } \\
\left(\mathrm{m}^{2} / \mathrm{g}\right)\end{array}$ & $\begin{array}{r}\mathrm{Hg}-\mathrm{PV} \\
(\mathrm{cc} / \mathrm{g})\end{array}$ & $\begin{array}{l}\text { Total PV } \\
\text { (cc/g) }\end{array}$ & SAR \\
\hline $\begin{array}{l}\text { Commercial } \\
\text { NaX } \\
\text { Adsorbent }\end{array}$ & 68 & 24.95 & 0.25 & 0.05 & 709 & 33 & 0.32 & 0.62 & 2.81 \\
\hline $\begin{array}{l}\text { Unrived } \\
\text { NaX Zeolite }\end{array}$ & 100 & 24.97 & 0.37 & 0.01 & 888 & 26 & $\mathrm{~N} / \mathrm{A}$ & $\mathrm{N} / \mathrm{A}$ & 2.46 \\
\hline $\begin{array}{l}\text { Unrived } \\
\text { NaX } \\
\text { Adsorbent }\end{array}$ & 68 & 24.97 & 0.25 & 0.04 & 632 & 31 & 0.31 & 0.60 & 2.95 \\
\hline $\begin{array}{l}\text { Rived } \mathrm{NaX} \\
\text { Zeolite }\end{array}$ & 70 & 24.96 & 0.27 & 0.12 & 767 & 119 & $\mathrm{~N} / \mathrm{A}$ & $\mathrm{N} / \mathrm{A}$ & 2.96 \\
\hline $\begin{array}{l}\text { Rived } \mathrm{NaX} \\
\text { Adsorbent }\end{array}$ & 46 & 24.94 & 0.17 & 0.12 & 499 & 90 & 0.42 & 0.71 & 3.35 \\
\hline $\begin{array}{l}\text { Unrived } \\
\text { NaY Zeolite }\end{array}$ & 100 & 24.66 & 0.38 & 0.02 & 949 & 21 & $\mathrm{~N} / \mathrm{A}$ & $\mathrm{N} / \mathrm{A}$ & 5.22 \\
\hline $\begin{array}{l}\text { Unrived } \\
\mathrm{NaY} \\
\text { Adsorbent }\end{array}$ & 72 & 24.62 & 0.31 & 0.07 & 794 & 41 & 0.56 & 0.94 & 5.63 \\
\hline $\begin{array}{l}\text { Rived NaY } \\
\text { Zeolite }\end{array}$ & 89 & 24.58 & 0.32 & 0.11 & 903 & 173 & $\mathrm{~N} / \mathrm{A}$ & $\mathrm{N} / \mathrm{A}$ & 6.41 \\
\hline $\begin{array}{l}\text { Rived } \mathrm{NaY} \\
\text { Adsorbent }\end{array}$ & 71 & 24.55 & 0.25 & 0.09 & 700 & 95 & 0.61 & 0.95 & 7.01 \\
\hline
\end{tabular}


It was determined to use moderately rived zeolites with $\sim 0.12 \mathrm{cc} / \mathrm{g} 20-300 \AA$ MesoPV for preparation of the "rived" adsorbents in order to minimize the impact on adsorbent capacity (MicroPV). The adsorbent particles (and the rived and unrived zeolites that go into the particles) are characterized by XRD, XRF, nitrogent adsorption/desorption, and mercury porosimetry. The results are listed in Table 4 above. Since only $Y$ and $X$ zeolites are considered for SMB process and pulse testing, results on A zeolites are excluded from this table. As a comparison, a commercial adsorbent made from $\mathrm{NaX}$ zeolite, crushed and sieved to the sme 20-60 mesh size, is also included in the table (and tested too in pulse test). The total pore volume of the adsorbent particles is calculated by adding the 0-300 $\AA$ pore volume form $\mathrm{N}_{2}$ adsorption measurements and the pore volume of $300 \AA-1 \mu \mathrm{m}$ from mercury intrusion measurements $(\mathrm{Hg}$ $\mathrm{PV})$.

In summary, the unrived $\mathrm{NaX}$ adsorbent prepared in Rive laboratory compares well with the commercial $\mathrm{NaX}$ adsorbent in terms of porosity and surface areas. The properties of the laboratory prepared adsorbents (unrived and rived) generally correspond well with the properties of the zeolites inside. The rived adsorbents ( $\mathrm{NaX}$ or $\mathrm{NaY}$ ) show lower MicroPV/ crystallinity and higher MesoPV and ESA ( 2 to 3 times) than the unrived counterparts. 


\section{Pulse Test Unit and Adsorbent Testing:}

\section{Pulse test unit}

Bench-scale, batch-wise pulse test units, which were invented by UOP,[14] provide a convenient way to evaluate/screen various adsorbents. The chromatographic separation test results can provide important information about the separation selectivity and kinetics, which can be used to provide meaningful directional projection of the performance of the adsorbents in a continuous SMB process. In order to operate at pressures high enough (>200 psig) to ensure all chemicals (propane, propylene, desorbent and tracer) remain in liquid phase under the test conditions, Rive Technology hired Guild Associates, an Ohio company specializing in adsorption system integrations, to customize and build a pulse test unit for this project. Figure 14 depicts a schematic of the pulse unit built. The unit consists of two tanks with one containing the feed mixture to be separated $\left(70: 30\right.$ wt $\left.\% \mathrm{C}_{3} \mathrm{H}_{6}: \mathrm{C}_{3} \mathrm{H}_{8}\right)$ diluted in varying amounts of desorbent (hexane) and the other tank containing the pure desorbent, a Valco 6-port Valve to direct flow through the system, a sample line that contains $9 \mathrm{~mL}$ of the feed mixture to be separated, a mass flow controller for accurately monitoring the rate at which the fluid is sent through the system, a thermostated convection oven that contains a steel column packed with the adsorbent used for the experiment, back pressure regulator, and an Agilent Technologies 7890A Gas Chromatograph (GC) equipped with a Valcobond Capillary column for on-line analysis of the effluent fluid mixture from the PTU. High Purity $\mathrm{H}_{2}$ was used as the carrier gas for the GC. Separate gas cylinders for $\mathrm{N}_{2}$ and air were also connected to the PTU to allow for purging the system with gas.

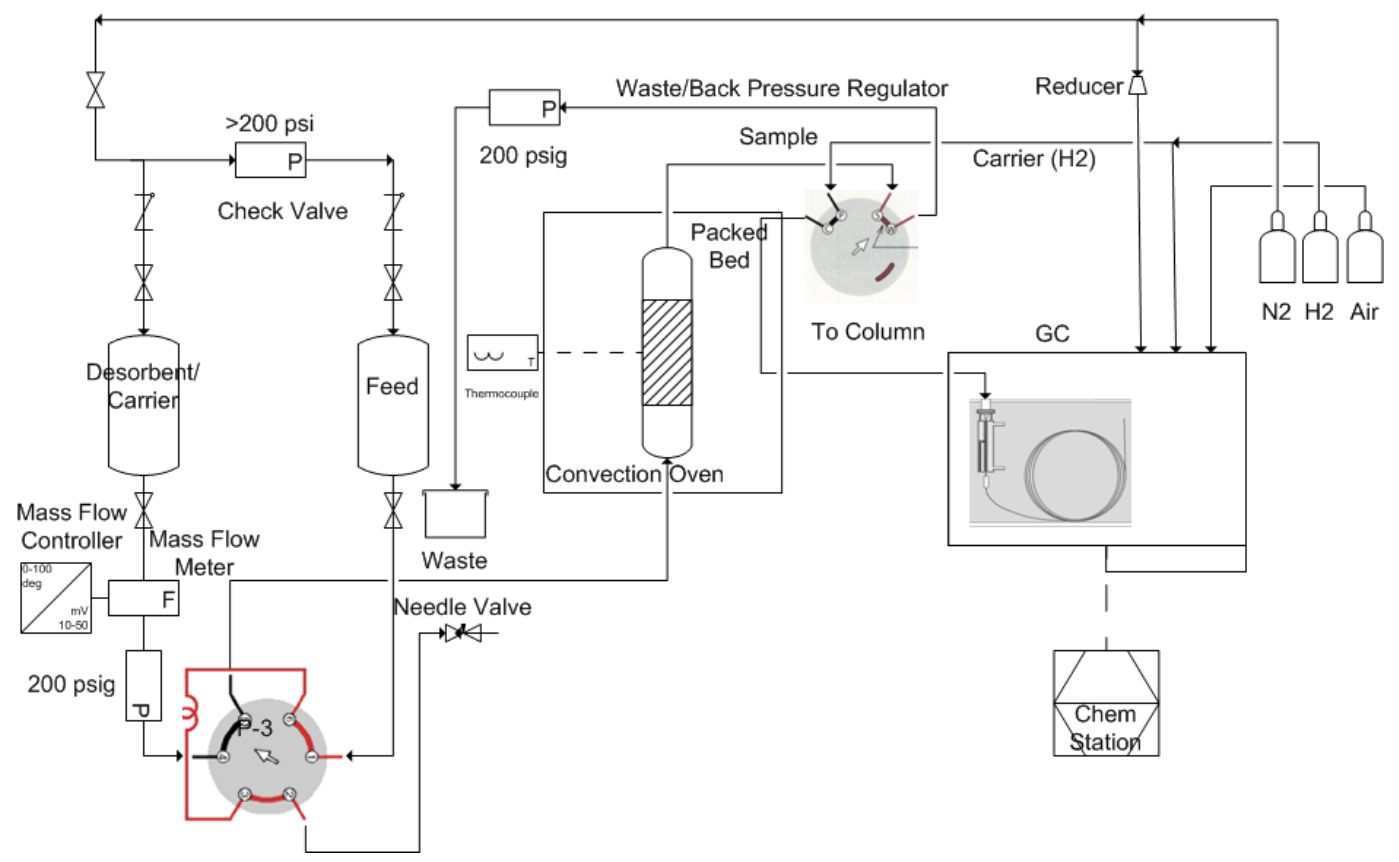

Figure 14. A schematic of the pulse test unit built and used in this project 


\section{Column packing, pulse testing and results treatment}

The adsorbent to be tested was ground and sieved between a mesh size of 20 and 60, corresponding to particle sizes of $0.853 \mathrm{~mm}$ and $0.251 \mathrm{~mm}$ respectively. The adsorbents were heated to $250^{\circ} \mathrm{C}$ for 2 hours under flowing air to remove all moisture. The adsorbent was then allowed to gain $\sim 4-5 \%$ wt. moisture by exposing it to the ambient air prior to being packed in the adsorbent bed.

The adsorbent bed is a $116.8 \mathrm{~cm}$ long coiled steel tube of $0.95 \mathrm{~cm}$ OD that was packed with a sample of adsorbent, usually around $40-45 \mathrm{~g}$. Prior to packing, the volume of the empty tube was measured by filling it with liquid water, and then pouring the water into a graduated beaker and measuring the volume of water the column contained. The volume of the empty column was $55 \mathrm{~mL}$. The empty tube was also filled with pressurized Helium at $50 \mathrm{psig}$, and then depressurized to ambient pressure. The volume of gas exiting the column upon depressurization was measured by water displacement from a graduated cylinder, and this measurement was used to determine packed column void fractions of the different adsorbents.

The column was tapped as it was packed with adsorbent to ensure good packing of the adsorbent in the bed. The bulk density of the adsorbent, $\rho_{b}\left(\mathrm{~g} / \mathrm{cm}^{3}\right)$, was measured from the mass of adsorbent packed in the filled column divided by the empty volume of the column. The bed void fractions, $\varepsilon$, were measured by pressurizing the packed columns with Helium to 50 psig and depressurizing to ambient pressure while measuring the volume of water displaced from a graduated cycling. $\varepsilon$ is equal to the ratio of volume of gas out from the packed column to volume of gas out from the empty column. A summary of measured bulk densities and column void fractions appears in Table 5. This table also contains information on the relative crystallinity, the unit cell size (UCS), and the silica:alumina ratio (SAR) as well. The crystallinity and UCS were measured in an XRD unit, with the crytallinity measured relative to CBV500 (USY) zeolite. The SAR was measured from XRF data.

Table 5. Packed column properties for different adsorbents

\begin{tabular}{llccccc}
\hline Sample & Notes & $\boldsymbol{\rho}_{\mathrm{b}}, \mathbf{g} / \mathbf{c m}^{\mathbf{3}}$ & $\boldsymbol{\varepsilon}$ & \%Crystallinity & UCS & SAR \\
\hline RP52-18X-20x60 & Commercial NaX & 0.75 & 0.73 & 68 & 24.96 & 2.81 \\
RP52-22X-D & In-house Unrived NaX & 0.71 & 0.73 & 68 & 24.97 & 2.95 \\
RP52-19X-D & Rived NaX & 0.61 & 0.76 & 49 & 24.912 & 3.35 \\
RP52-23Y-D & In-house Unrived NaY & 0.6 & 0.79 & 72 & 24.62 & 5.60 \\
RP52-24Y-D & Rived NaY & 0.54 & 0.83 & 71 & 24.55 & 7.00 \\
\hline
\end{tabular}

As can be seen from the table, as expected due to the introduction of mesopores into the Rived samples, the bulk density is lower and the packed column void fraction is higher for the Rived adsorbents. The packed column was then placed inside of the convection oven and the experiments were then ready to be performed. To carry out the experiments, the system was 
pressurized to 200 psig under flowing pure desorbent at a rate set by the mass flow controller. The oven temperature was set at the desired temperature. The $9 \mathrm{~mL}$ sample line is filled with the feed and desorbent mixture. Table 6 gives the different experimental temperatures, flow rates, and sample line compositions used for all adsorbents tested. The desorbent of choice at this time has been chosen to be hexane. The GC sampling is set at a rate of 1 sample per 2 minutes, and the switch valve is set so that the desorbent flows through the mass flow controller and through the sample line to push the sample through the column. As the experiment proceeds, the more strongly adsorbed species (propylene) is retained on the adsorbent and takes longer to travel through the column, while the less strongly adsorbed component (propane) emerges from the column first.

Table 6. Test conditions for all adsorbents

\begin{tabular}{ccc}
\hline Column Temperature $\left({ }^{\circ} \mathbf{C}\right)$ & Flow rate $(\mathbf{m L} / \mathbf{h r})$ & $\mathbf{C}_{3}$ mixture $\%$ \\
\hline 30 & 50 & 4 \\
& 70 & 4 \\
& 100 & 4 \\
50 & 50 & 4 \\
& 70 & 4 \\
& 100 & 4 \\
50 & 50 & 25 \\
& 70 & 25 \\
70 & 100 & 25 \\
& 50 & 4 \\
& 70 & 4 \\
\hline
\end{tabular}

Figure 15 shows an example of a pulse test result comparing the separation performance of Rived and Unrived $\mathrm{NaX}$ zeolite at a temperature of $50^{\circ} \mathrm{C}$, flowrate of $100 \mathrm{~mL} / \mathrm{hr}$, and feed concentration of $25 \%$. This Figure shows the normalized height of the GC detector response as a function of volume of desorbent passed through the column. The first peak observed has a sharp Gaussian shaped peak and corresponds to propane exiting the system, which is the less strongly adsorbed component. The second peak to emerge has a sharp rise to its peak maximum, followed by a tailing decrease to the baseline. This peak is propylene, the more strongly adsorbed species. The peak has a long tail that is more pronounced on the commercial $\mathrm{NaX}$ sample, and this is due to the high concentration of $\mathrm{C}_{3} \mathrm{H}_{6}$ used in this particular experiment. The principles of chromatography are to use a low enough concentration of adsorbate to 
operate where the fluid-solid equilibrium relation is linear (Henry's Law region), which will result in a Gaussian peak shape. At higher concentrations, the equilibrium relationship deviates from linearity and causes the peak tail that we observe in the pulse test. The peak asymmetry was measured for the chromatograms by taking the ratio of b/a at $10 \%$ of the maximum peak height.[15] For a Gaussian peak, b/a = 1. A measure of the peak broadening (due to adsorption kinetics) is obtained by looking at the peak width at half height, and is given by $\Delta \mathrm{w}_{1 / 2}$ on the Figure. The other values on the figure are $\mathrm{V}_{\mathrm{C3} 8}, \mathrm{~V}_{\mathrm{C3} \text { 6 }}$, and $\mathrm{V}_{\mathrm{T}}$, which are respectively the retention volumes of propane, propylene, and a tracer component. The retention volume of each component is rigorously calculated by taking the zeroth and $1^{\text {st }}$ statistical moments, $\mu_{0}$ and $\mu_{1}$ respectively, of the peak as [16]

$$
\begin{array}{cc}
\mu_{0}=\int_{0}^{\infty} h_{i} d t & 1 \\
\mu_{1}=\frac{1}{\mu_{0}} \int_{0}^{\infty} h_{i} t d t & 2 \\
V_{i}=Q \mu_{1} & 3
\end{array}
$$

where $h_{i}$ is the height of the chromatograph response at time $t$, and $Q$ is the volumetric flowrate. $\mu_{0}$ gives the total area under the peak.
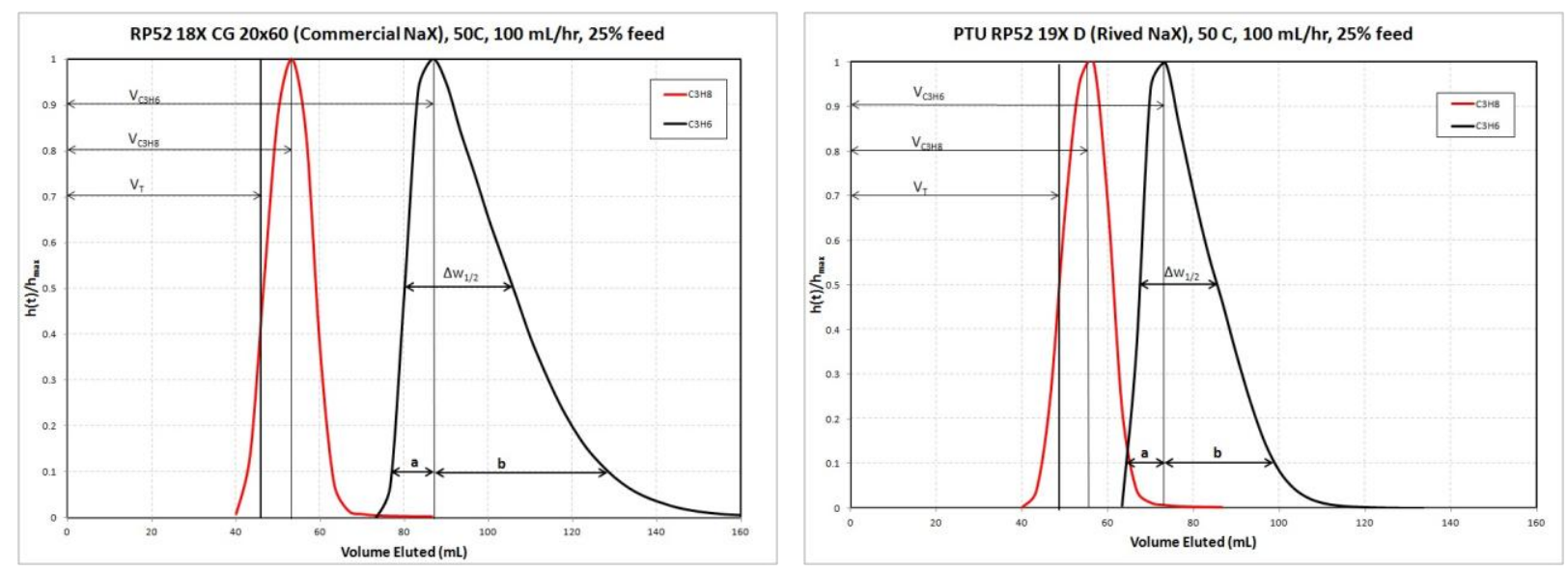

Figure 15. Comparison of Pulse Test Experiments on Commercial NaX(left) and Rived $\mathrm{NaX}$ (right) at $50^{\circ} \mathrm{C}, 100 \mathrm{~mL} / \mathrm{hr}$, and $25 \%$ feed

An issue that is integral to analyzing pulse test data is performing a tracer run using a nonadsorbing component to measure the retention volume of a component that simply passes through the column without adsorbing. The tracer experiments are performed as follows. The feed tank is filled with toluene and the sample line is filled. The experiment is started using isobutane as the carrier fluid and after a few minutes, a second pulse of toluene is sent through the system. The effluent is monitored until a toluene band is observed in the GC. For these experiments, only one band is observed as most of the toluene has adsorbed on the adsorbent surface. A second feed tank replaces the toluene tank that contains $\sim 1.5 \%$ ethane dissolved in 
isobutane, and a standard pulse test as described previously is run. The ethane is observed to emerge from the column at generally 4-6 minutes earlier than the propane peaks observed in the separation experiments. Isobutane was found to be a suitable purge fluid for the tracer experiments as a longer hydrocarbon molecule interacts too strongly with the toluene-saturated adsorbent, displacing toluene and allowing the ethane to adsorb, and therefore does not give an accurate measurement of system dead volume.

Once the tracer run was established, the pulse test experiment data could be used to calculate the Equilibrium adsorption selectivey from the relative retention volumes. First the retention factors for each component are calculated as

$$
k_{i}^{\prime}=\frac{V_{i}-V_{T}}{V_{T}}
$$

and the adsorption selectivity is calculated by

$$
S=\frac{k_{C 3 H 6}^{\prime}}{k_{C 3 H 8}^{\prime}}
$$

A relative measure of the equilibrium constants, $\mathrm{K}_{\mathrm{A}}$, for propane and propylene can be calculated from $\mu_{1}[16]$ by carrying out the experiment at different flow rates using the following equation: [17]

$$
\frac{\Delta \mu_{1}-\frac{t_{i n j}}{2}}{\frac{1-\varepsilon}{\varepsilon}}=K_{A}\left(\frac{L}{v}\right)
$$

In this equation, $\Delta \mu_{1}$ is the difference between the component and tracer $1^{\text {st }}$ moment, $t_{\text {inj }}$ is the sample injection time, $L$ is the column length, $\varepsilon$ is the packed column void fraction, and $v$ is the fluid velocity. $K_{A}$ is a dimensionless equilibrium constant. To obtain $\mathrm{K}_{\mathrm{A}}$, the left hand side is plotted vs. L/v, and the slope of the line passing through the origin is equal to $\mathrm{K}_{\mathrm{A}}$.

The pulse test experiments also give information to the overall transport diffusivity (mass transfer resistance) on the adsorbent material. First, the $2^{\text {nd }}$ central moment of each peak is calculated using the $1^{\text {st }}$ moment by:

$$
\mu_{2}=\sigma^{2}=\frac{1}{\mu_{0}} \int_{0}^{\infty} h_{i}\left(t-\mu_{1}\right)^{2} d t
$$

The $2^{\text {nd }}$ central moment is also called the variance of the peak response, and it is used to calculate the height equivalent to a theoretical transfer plate, HETP, by

$$
\text { HETP }=\frac{\sigma^{2}}{\mu_{1}^{2}} L
$$

where $L$ is the column length. A low HETP is desirable for a high column efficiency. Using the HETP values measured at different flow rates, a Van Deemter [18] approach is used where HETP is plotted vs. the fluid velocity, $v$, to give the following relation:

$$
H E T P=\frac{2 D_{L}}{v}+2 \frac{\varepsilon}{1-\varepsilon} \frac{1}{15 K_{A}} \frac{R_{p}^{2}}{D} v
$$


Here, $D_{L}$ is the axial dispersion coefficient, $R_{p}$ is the adsorbent particle radius, and $D$ is the overall transport diffusivity, calculated as $\mathrm{cm}^{2} / \mathrm{s}$. The slope of these plots along with the previously calculated equilibrium constants allows for a measure of the overall transport diffusivity for each adsorbate on the adsorbent.

\section{Test results on rived and unrived $\mathrm{NaX}$ zeolites}

The above calculations are suitable for a linear equilibrium relationship, and it was believed that the concentration of propylene was too high to validate this assumption. Pulse Test experiments were carried out at lower feed concentrations (4\%) at the conditions listed in Table 6. Figure 16 shows an example of the results using $50^{\circ} \mathrm{C}, 100 \mathrm{~mL} / \mathrm{hr}$, and $4 \%$ feed (same as Figure 15 but different feed concentrations). When compared with Figure 15, we can see that the retention of propane remains relatively unchanged while that for propylene is extended, increasing the selectivity. This is consistent with the fact that maximal selectivity is achieved when operating at sufficiently low concentrations approaching the linear equilibrium relation region.[17] The peak tailing for both materials is reduced, and that of the Rived $\mathrm{NaX}$ is greatly reduced and has a much more symmetric shape than its UnRived counterpart. This reduction in peak tailing also allows the sample to be fully eluted using much less desorbent and hence a shorter time.
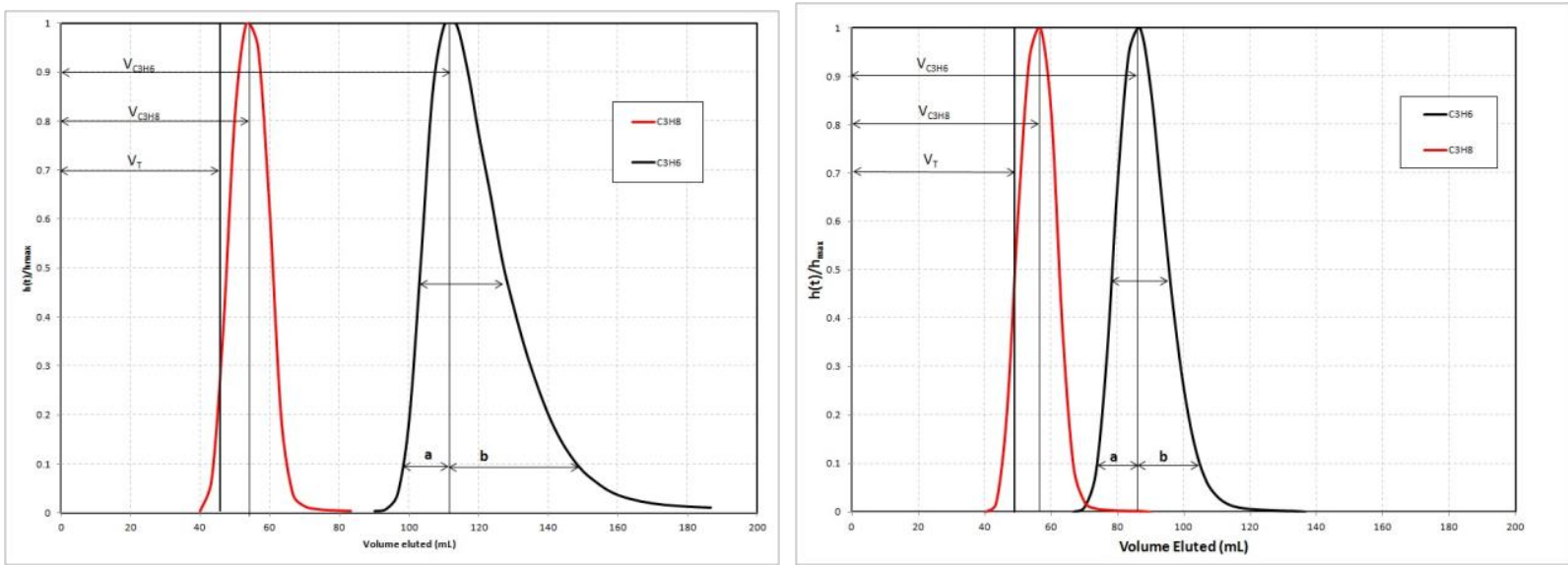

Figure 16. Comparison of pulse test results on Commercial $\mathrm{NaX}$ (left) and Rived $\mathrm{NaX}$ (right) at $50^{\circ} \mathrm{C}, 100 \mathrm{~mL} / \mathrm{hr}$, and $4 \%$ feed

The differences between the Rived and Commercial $\mathrm{NaX}$ samples were consistently the same for every Pulse Test experiment carried out, and Figures $15 \& 16$ give a good representation of the difference between the two materials; therefore none of the other test results will be shown. It should also be noted that the Commercial $\mathrm{NaX}$ and In House Unrived $\mathrm{NaX}$ zeolites showed almost the same adsorption characteristics and will not be shown. Table 7 summarizes all of the experimental results on the different $\mathrm{NaX}$ zeolites, and includes measures of peak tailing, $\Delta \mathrm{w}_{1 / 2}$ $(\mathrm{min})$, measured relative $\mathrm{K}_{\mathrm{A}}$, selectivity, the height equivalent to a theoretical transfer plate (HETP), and measured overall transport diffusivity, $D\left(\mathrm{~cm}^{2} / \mathrm{s}\right)$. As can be seen from the table, the effects of Riving on the $\mathrm{X}$ zeolite are as follows:

- Lower relative dimensionless Equilibrium constants for propylene. 
- $30-50 \%$ reduction in $\Delta \mathrm{w}_{1 / 2}$ for propylene at all conditions.

- $30-50 \%$ reduction in calculated $2^{\text {nd }}$ central moment, $\sigma^{2}$, at all conditions.

- 2-3 x's increased overall transport diffusivity for propylene at all conditions.

- Lowered selectivity that is a weaker function of temperature.

Table 7. Tabulated pulse test results for Commercial $\mathrm{NaX}$ (top), In-house Unrived $\mathrm{NaX}$ (middle), and Rived $\mathrm{NaX}$ (bottom)

\begin{tabular}{|c|c|c|c|c|c|c|c|c|c|c|}
\hline \multicolumn{11}{|c|}{ Commercial $\mathrm{NaX}$ zeolite } \\
\hline Component & Bed $\mathrm{T}\left({ }^{\circ} \mathrm{C}\right)$ & $\begin{array}{l}\begin{array}{l}\text { Flow rate } \\
(\mathrm{mL} / \mathrm{hr})\end{array} \\
\end{array}$ & Feed \% & $\begin{array}{c}\mathrm{A}_{\mathrm{s}, 10 \%} \\
\text { Peak } \\
\text { Asymmetry }\end{array}$ & $\begin{array}{c}\Delta w_{0.5} \\
\text { Chromatogram } \\
\text { peak width at half- } \\
\text { height }\end{array}$ & $\begin{array}{c}\sigma^{2} \\
\text { Peak 2nd } \\
\text { moment }\end{array}$ & HETP & $\begin{array}{r}\text { Measured } \\
\text { Equilibrium } \\
\text { constant, } \mathrm{K}\end{array}$ & $\begin{array}{c}\text { Overal } \\
\text { Transport } \\
\text { Diffusivity } \\
\text { D }\left(\mathrm{cm}^{2} / \mathrm{s}\right)\end{array}$ & Selectivity \\
\hline \multirow[b]{12}{*}{$\mathrm{C} 3 \mathrm{H} 6$} & 30 & 50 & 4 & 3.3 & 31.8 & 231.3 & 0.36 & \multirow[b]{3}{*}{4.4} & \multirow[b]{3}{*}{$1.9 \mathrm{E}-05$} & \multirow[b]{3}{*}{9.3} \\
\hline & 30 & 70 & 4 & 3.1 & 23.8 & 134.1 & 0.43 & & & \\
\hline & 30 & 100 & 4 & 2.9 & 17.5 & 72.3 & 0.49 & & & \\
\hline & 50 & 50 & 4 & 3.1 & 24.7 & 136.0 & 0.32 & \multirow[b]{3}{*}{3.4} & \multirow[b]{3}{*}{$2.7 \mathrm{E}-05$} & \multirow[b]{3}{*}{8.0} \\
\hline & 50 & 70 & 4 & 2.8 & 19.6 & 89.0 & 0.38 & & & \\
\hline & 50 & 100 & 4 & 2.7 & 13.9 & 50.6 & 0.46 & & & \\
\hline & 50 & 50 & 25 & 4.9 & 29.2 & 165.6 & 0.55 & \multirow[b]{3}{*}{2.3} & \multirow[b]{3}{*}{$3.9 \mathrm{E}-05$} & \multirow[b]{3}{*}{6.6} \\
\hline & 50 & 70 & 25 & 4.4 & 21 & 92.5 & 0.62 & & & \\
\hline & 50 & 100 & 25 & 4.0 & 15.6 & 50.3 & 0.69 & & & \\
\hline & 70 & 50 & 4 & 2.3 & 21.4 & 107.5 & 0.31 & \multirow[b]{3}{*}{2.6} & \multirow[b]{3}{*}{ 6.6E-05 } & \multirow[b]{3}{*}{7.0} \\
\hline & 70 & 70 & 4 & 2.1 & 15.9 & 59.6 & 0.35 & & & \\
\hline & 70 & 100 & 4 & 2.1 & 11.4 & 30.4 & 0.38 & & & \\
\hline \multirow[b]{12}{*}{$\mathrm{C} 3 \mathrm{H} 8$} & 30 & 50 & 4 & 1.0 & 16.2 & 35.8 & 0.35 & \multirow[b]{3}{*}{0.3} & \multirow[b]{3}{*}{ 1.1. $\mathrm{E}-04$} & \multirow[b]{3}{*}{-} \\
\hline & 30 & 70 & 4 & 1.0 & 11.3 & 18.4 & 0.36 & & & \\
\hline & 30 & 100 & 4 & 1.0 & 7.7 & 9.3 & 0.38 & & & \\
\hline & 50 & 50 & 4 & 1.0 & 15.2 & 34.1 & 0.35 & \multirow[b]{3}{*}{0.2} & \multirow[b]{3}{*}{$1.5 \mathrm{E}-04$} & \multirow[b]{3}{*}{-} \\
\hline & 50 & 70 & 4 & 1.0 & 10.8 & 17.3 & 0.35 & & & \\
\hline & 50 & 100 & 4 & 1.2 & 7.6 & 8.9 & 0.38 & & & \\
\hline & 50 & 50 & 25 & 0.9 & 15.1 & 30.4 & 0.32 & \multirow[b]{3}{*}{0.2} & \multirow[b]{3}{*}{$1.5 \mathrm{E}-04$} & \multirow[b]{3}{*}{-} \\
\hline & 50 & 70 & 25 & 0.9 & 7.5 & 15.3 & 0.33 & & & \\
\hline & 50 & 100 & 25 & 1.1 & 7.5 & 8.0 & 0.36 & & & \\
\hline & 70 & 50 & 4 & 0.8 & 15.6 & 32.4 & 0.33 & \multirow[b]{3}{*}{0.2} & \multirow[b]{3}{*}{$8.2 \mathrm{E}-04$} & \multirow[b]{3}{*}{ - } \\
\hline & 70 & 70 & 4 & 0.9 & 11.3 & 17.2 & 0.37 & & & \\
\hline & 70 & 100 & 4 & 1.0 & 7.7 & 8.6 & 0.39 & & & \\
\hline
\end{tabular}


RP52 22X D

In house UnRived $\mathrm{NaX}$ zeolite

\begin{tabular}{|c|c|c|c|c|c|c|c|c|c|c|}
\hline Component & Bed T $\left({ }^{\circ} \mathrm{C}\right)$ & $\begin{array}{l}\begin{array}{l}\text { Flow rate } \\
(\mathrm{mL} / \mathrm{hr})\end{array} \\
\end{array}$ & Feed $\%$ & $\begin{array}{c}\mathrm{A}_{\mathrm{s}, 10 \%} \\
\text { Peak } \\
\text { Asymmet } \\
\text { ry }\end{array}$ & $\begin{array}{c}\Delta w_{0.5} \\
\text { Chromatogr } \\
\text { am peak } \\
\text { width at } \\
\text { half-height }\end{array}$ & $\begin{array}{c}\sigma^{2} \\
\text { Peak 2nd } \\
\text { moment }\end{array}$ & HETP & $\begin{array}{r}\text { Measured } \\
\text { Equilibrium } \\
\text { constant, } \mathrm{K}\end{array}$ & $\begin{array}{c}\text { Overal } \\
\text { Transport } \\
\text { Diffusivity } \\
\mathrm{D}\left(\mathrm{cm}^{2} / \mathrm{s}\right)\end{array}$ & Selectivity \\
\hline \multirow[b]{12}{*}{$\mathrm{C} 3 \mathrm{H} 6$} & 30 & 50 & 4 & 3.5 & 32.8 & 298.2 & 0.42 & \multirow[b]{3}{*}{4.9} & \multirow[b]{3}{*}{ 2.2E-05 } & \multirow[b]{3}{*}{9.0} \\
\hline & 30 & 70 & 4 & 3.3 & 26.3 & 182.4 & 0.49 & & & \\
\hline & 30 & 100 & 4 & 3.1 & 20.9 & 102.7 & 0.54 & & & \\
\hline & 50 & 50 & 4 & 3.1 & 27.8 & 185.7 & 0.37 & \multirow[b]{3}{*}{3.7} & \multirow[b]{3}{*}{$6.1 \mathrm{E}-05$} & \multirow[b]{3}{*}{7.2} \\
\hline & 50 & 70 & 4 & 2.8 & 19.7 & 97.4 & 0.39 & & & \\
\hline & 50 & 100 & 4 & 2.8 & 14.7 & 51.5 & 0.42 & & & \\
\hline & 50 & 50 & 25 & 5.9 & 30.0 & 335.1 & 0.96 & \multirow[b]{3}{*}{2.6} & \multirow[b]{3}{*}{ 7.6E-05 } & \multirow[b]{3}{*}{5.6} \\
\hline & 50 & 70 & 25 & 5.4 & 21.5 & 168.1 & 0.98 & & & \\
\hline & 50 & 100 & 25 & 4.5 & 18.7 & 84.3 & 1.02 & & & \\
\hline & 70 & 50 & 4 & 2.6 & 22.6 & 114.6 & 0.31 & \multirow[b]{3}{*}{2.8} & \multirow[b]{3}{*}{ 7.1E-05 } & \multirow[b]{3}{*}{6.3} \\
\hline & 70 & 70 & 4 & 2.3 & 16.6 & 63.0 & 0.34 & & & \\
\hline & 70 & 100 & 4 & 2.4 & 12.1 & 33.5 & 0.37 & & & \\
\hline \multirow[b]{12}{*}{$\mathrm{C} 3 \mathrm{H} 8$} & 30 & 50 & 4 & 1.0 & 16.1 & 35.0 & 0.33 & \multirow[b]{3}{*}{0.4} & \multirow[b]{3}{*}{ 6.2E-04 } & \multirow[b]{3}{*}{ - } \\
\hline & 30 & 70 & 4 & 1.1 & 11.3 & 19.0 & 0.36 & & & \\
\hline & 30 & 100 & 4 & 1.1 & 7.7 & 9.8 & 0.38 & & & \\
\hline & 50 & 50 & 4 & 0.95 & 15.7 & 35.0 & 0.34 & \multirow[b]{3}{*}{0.3} & \multirow[b]{3}{*}{ 2.6E-03 } & \multirow[b]{3}{*}{-} \\
\hline & 50 & 70 & 4 & 1 & 11.6 & 17.5 & 0.34 & & & \\
\hline & 50 & 100 & 4 & 1.0 & 7.7 & 8.6 & 0.35 & & & \\
\hline & 50 & 50 & 25 & 0.95 & 15.3 & 32.7 & 0.32 & \multirow[b]{3}{*}{0.3} & \multirow[b]{3}{*}{$1.5 \mathrm{E}-03$} & \multirow[b]{3}{*}{ - } \\
\hline & 50 & 70 & 25 & 1 & 10.3 & 16.8 & 0.33 & & & \\
\hline & 50 & 100 & 25 & 0.94 & 8.2 & 8.4 & 0.35 & & & \\
\hline & 70 & 50 & 4 & 0.87 & 16.2 & 33.5 & 0.33 & \multirow[b]{3}{*}{0.3} & \multirow[b]{3}{*}{$1.9 \mathrm{E}-03$} & \multirow[b]{3}{*}{-} \\
\hline & 70 & 70 & 4 & 0.89 & 10.8 & 17.1 & 0.35 & & & \\
\hline & 70 & 100 & 4 & 0.89 & 7.7 & 8.5 & 0.36 & & & \\
\hline
\end{tabular}


RP52 19X D CG20x60 Rived NaX zeolite

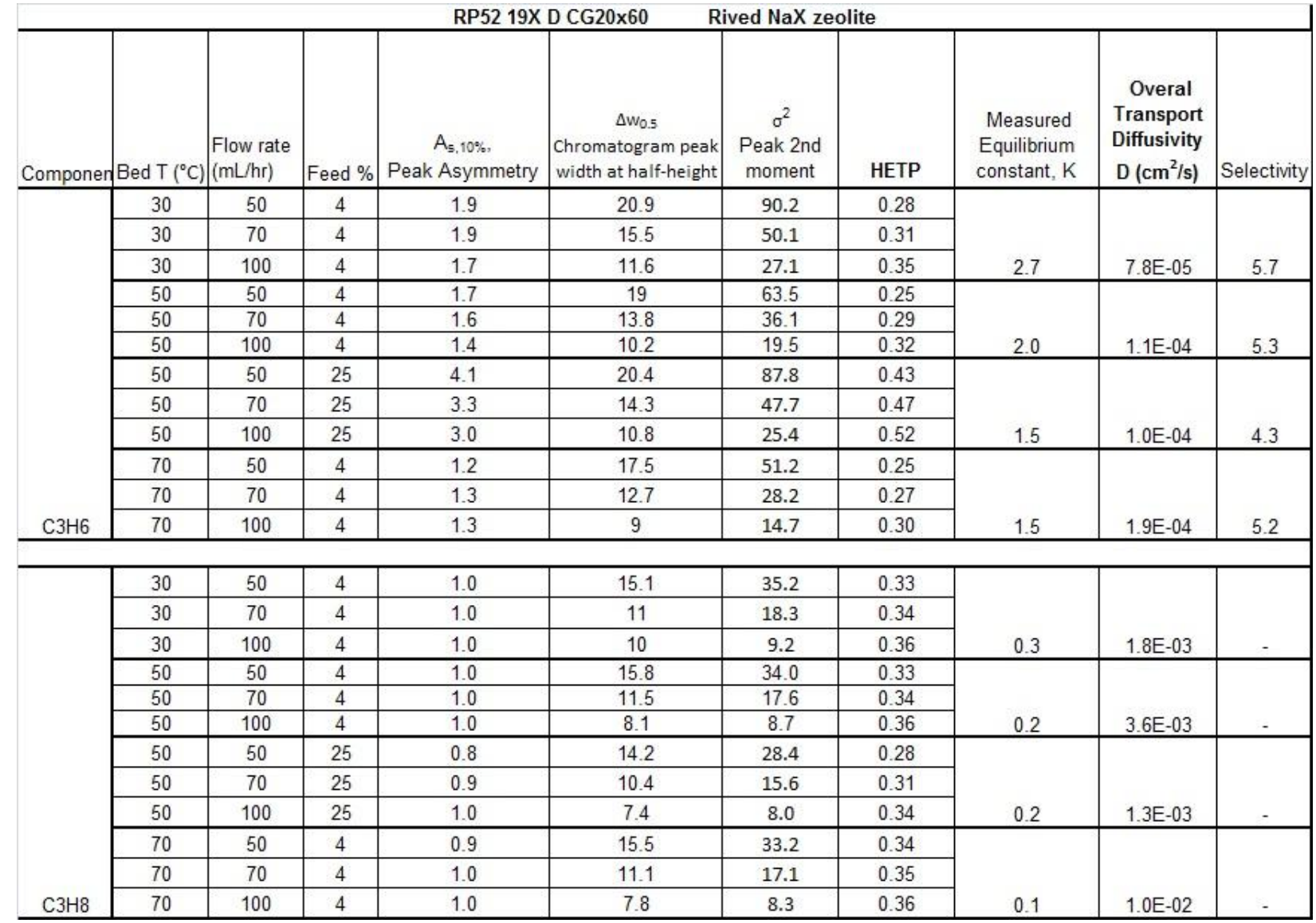

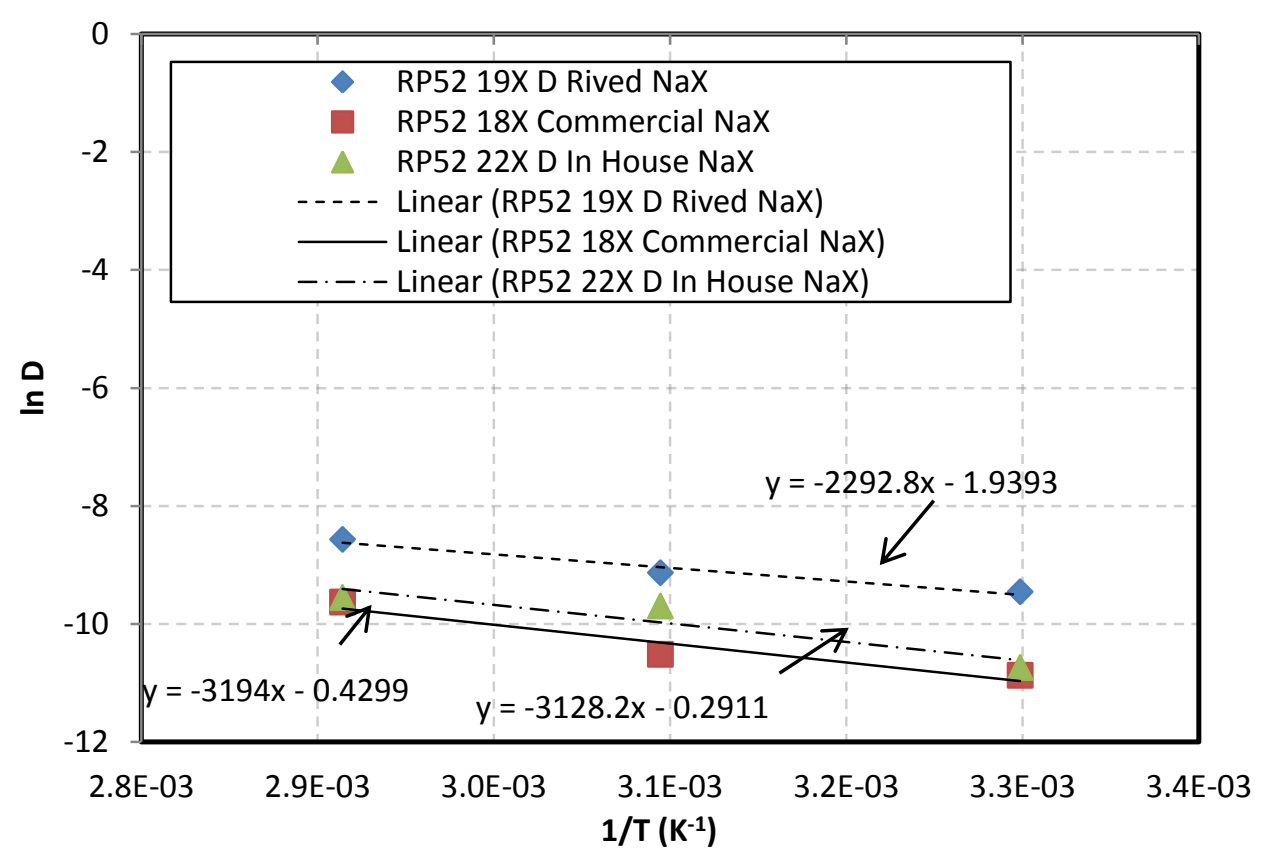

Figure 17. Arrhenius plot showing temperature dependence of $\mathrm{C}_{3} \mathrm{H}_{6}$ transport in Rived and Unrived NaX zeolites 
An interesting feature to be noted is that the propane peaks remained relatively unchanged at all conditions tested on the Rived and UnRived Materials. This is most likely that for very fast diffusing species, chromatographic measurements are not very suitable for these calculations. It can be concluded that propane transport is very fast on both Rived and UnRived materials. The diffusivities at the low concentration runs (4\%) were plotted on an Arrhenius plot as functions of temperature (In D vs. 1/T). The slope of this plot gives the value of the activation energy to diffusional resistance, $-E_{D} / R$, and the plot appears linear for propylene in Figure 17. This figure only shows the propylene adsorption data on Rived, Commercial UnRived, and In-House UnRived $\mathrm{NaX}$ as the propane was deemed too fast to obtain accurate measurements. The resulting values of $E_{D}$ were respectively found to be $26.6,26.0$, and $19.1 \mathrm{~kJ} / \mathrm{mol}$ on the Commercial $\mathrm{NaX}$, the In House Unrived $\mathrm{NaX}$, and the Rived $\mathrm{NaX}$, respectively. This lower diffusional activation energy on the Rived $\mathrm{NaX}$ confirms that the propylene molecule encounters less restriction to motion within the $\mathrm{NaX}$ particle, and therefore exhibits higher rates of transport.[19]

Gas phase adsorption isotherms of propylene and propane were measured independently on the samples of Rived and UnRived NaX by Thermogravimetric Analysis (TGA). A small sample ( $\sim 40 \mathrm{mg}$ ) of adsorbent was placed in the pan of the TGA unit and initially heated to $400^{\circ} \mathrm{C}$ under flowing $\mathrm{N}_{2}$ and held there until the measured sample mass remained constant. The sample was then cooled to the desired adsorption temperature and exposed to a different partial pressures of either propane or propylene. At each partial pressure, the mass was allowed to stabilize, and then the partial pressure of hydrocarbon was increased. The total system pressure was $1 \mathrm{~atm}$. After the final isotherm point was measured, the sample was again heated to $400^{\circ} \mathrm{C}$, and the sample mass was observed to stabilize at the initial mass (that following the first heat treatment) indicating complete reversibility of the adsorption of either propane or propylene. The crystallinity of the samples appears in Table 5. Figures 18 \& 19 show the respective corrected propylene and propane adsorption isotherms measured on the Rived $\mathrm{NaX}$ and UnRived $\mathrm{NaX}$ samples. These plots all measure the adsorbed phase loading in mol gas adsorbed/g adsorbent plotted as a function of the gas phase partial pressure. Due to the exothermic nature of adsorption, a higher capacity is achieved for a given gas phase partial pressure at lower temperatures.

The adsorbents containing Rived $\mathrm{NaX}$ zeolite desplayed a decrease of $\sim 20 \%$ capacity for both propylene and propane compared to the UnRived NaX adsorbent samples. The heats of adsorption which are the strength with which the adsorbate is bound to the adsorbent were estimated from the adsorption isotherms using thermodynamic relations.[20] The heats for propylene and propane on the Commercial and UnRived materials were very similar and estimated to be $\sim-43.1 \mathrm{~kJ} / \mathrm{mol}$ and $-31.4 \mathrm{~kJ} / \mathrm{mol}$ respectively. These values correspond well with other measured values over $13 \mathrm{X}$ reported by other literature sources (-42.5 and -35.8 $\mathrm{kJ} / \mathrm{mol}$,[21] -46.1 and $-32.9 \mathrm{~kJ} / \mathrm{mol}$ [22]) The corresponding heats for propylene and propane on the Rived samples were estimated to be $-41.0 \mathrm{~kJ} / \mathrm{mol}$ and $-31.8 \mathrm{~kJ} / \mathrm{mol}$ respectively. It should be noted that better estimates of the heats of adsorption from the isotherms would be obtained if more low pressure sorption data were available at low adsorbate loadings. The heats of adsorption are often decreasing functions of surface coverage, and the largest heat is that obtained at zero coverage.[17] A better and more accurate method for heat of adsorption 
measurements would be to use the Sorption Isosteric Technique (SIT) which incorporates the use of a calorimeter to precisely measure the heat evolved due to adsorption as a function of the adsorbate loading.[22] Such a study is beyond the scope of this work.
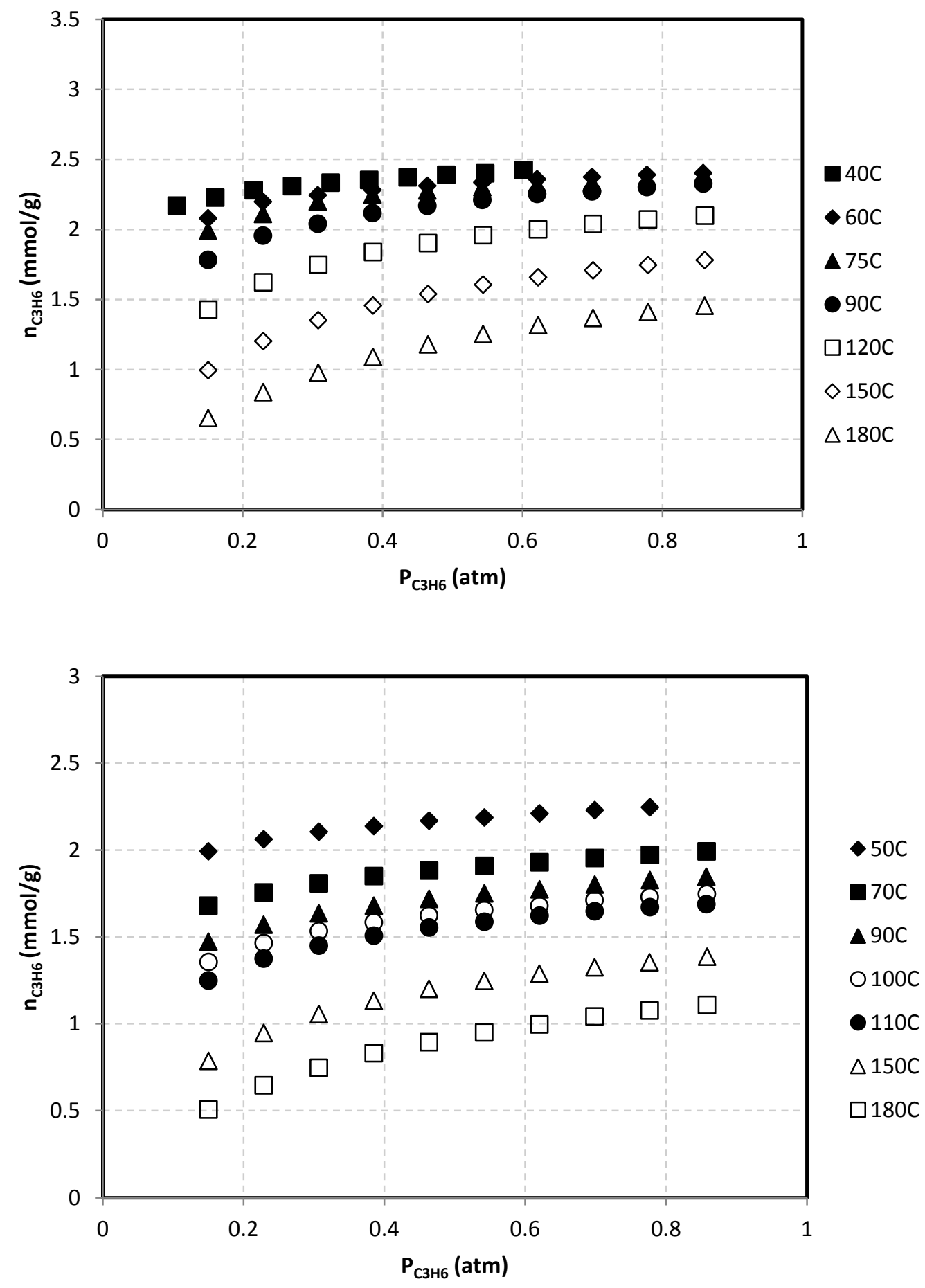


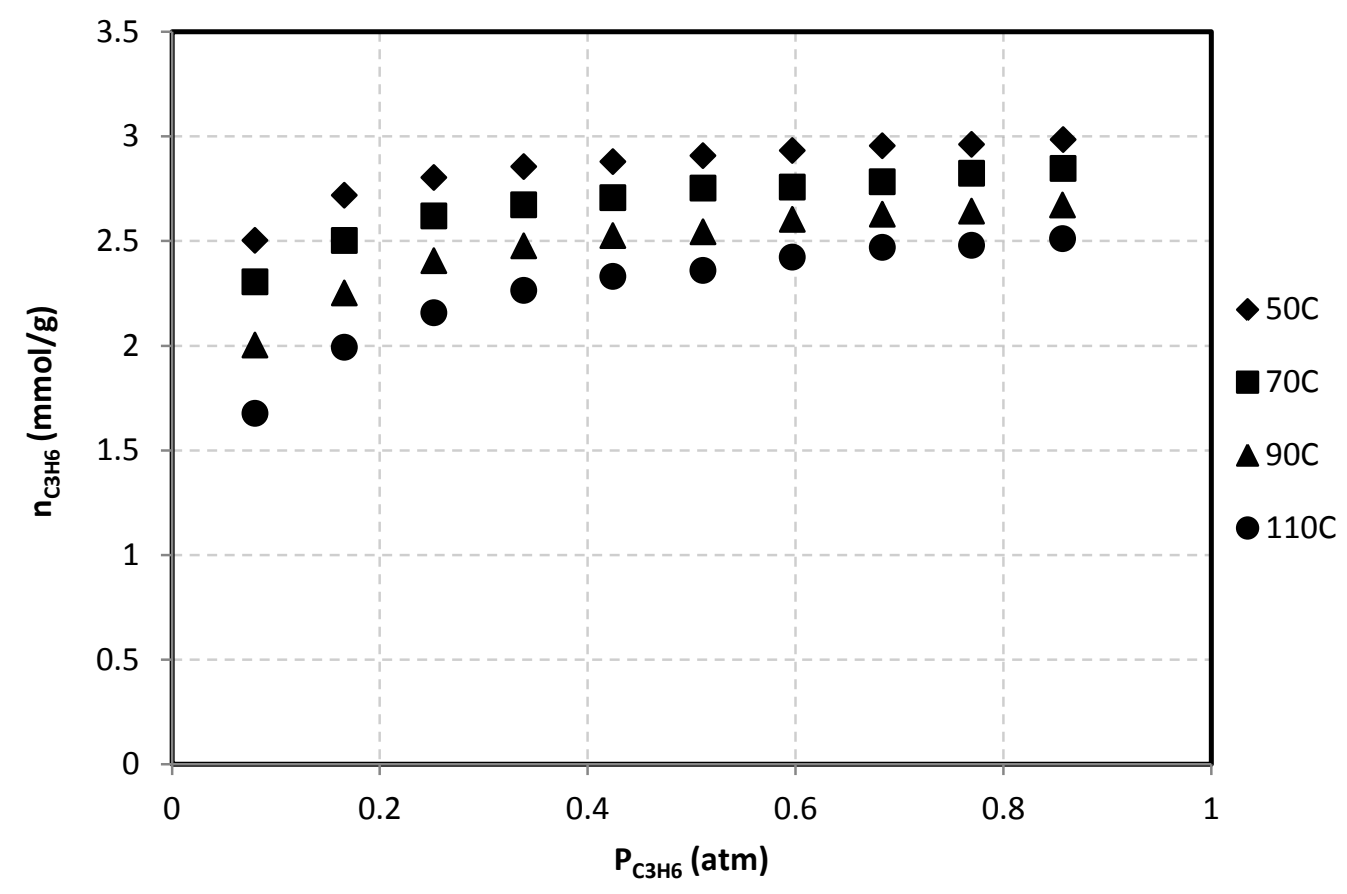

Figure 18. Propylene adsorption isotherms on Commercial $\mathrm{NaX}$ (top), Rived $\mathrm{NaX}$ (middle), and In-house UnRived NaX (bottom) zeolite adsorbents

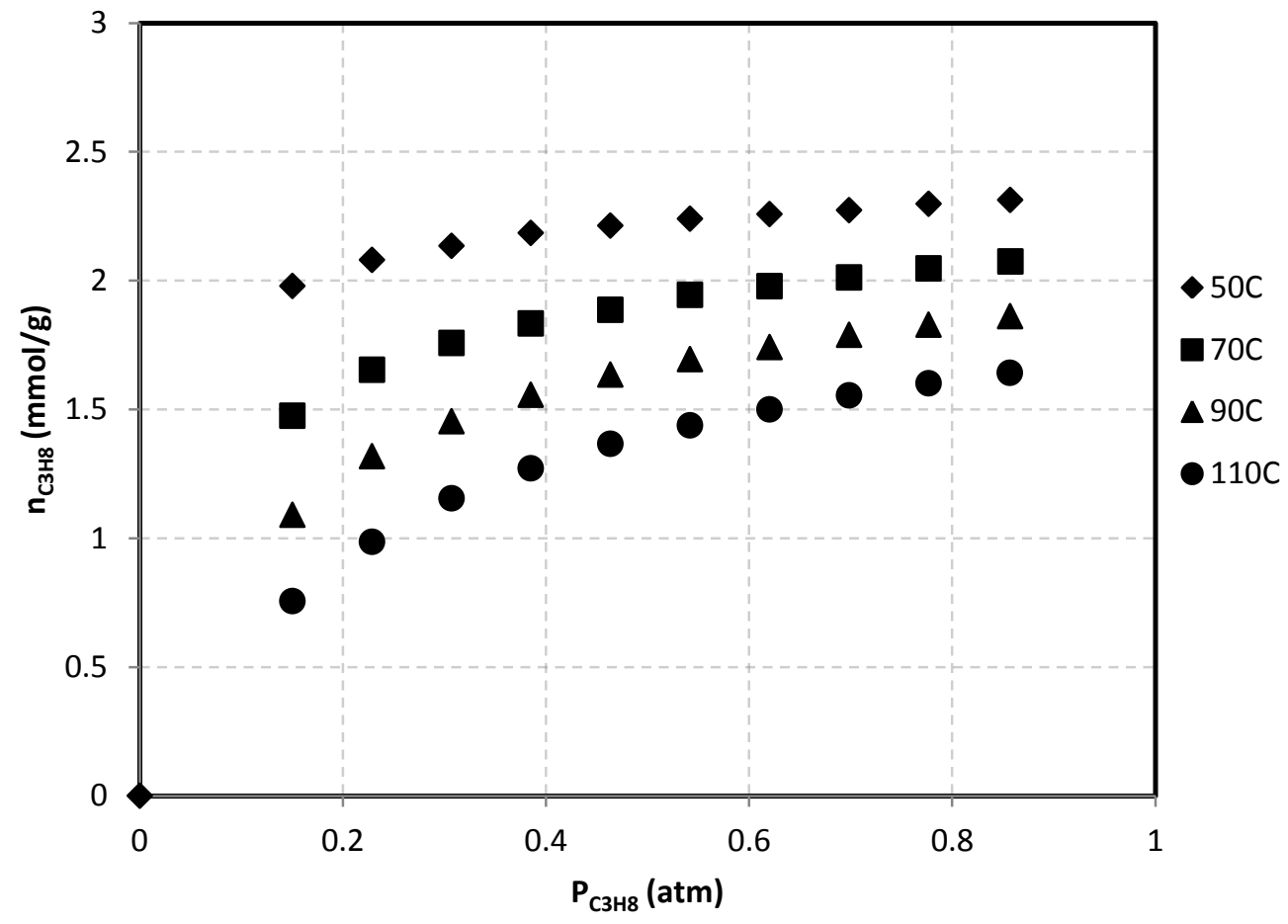



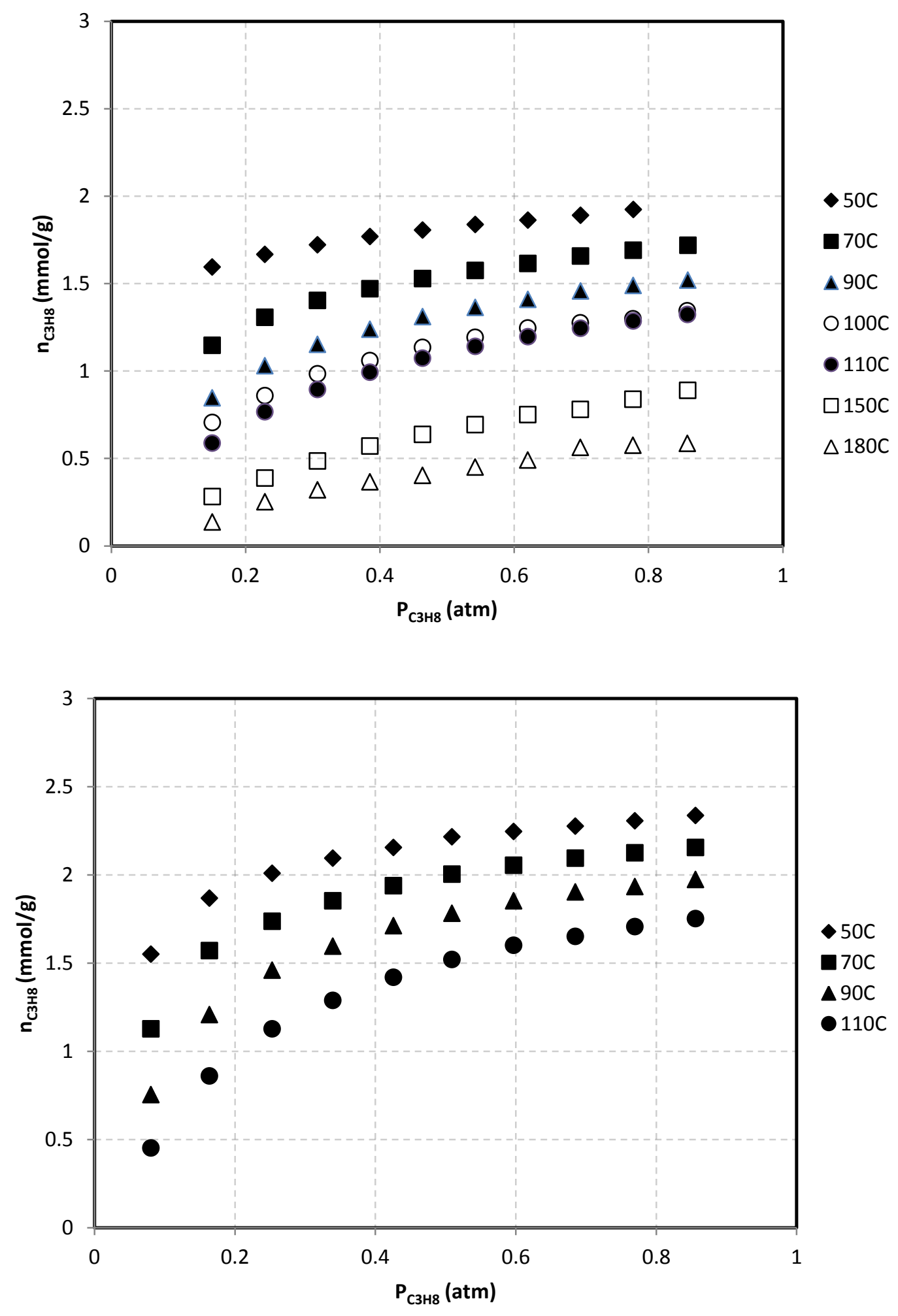

Figure 19. Propane adsorption isotherms on Commercial $\mathrm{NaX}$ (top), Rived $\mathrm{NaX}$ (middle), and In-house Unrived $\mathrm{NaX}$ (bottom)zeolites 
In summary, the riving of $\mathrm{NaX}$ zeolite (intracrystalline mesoporosity) impacted the results of the pulse tests in the following ways:

- Lower relative dimensionless Equilibrium constants for propylene

- $\quad 30-50 \%$ reduction in $\Delta \mathrm{w}_{1 / 2}$ for propylene at all conditions

- $\quad 30-50 \%$ reduction in calculated $2^{\text {nd }}$ central moment, $\sigma^{2}$, at all conditions

- $\quad$ 2-3 x's increased overall transport diffusivity for propylene at all conditions

- Lowered selectivity that is a weaker function of temperature

- No clear distinction in kinetics of propane adsorption can be deduced as it is very fast on all materials

An Arrhenius plot of the measured diffusivities as functions of temperature showed that the diffusional activation energy for propylene was lowered from $26.6 \mathrm{~kJ} / \mathrm{mol}$ on the commercial $\mathrm{NaX}$ sample to $19.1 \mathrm{~kJ} / \mathrm{mol}$ on the Rived $\mathrm{NaX}$ sample. This reduction in diffusional activation energy shows that the propylene molecule experiences much more freedom to move within the Rived NaX zeolite.

The adsorption isotherms of the Rived $\mathrm{NaX}$ adsorbent shows that the adsorption capacity of both propylene and propane are $\sim 20 \%$ lower than those observed on the UnRived $\mathrm{NaX}$ samples. The lower crystallinity observed on the Rived $\mathrm{NaX}$ adsorbent sample tells that some of the zeolite was damaged in making the adsorbent particles. The decrease that is observed on the Rived $\mathrm{NaX}$ adsorbent particles could be overcome by either using a higher percentage of the Rived $\mathrm{NaX}$ zeolite in the adsorbent-binder mixture, or by reducing the amount of damage to the zeolite in preparing the samples. The heats of adsorption on the commercial sample of $\mathrm{NaX}$ were determined to be -43.1 and $-31.4 \mathrm{~kJ} / \mathrm{mol}$ respectively for propylene and propane, while on the Rived sample they were determined to be -41.0 and $-31.8 \mathrm{~kJ} / \mathrm{mol}$ respectively.

\section{Test results on rived and unrived NaY zeolites}

Following the experiments on the $\mathrm{NaX}$ zeolites, the exact same sets of experiments listed in Table 6 were carried out on samples of In-house Unrived NaY and Rived NaY zeolite based adsorbents. No commercial sample was available for testing. The bulk density, $\rho_{\mathrm{b}}$, and packed column void fractions, $\varepsilon$, appear in Table 5 . The same procedure described before for packing the adsorbent bed was used for the NaY samples. Figure 20 shows the pulse test results from runs on the UnRived and Rived NaY zeolites at $50^{\circ} \mathrm{C}, 100 \mathrm{~mL} / \mathrm{hr}$, and $25 \%$ feed concentration. As with the $\mathrm{NaX}$, the position of the propane remains relatively unchanged, but broadening of the propane peak was observed, indicating slower kinetics on the $\mathrm{NaY}$ compared to $\mathrm{NaX}$. It is interesting that "riving" effect (introduced mesoporosity improving diffusion kinetics) can be observed for the narrower propane peak on rived NaY zeolite. The propylene peak on the commercial sample is broad, and Riving reduces the retention time and sharpens this peak as 
well. However, at this high feed loading ( $25 \%$ concentration), there is still significant peak tailing on both the Rived and UnRived NaY for propylene.
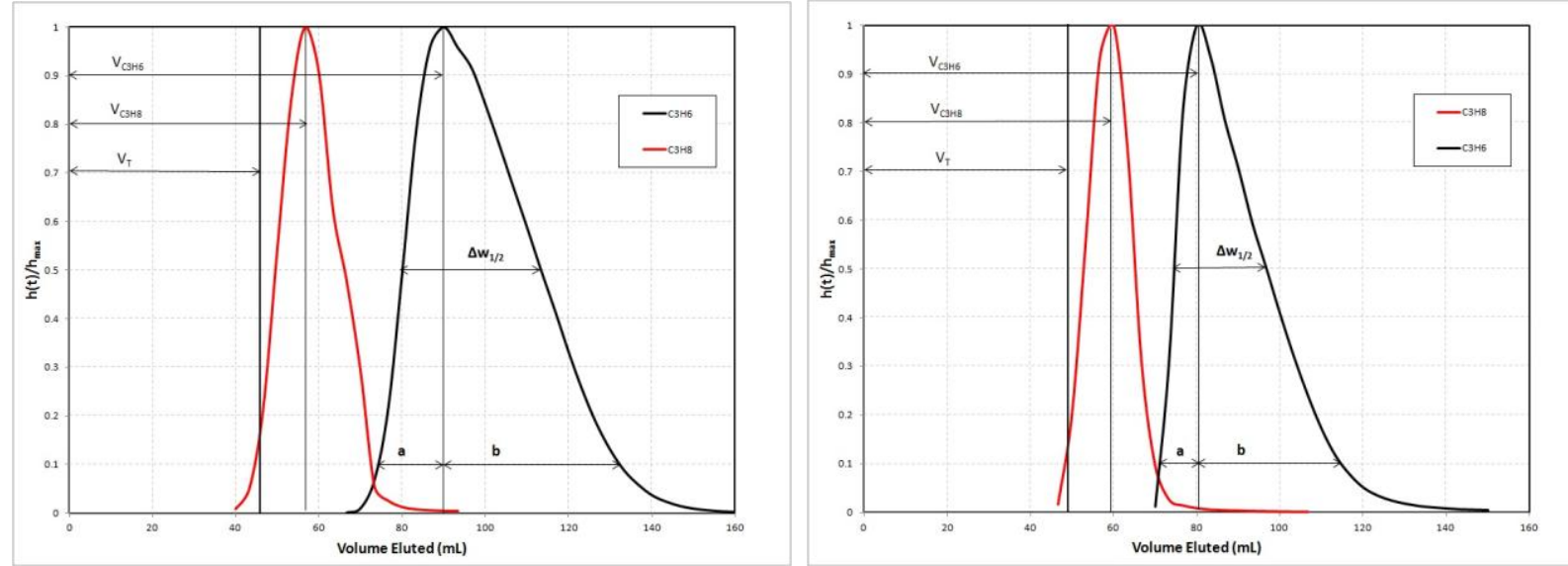

Figure 20. Pulse test results on UnRived $\mathrm{NaY}$ zeolite (left) and Rived $\mathrm{NaY}$ zeolite (right) at $50^{\circ} \mathrm{C}$, $100 \mathrm{~mL} / \mathrm{hr}$, and $25 \%$ feed concentration

Figure 21 shows the pulse test results on the UnRived and Rived NaY zeolites at $50^{\circ} \mathrm{C}, 100$ $\mathrm{mL} / \mathrm{hr}$, and $4 \%$ feed concentration. The retention volume of propane is relatively unchanged but that for the propylene has been pushed to further retention volumes due to the lower concentration of feed. Table 8 summarizes all of the experimental results on the UnRived and Rived $\mathrm{NaY}$ zeolites, and includes measures of peak tailing, $\Delta \mathrm{w}_{1 / 2}(\mathrm{~min})$, measured $\mathrm{K}_{\mathrm{A}}$, selectivity, the height equivalent to a theoretical transfer plate (HETP), and measured overall transport diffusivity, $\mathrm{D}\left(\mathrm{cm}^{2} / \mathrm{s}\right)$.
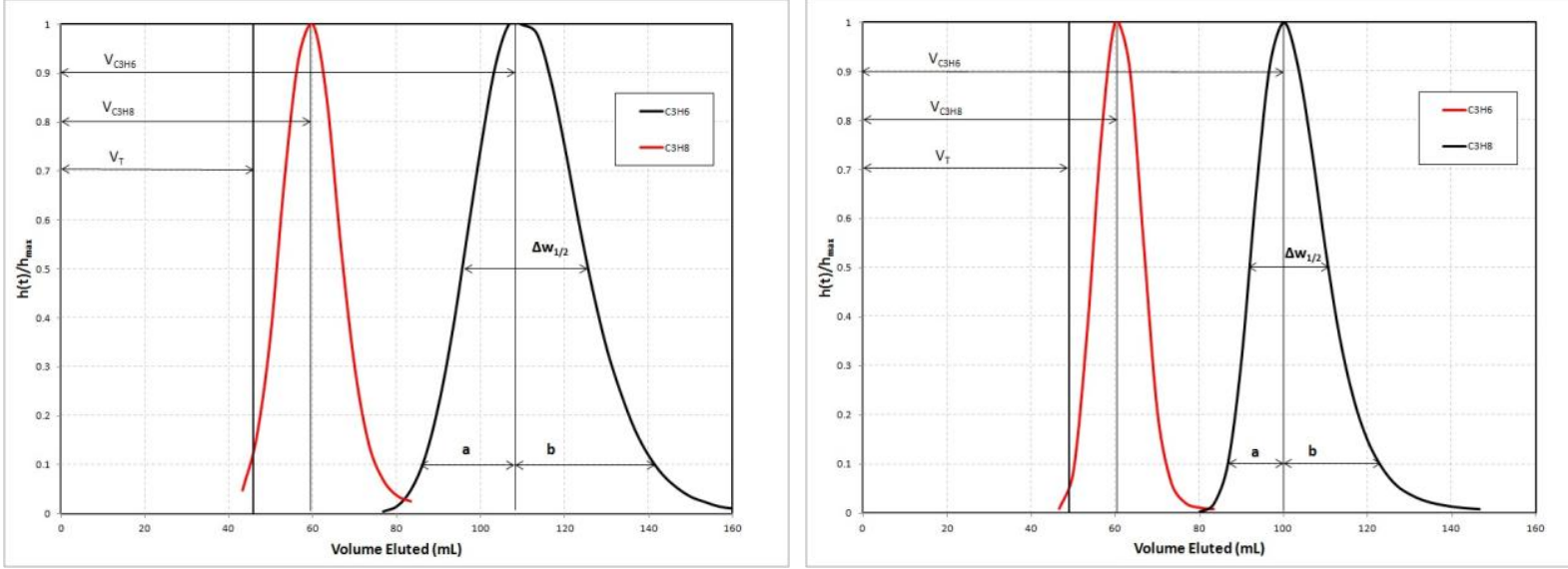

Figure 21. Pulse test tesults on UnRived $\mathrm{NaY}$ zeolite (left) and Rived $\mathrm{NaY}$ zeolite (right) at $50^{\circ} \mathrm{C}$, $100 \mathrm{~mL} / \mathrm{hr}$, and $4 \%$ feed concentration 
Table 8. Tabulated pulse test results for In-house Unrived $\mathrm{NaY}$ (top) and Rived $\mathrm{NaY}$ (bottom) adsorbents

\begin{tabular}{|c|c|c|c|c|c|c|c|c|c|c|}
\hline \multicolumn{5}{|c|}{ RP52 23Y D } & \multicolumn{6}{|c|}{ In house UnRived $\mathrm{NaY}$ zeolite } \\
\hline Componen & Bed T $\left({ }^{\circ} \mathrm{C}\right)$ & $\begin{array}{l}\begin{array}{l}\text { Flow rate } \\
(\mathrm{mL} / \mathrm{hr})\end{array} \\
\end{array}$ & Feed $\%$ & $\begin{array}{c}\mathrm{A}_{\mathrm{s}, 10 \%}, \\
\text { Peak } \\
\text { Asymmet } \\
\text { ry }\end{array}$ & $\begin{array}{c}\Delta w_{0.5} \\
\text { Chromato } \\
\text { gram peak } \\
\text { width at } \\
\text { half- } \\
\text { height } \\
\end{array}$ & \begin{tabular}{|c|} 
\\
$\sigma^{2}$ \\
Peak 2nd \\
moment \\
\end{tabular} & HETP & $\begin{array}{r}\text { Measured } \\
\text { Equilibrium } \\
\text { constant, K }\end{array}$ & \begin{tabular}{|c} 
Overal \\
Transport \\
Diffusivity \\
$\mathrm{D}\left(\mathrm{cm}^{2} / \mathrm{s}\right)$ \\
\end{tabular} & Selectivity \\
\hline \multirow[b]{12}{*}{$\mathrm{C} 3 \mathrm{H} 6$} & 30 & 50 & 4 & 1.4 & 40.9 & 294.6 & 0.52 & \multirow[b]{3}{*}{5.6} & \multirow[b]{3}{*}{ 2.2E-05 } & \multirow[b]{3}{*}{5.4} \\
\hline & 30 & 70 & 4 & 1.4 & 30.5 & 168.7 & 0.59 & & & \\
\hline & 30 & 100 & 4 & 1.3 & 22.2 & 91.8 & 0.66 & & & \\
\hline & 50 & 50 & 4 & 1.5 & 33.3 & 211.7 & 0.52 & \multirow[b]{3}{*}{4.2} & \multirow[b]{3}{*}{ 4.0E-05 } & \multirow[b]{3}{*}{4.7} \\
\hline & 50 & 70 & 4 & 1.4 & 25.4 & 122.7 & 0.59 & & & \\
\hline & 50 & 100 & 4 & 1.5 & 18.0 & 61.6 & 0.63 & & & \\
\hline & 50 & 50 & 25 & 2.5 & 37.8 & 258.1 & 0.83 & \multirow[b]{3}{*}{3.3} & \multirow[b]{3}{*}{$5.9 \mathrm{E}-05$} & \multirow[b]{3}{*}{4.4} \\
\hline & 50 & 70 & 25 & 2.8 & 28.0 & 135.0 & 0.86 & & & \\
\hline & 50 & 100 & 25 & 2.6 & 20.1 & 70.5 & 0.91 & & & \\
\hline & 70 & 50 & 4 & 1.3 & 28.0 & 144.3 & 0.49 & \multirow[b]{3}{*}{3.1} & \multirow[b]{3}{*}{ 6.7E-05 } & \multirow[b]{3}{*}{4.3} \\
\hline & 70 & 70 & 4 & 1.4 & 20.7 & 79.5 & 0.53 & & & \\
\hline & 70 & 100 & 4 & 1.4 & 15.2 & 41.8 & 0.57 & & & \\
\hline \multirow[b]{12}{*}{$\mathrm{C} 3 \mathrm{H} 8$} & 30 & 50 & 4 & 1.1 & 19.6 & 69.1 & 0.56 & \multirow[b]{3}{*}{0.8} & \multirow[b]{3}{*}{ 2. $2 \mathrm{E}-04$} & \multirow[b]{3}{*}{ - } \\
\hline & 30 & 70 & 4 & 1.1 & 14.0 & 38.7 & 0.62 & & & \\
\hline & 30 & 100 & 4 & 1.0 & 10.2 & 19.8 & 0.66 & & & \\
\hline & 50 & 50 & 4 & 1.06 & 18.8 & 66.8 & 0.57 & \multirow[b]{3}{*}{0.7} & \multirow[b]{3}{*}{$3.9 E-04$} & \multirow[b]{3}{*}{ - } \\
\hline & 50 & 70 & 4 & 1.03 & 13.8 & 34.3 & 0.58 & & & \\
\hline & 50 & 100 & 4 & 1.1 & 9.4 & 17.8 & 0.63 & & & \\
\hline & 50 & 50 & 25 & 1.03 & 17.0 & 53.0 & 0.49 & \multirow[b]{3}{*}{0.5} & \multirow[b]{3}{*}{$2.4 \mathrm{E}-04$} & \multirow[b]{3}{*}{ - } \\
\hline & 50 & 70 & 25 & 1 & 12.9 & 29.2 & 0.54 & & & \\
\hline & 50 & 100 & 25 & 1.09 & 9.9 & 17.0 & 0.64 & & & \\
\hline & 70 & 50 & 4 & 1.03 & 17.6 & 56.6 & 0.52 & \multirow[b]{3}{*}{0.5} & \multirow[b]{3}{*}{ 4. $9 \mathrm{E}-04$} & \multirow[b]{3}{*}{ - } \\
\hline & 70 & 70 & 4 & 1.06 & 12.6 & 30.6 & 0.55 & & & \\
\hline & 70 & 100 & 4 & 1.06 & 9.1 & 16.0 & 0.59 & & & \\
\hline
\end{tabular}




\begin{tabular}{|c|c|c|c|c|c|c|c|c|c|c|}
\hline \multicolumn{5}{|c|}{ RP52 24Y D } & \multicolumn{3}{|c|}{ In house Rived NaY zeolite } & \multirow[b]{2}{*}{$\begin{array}{c}\text { Measured } \\
\text { Equilibrium } \\
\text { constant, K }\end{array}$} & \multirow[b]{2}{*}{$\begin{array}{c}\text { Overal } \\
\text { Transport } \\
\text { Diffusivity } \\
\text { D }\left(\mathrm{cm}^{2} / \mathrm{s}\right)\end{array}$} & \multirow[b]{2}{*}{ Selectivity } \\
\hline Componen & Bed T $\left({ }^{\circ} \mathrm{C}\right)$ & $\begin{array}{l}\text { Flow rate } \\
(\mathrm{mL} / \mathrm{hr})\end{array}$ & Feed $\%$ & $\begin{array}{c}\mathrm{A}_{\mathrm{s}, 10 \%} \\
\text { Peak } \\
\text { Asymmet } \\
\text { ry }\end{array}$ & \begin{tabular}{|c|}
$\Delta w_{0.5}$ \\
Chromato \\
gram peak \\
width at \\
half- \\
height \\
\end{tabular} & \begin{tabular}{|c|}
$\sigma^{2}$ \\
Peak 2nd \\
moment
\end{tabular} & HETP & & & \\
\hline \multirow[b]{12}{*}{$\mathrm{C} 3 \mathrm{H} 6$} & 30 & 50 & 4 & 2.0 & 23.7 & 138.2 & 0.31 & \multirow[b]{3}{*}{5.7} & \multirow[b]{3}{*}{ 4.4E-05 } & \multirow[b]{3}{*}{5.0} \\
\hline & 30 & 70 & 4 & 1.9 & 18.1 & 76.6 & 0.34 & & & \\
\hline & 30 & 100 & 4 & 1.8 & 13.6 & 42.2 & 0.39 & & & \\
\hline & 50 & 50 & 4 & 1.6 & 21.1 & 99.6 & 0.28 & \multirow[b]{3}{*}{4.5} & \multirow[b]{3}{*}{ 9.2E-05 } & \multirow[b]{3}{*}{4.5} \\
\hline & 50 & 70 & 4 & 1.9 & 15.7 & 54.4 & 0.31 & & & \\
\hline & 50 & 100 & 4 & 1.7 & 11.1 & 27.9 & 0.34 & & & \\
\hline & 50 & 50 & 25 & 4.0 & 27.3 & 164.9 & 0.63 & \multirow[b]{3}{*}{3.3} & \multirow[b]{3}{*}{$8.0 \mathrm{E}-05$} & \multirow[b]{3}{*}{3.9} \\
\hline & 50 & 70 & 25 & 0.0 & 19.5 & 89.4 & 0.69 & & & \\
\hline & 50 & 100 & 25 & 3.4 & 13.1 & 44.8 & 0.72 & & & \\
\hline & 70 & 50 & 4 & 1.5 & 19.4 & 71.7 & 0.27 & \multirow[b]{3}{*}{3.3} & \multirow[b]{3}{*}{ 1.2E-04 } & \multirow[b]{3}{*}{4.2} \\
\hline & 70 & 70 & 4 & 1.6 & 13.3 & 39.3 & 0.30 & & & \\
\hline & 70 & 100 & 4 & 1.7 & 9.9 & 20.7 & 0.33 & & & \\
\hline \multirow[b]{12}{*}{$\mathrm{C} 3 \mathrm{H} 8$} & 30 & 50 & 4 & 1.1 & 15.5 & 38.2 & 0.30 & \multirow[b]{3}{*}{0.8} & \multirow[b]{3}{*}{ 7.7E-04 } & \multirow[b]{3}{*}{-} \\
\hline & 30 & 70 & 4 & 1.1 & 10.5 & 19.9 & 0.31 & & & \\
\hline & 30 & 100 & 4 & 1.1 & 7.7 & 10.1 & 0.33 & & & \\
\hline & 50 & 50 & 4 & 1.08 & 14.4 & 35.1 & 0.29 & \multirow[b]{3}{*}{0.7} & \multirow[b]{3}{*}{$9.4 \mathrm{E}-04$} & \multirow[b]{3}{*}{-} \\
\hline & 50 & 70 & 4 & 1.14 & 10.3 & 18.5 & 0.30 & & & \\
\hline & 50 & 100 & 4 & 1.2 & 7.7 & 9.7 & 0.32 & & & \\
\hline & 50 & 50 & 25 & 1 & 15.0 & 33.5 & 0.29 & \multirow[b]{3}{*}{0.5} & \multirow[b]{3}{*}{ 7.2E-04 } & \multirow[b]{3}{*}{-} \\
\hline & 50 & 70 & 25 & 1.08 & 10.5 & 18.4 & 0.32 & & & \\
\hline & 50 & 100 & 25 & 0.92 & 7.5 & 9.6 & 0.35 & & & \\
\hline & 70 & 50 & 4 & 0.875 & 15.3 & 32.8 & 0.29 & \multirow[b]{3}{*}{0.5} & \multirow[b]{3}{*}{ 1. $4 \mathrm{E}-03$} & \\
\hline & 70 & 70 & 4 & 1.07 & 10.5 & 17.1 & 0.30 & & & \\
\hline & 70 & 100 & 4 & 0.96 & 7.2 & 8.7 & 0.32 & & & \\
\hline
\end{tabular}

As can be seen from the table, the effects of Riving the $Y$ zeolite are as follows:

- $\quad 30-50 \%$ reduction in $\Delta \mathrm{w}_{1 / 2}$ for propylene at all conditions

- $\quad 20 \%$ reduction in $\Delta \mathrm{w}_{1 / 2}$ for propane at all conditions

- $\quad 30-50 \%$ reduction in calculated $2^{\text {nd }}$ central moment, $\sigma^{2}$, at all conditions for both propylene and propane

- $\quad$ 2x's increased overall transport diffusivity for propylene at all conditions and $\sim 3 x$ 's increased overall transport diffusivity for propane at all conditions

- Slightly lowered selectivity that is a weaker function of temperature

The diffusivities at the low concentration runs (4\%) were plotted on an Arrhenius plot as functions of temperature (In D vs. 1/T). The slope of this plot gives the value of the activation energy to diffusional resistance, $-E_{D} / R$, and the plot appears for both propane and propylene in Figure 22. The resulting values of $E_{D}$ for propylene were respectively found to be 23.6, and 20.6 
$\mathrm{kJ} / \mathrm{mol}$ on the In-house Unrived $\mathrm{NaY}$ and the Rived $\mathrm{NaY}$, respctively. The $\mathrm{E}_{\mathrm{d}}$ values for propane we respectively determined to be 17.3 and $12.5 \mathrm{~kJ} / \mathrm{mol}$ on the In House $\mathrm{NaY}$, and the Rived $\mathrm{NaY}$. This lower diffusional activation energy on the Rived $\mathrm{NaY}$ confirms that both the propylene and propane molecules encounters less restriction of motion within the NaY particle, and therefore displays higher rates of transport.[19]

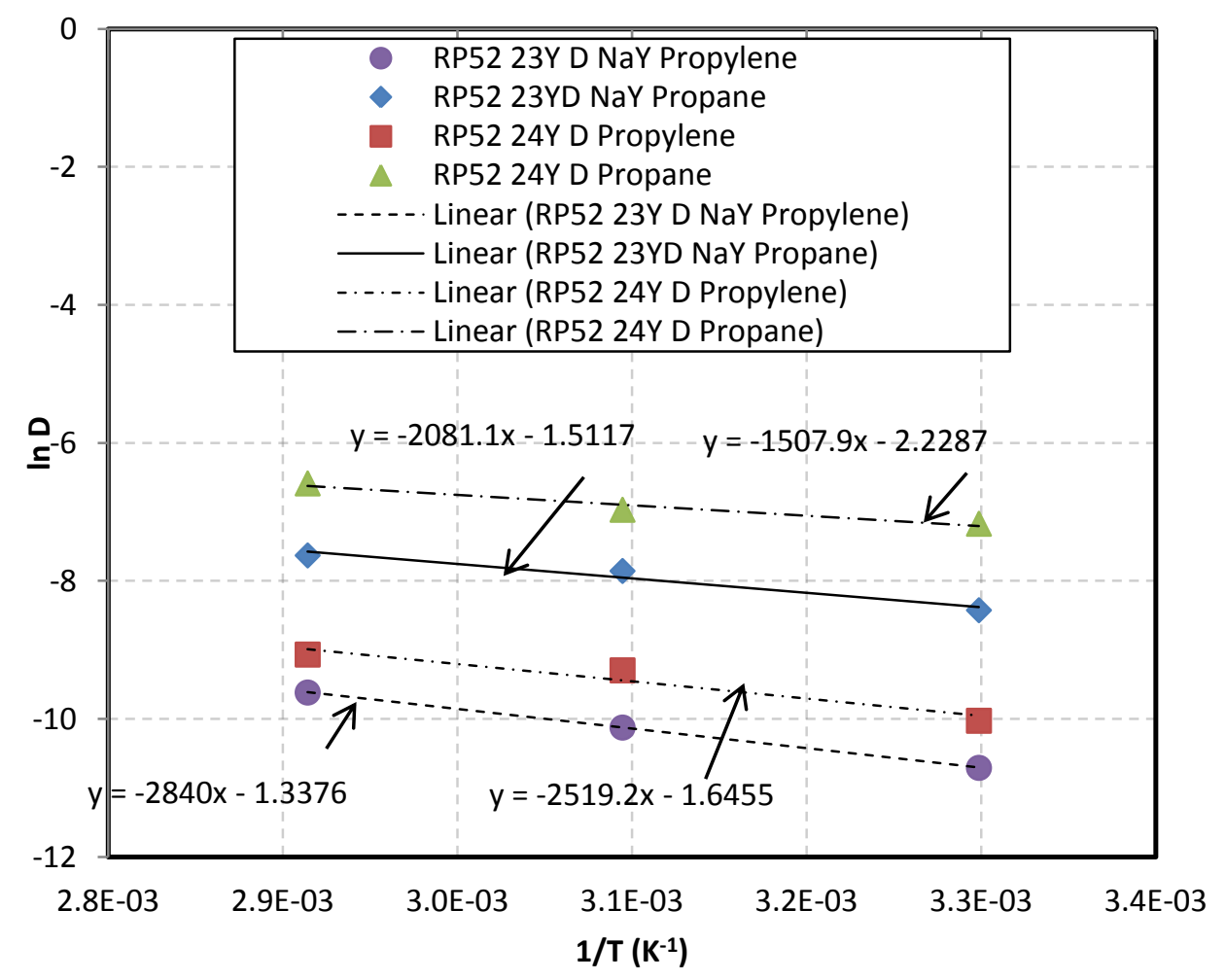

Figure 22. Arrhenius plot showing temperature dependence of $\mathrm{C}_{3} \mathrm{H}_{6}$ and $\mathrm{C}_{3} \mathrm{H}_{8}$ transport in Rived and Unrived NaY zeolites

Gas phase adsorption isotherms of propylene and propane were measured independently on the samples of Rived and UnRived NaY by Thermogravimetric Analysis (TGA). A small sample $(\sim 40 \mathrm{mg})$ of adsorbent was placed in the pan of the TGA unit and initially heated to $400^{\circ} \mathrm{C}$ under flowing $\mathrm{N}_{2}$ and held there until the measured sample mass remained constant. The sample was then cooled to the desired adsorption temperature and exposed to different partial pressures of either propane or propylene. At each partial pressure, the mass was allowed to stabilize, and then the partial pressure of hydrocarbon was increased. The total system pressure was $1 \mathrm{~atm}$. After the final isotherm point was measured, the sample was again heated to $400^{\circ} \mathrm{C}$, and the sample mass was observed to stabilize at the initial mass (that following the first heat treatment) indicating complete reversibility of the adsorption of either propane or propylene. Figure 23 shows the adsorption isotherms for propylene on the samples of Rived and In-house UnRived $\mathrm{NaY}$. Figure 24 shows the adsorption isotherms for propane on the same samples of NaY. Due to the exothermic nature of adsorption, a higher capacity is achieved for a given gas phase 
partial pressure at lower temperatures. The effect of Riving on the NaY zeolite was almost negligible on the equilibrium adsorption capacity. From Figures 23 and 24, it can be seen that the effect of Riving on the $\mathrm{NaY}$ zeolite for propylene adsorption is negligible, with maybe a very slight decrease at the measured isotherm temperatures. The same is true for the adsorption capacity of propane on the Rived and UnRived NaY zeolites. This would explain why there is very little change in experimentally measured selectivities for the Rived vs. UnRived Nay zeolites.

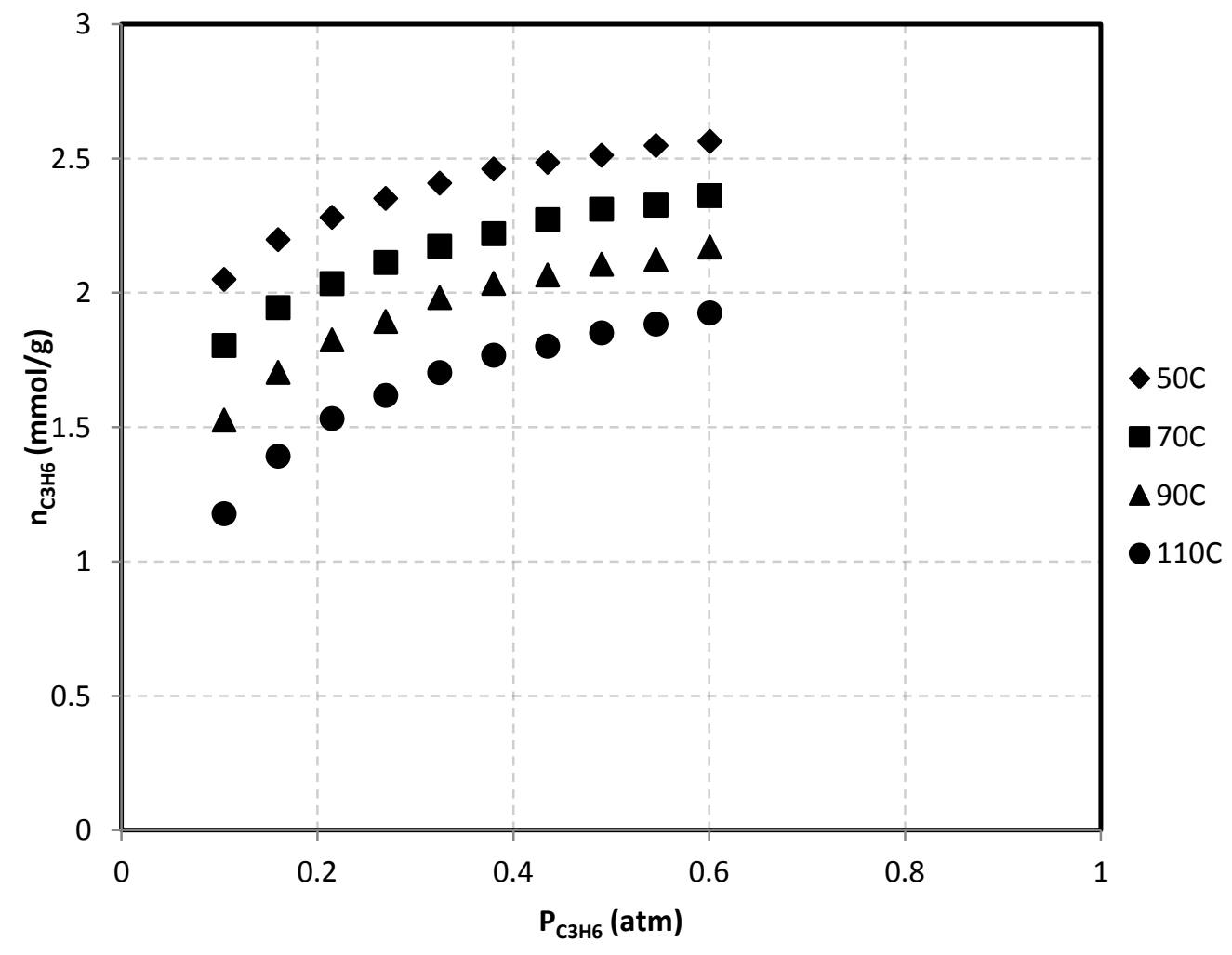




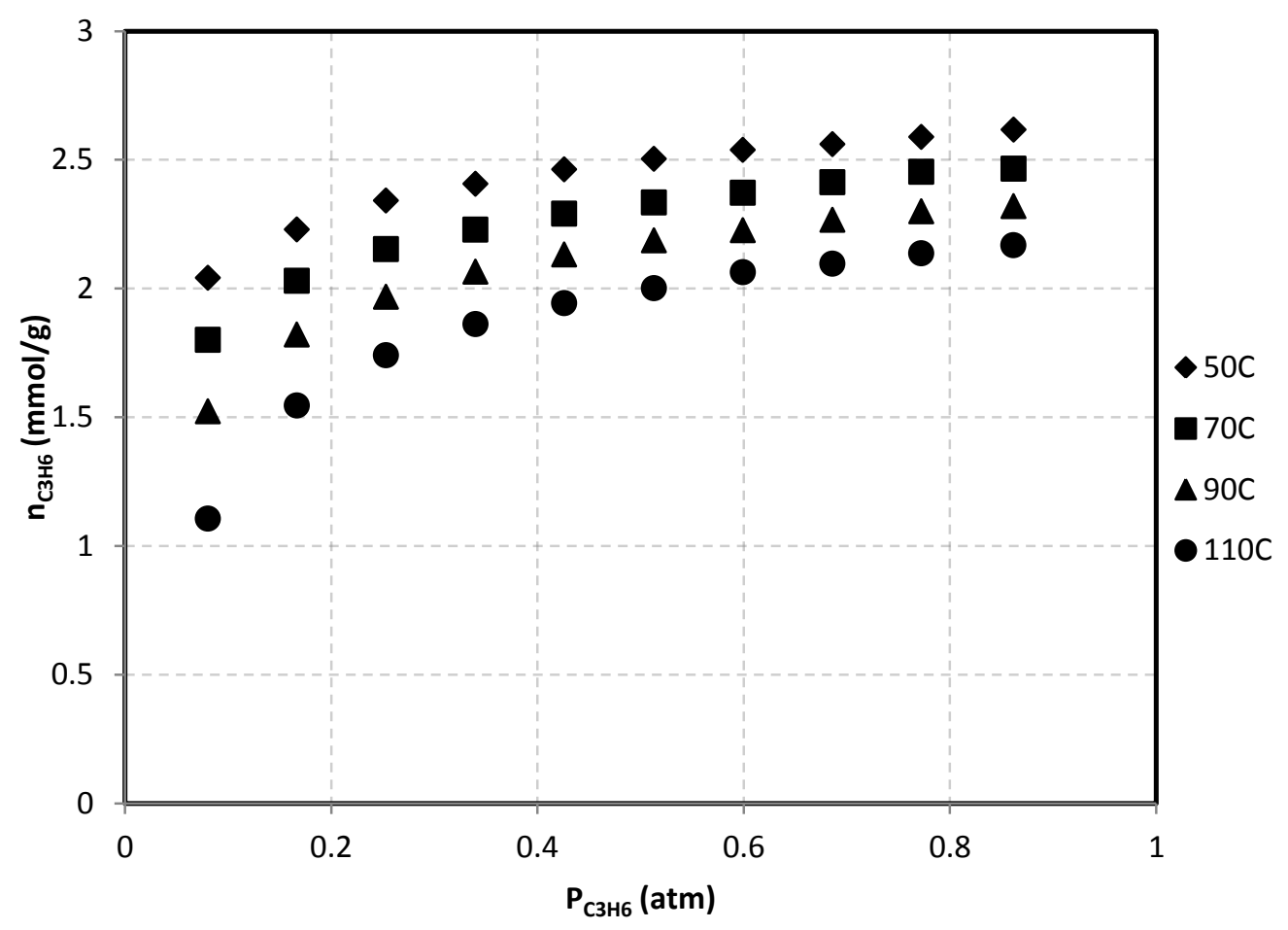

Figure 23. Propylene adsorption isotherms on Rived $\mathrm{NaY}$ (top) and Unrived $\mathrm{NaY}$ (bottom)

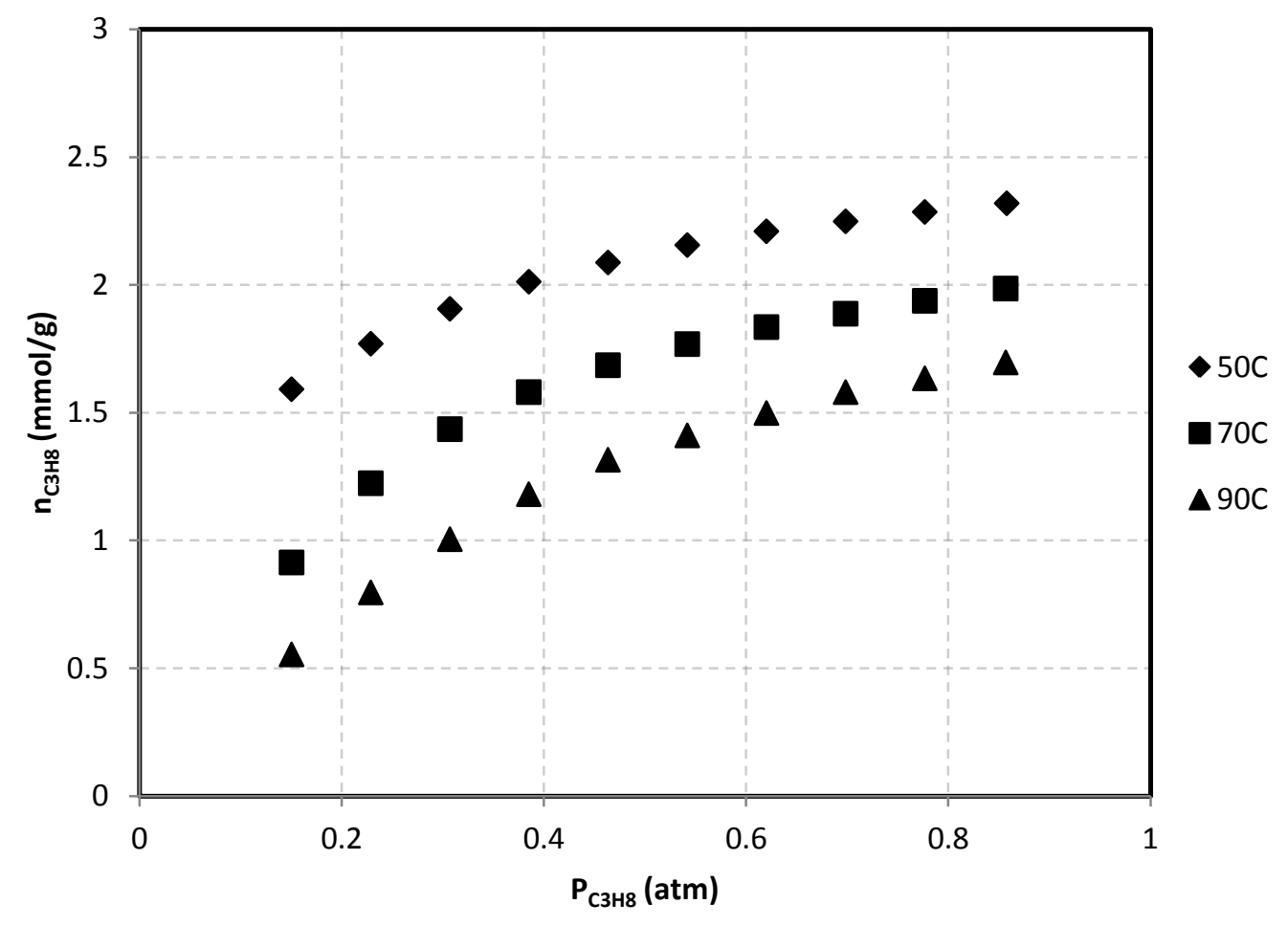




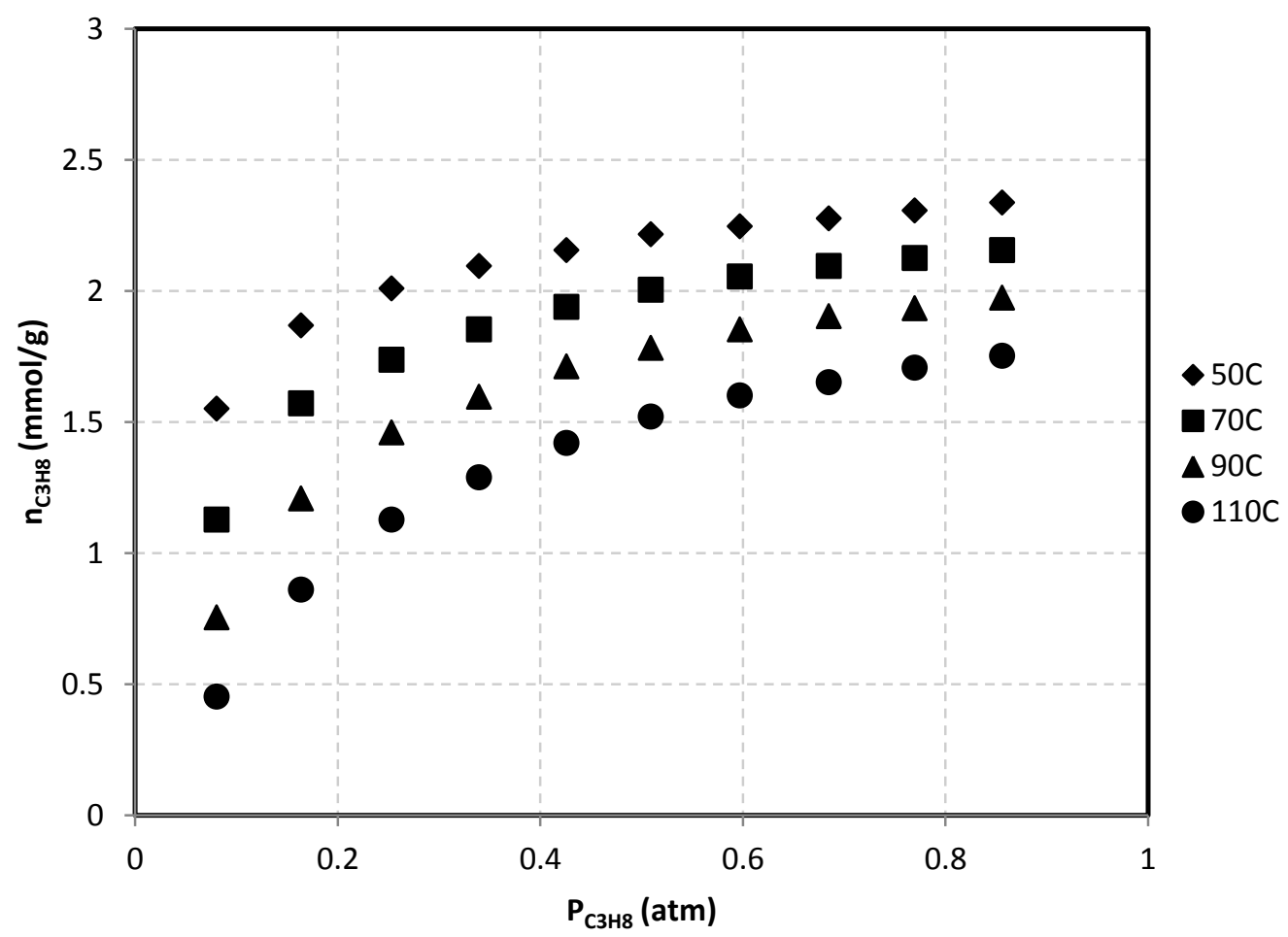

Figure 24. Propane adsorption isotherms on Rived $\mathrm{NaY}$ (top) and Unrived $\mathrm{NaY}$ (bottom)

An attempt was made to calculate the heats of adsorption for both propylene and propane from the adsorption isotherm data, but upon analysis it was deemed that more sorption data would be required to get an accurate measure of these quantities. Here again the use of calorimetry would be a great aid in accurately quantifying heats of adsorption as functions of surface loading.

In summary, the "riving" of NaY zeolite impacted the results of the pulse tests in the following ways:

- $30-50 \%$ reduction in $\Delta \mathrm{w}_{1 / 2}$ for propylene at all conditions

- $\sim 20 \%$ reduction in $\Delta \mathrm{w}_{1 / 2}$ for propane at all conditions

- $30-50 \%$ reduction in calculated $2^{\text {nd }}$ central moment, $\sigma^{2}$, at all conditions for both propylene and propane

- $\quad 2 x$ 's increased overall transport diffusivity for propylene at all conditions and $\sim 3 x$ 's increased overall transport diffusivity for propane at all conditions

- Slightly lowered selectivity that is a weaker function of temperature

An Arrhenius plot of the measured diffusivities as functions of temperature showed that the diffusional activation energy for propylene was lowered from $23.6 \mathrm{~kJ} / \mathrm{mol}$ on the commercial $\mathrm{NaY}$ sample to $20.6 \mathrm{~kJ} / \mathrm{mol}$ on the Rived $\mathrm{NaY}$ sample. The diffusional activation energy for 
propane was also reduced from $17.3 \mathrm{~kJ} / \mathrm{mol}$ on the UnRived $\mathrm{NaY}$ to $12.5 \mathrm{~kJ} / \mathrm{mol}$ on the Rived $\mathrm{NaY}$. These reductions in diffusional activation energy show that both the propylene and propane molecules experience much more freedom to move within the Rived NaY zeolite.

The adsorption capacity of both propylene and propane on the Rived and UnRived NaY adsorbents were negligible. This would explain why there is very little change in experimentally measured selectivities from the pulse tests for the Rived vs. UnRived NaY adsorbents. The sorption data collected for both Rived and UnRived NaY was incomplete to get meaningful measures of the heats of adsorption on these materials. 


\section{Energy Saving Calculation:}

A hypothetical moving bed adsorption system is shown in Figure 25 along with the corresponding liquid-phase composition profile. The solid adsorbent is continuously circulated in a closed loop and flows up through the adsorber. Liquid flows counter currently to the solid flow. The fluid mixture to be separated, $A+B$, is fed at the feed port. The feed may also be diluted with the desorbent, D. Here, A is the more strongly adsorbed species. Raffinate is withdrawn from the system below the feed entry point and consists of the less strongly adsorbed component, B, and desorbent, D. Only a portion of flowing liquid is withdrawn as the rest continues to flow into the next bed. Extract is withdrawn from above the feed port and consists of the more strongly adsorbed $A$ along with $D$. As with the Raffinate, only a portion of liquid is withdrawn at this point. The placement of feed/desorbent introduction and extract/raffinate withdrawal results in the formation of 4 generic zones that each performs a different function. Following the zone numbers in Figure 25, zone 1 serves to adsorb A from the liquid, zone 2 serves to purge $B$ from the solid, zone 3 serves to desorb $A$ from the solid, and zone 4 serves as a buffer to prevent component $B$ from contaminating the extract component $A$.

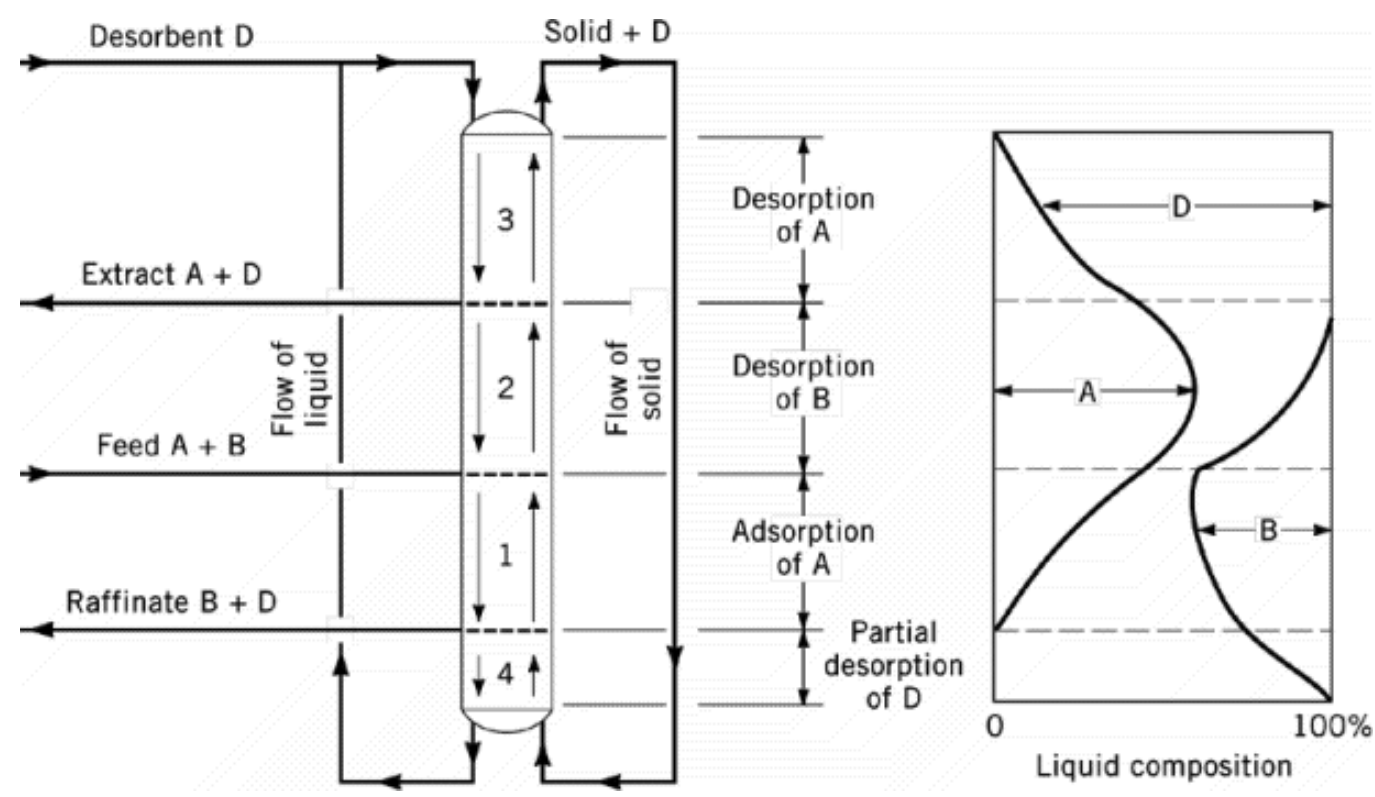

Figure 25. Schematic of True Moving Bed adsorption system and corresponding liquid composition profiles

Several practical issues arise from flowing solids such as particle attrition and obtaining uniform flow of liquid and solid in beds of large diameter. The fluidized bed system also suffers from mass transfer inefficiency as a prohibitively large number of beds may be necessary to achieve a desired separation performance.

To overcome these challenges, the movement of solid can be realized by maintaining a stationary bed and periodically shifting the positions at which the feed, desorbent, extract, and raffinate streams enter and leave. This port shifting simulates the flow of solid countercurrent to liquid flow, hence the name Simulated Moving Bed. The commercial application of SMB is 
shown in Figure 26 where the adsorbent is in a fixed bed and a circulating pump is used to pump the liquid from the bottom of the column to the top. A rotary valve directs the flow of fluid appropriately through the bed. Distributors within the bed allow for appropriate introduction and withdrawal of the four streams from the bed. Smaller SMB systems may use extensive systems of switch valves instead of the complicated rotary valves. The number of beds in SMB applications can vary from 4 up to 24 beds, the latter of which may require more than 100 different rotary valves to achieve the desired switching performance. Due to the switching of ports, the circulating pump must shift its pumping rate to accommodate the necessary flow rate for whatever zone is above it. Sequential samples taken from the liquid circulating pump can trace the composition profile in the entire bed. In SMB the temperature is set to achieve rapid mass transfer or achieve a desired adsorbent selectivity. Pressure is not a critical operating variable, but is set sufficiently high to avoid vaporization of the fluid.

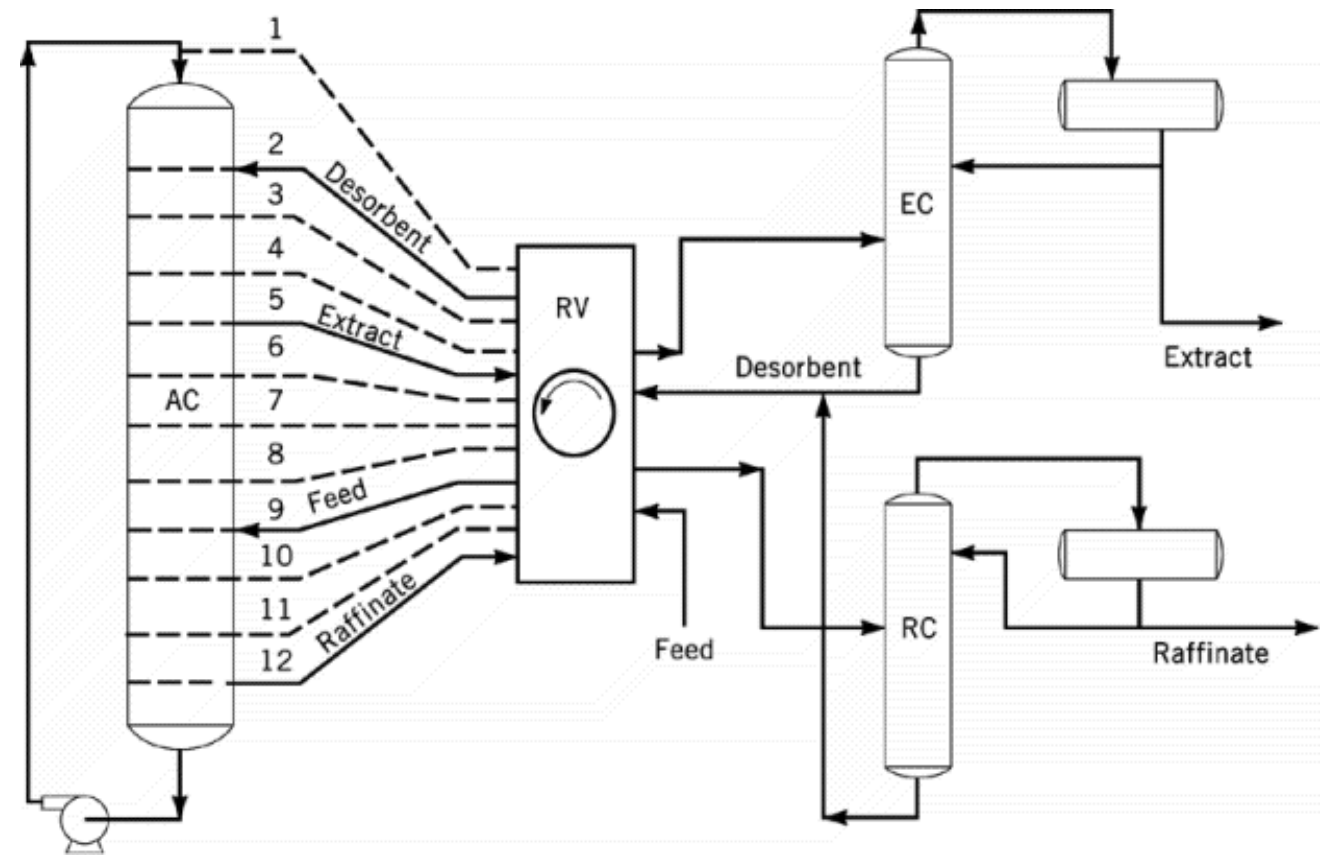

Figure 26. Schematic of Simulated Moving Bed adsorption system

The raffinate and extract products withdrawn from the SMB system are subsequently fed to a set of distillation columns for recovery of the products $A \& B$, and for solvent recovery back into the SMB process. Solvent recovery is critical to avoid excessive make-up of desorbent to the system. The major consumption of energy in an SMB process is this subsequent extract/raffinate recovery. Therefore choice of desorbent is a critical issue in energy consumption of the system.

As the proposed energy saving consumption comparison is between a C3 splitter (already simulated in the front-end calculation in Appendix) and an adsorptive separation system using rived zeolite based adsorbents, it is not necessary to take into consideration of the improved diffusion kinetics for the rived compared to the unrived and rigorous SMB process simulation is not necessary. Therefore, the energy consumption of a SMB separation process herein can be carried out by the well-developed Equilibrium Theory for simulated moving bed adsorption.[24- 
29] This section is based on the work presented in these references. In this analysis, the operation of a 4-bed SMB unit is approximated by the established equivalence of a True Counter-Current (TCC) adsorption unit where fluid and solid flow counter-currently to one another as depicted in Figure 25. Local equilibrium is assumed to prevail at all times and locations in the column, hence there is no resistance to mass transfer in the system or axial mixing (this assumption, of course would be more valid for a rived adsorbent than an unived adsorbent under the same operating conditions). Complete separation is achieved, so that only propylene and desorbent appear in the extract, and only propane and desorbent appear in the raffinate, which are then further separated by distillation.

The key parameters for design of the steady state system have been demonstrated to be the flow rate ratios, $m_{j}$, in the different sections of the unit. These flow ratios are defined as

$$
m_{j}=\frac{\text { net fluid flow rate }}{\text { adsorbed phase flow rate }}=\frac{G_{j} t^{*}-A L \varepsilon \rho_{f}}{A L \rho_{s} \gamma^{\infty}(1-\varepsilon)}
$$

where $G_{j}$ is the fluid mass flow rate through section $j$ of the column, $t^{*}$ is the switching time in the SMB unit, $A$ is the column cross sectional area, $L$ is the column length, $\varepsilon$ is the packed column void fraction, $\rho_{f}$ and $\rho_{s}$ are the respective fluid and solid densities, and $\Gamma^{\circ}$ is the adsorbent saturation capacity in mass adsorbate/mass adsorbent. The bottom term of equation 10 represents the total mass of adsorbate that must be adsorbed during the step of the cycle. Determining these flow ratios provides boundaries for conditions in which complete separation can be achieved. This region can be graphically depicted by the proper choice of the variables $\left(m_{2}, m_{3}\right)$ to define the space where optimal and robust operation of the system can be realized to achieve complete separation. With these parameters properly chosen, the flow rates of the desorbent, extract and raffinate streams can all be calculated, along with the stream compositions, from the relative equilibrium constants $\left(K_{i}\right)$ calculated from the pulse test experiments and the feed concentrations of propylene, propane, and desorbent. The flow rate of $\mathrm{C}_{3}$ to the system was chosen as 6000 BPSD (same as in the front-end calculation in Appendix), which is equivalent to the flow rate of a C3 stream obtained from a 50,000 BPSD FCC unit. In commercial SMB, the feed is often diluted with the desorbent so the feed stream contains $75 \%$ desorbent with a balance of mixture to be separated (C3 mixture is 70:30 propylene: propane). The desorbent in this case was hexane, however, the actual value of the equilibrium constant for hexane was not experimentally determined. It is known that hexane adsorbs more strongly than either propane or propylene, so a value of $K_{D}$ greater than $K_{C 3 H 6}$ was arbitrarily chosen. Another assumption in the system is that the adsorption of each component follows the stoichiometric, constant selectivity isotherm model, which has been observed to hold fairly true for several systems of SMB interest as it does account for adsorbate-adorbate interactions. This model is given as

$$
\theta_{i}=\frac{K_{i} y_{i}}{\sum_{i=1}^{3} K_{j} y_{j}}
$$

Where $\theta_{i}$ is the surface coverage of species $i$, and $K_{i} \& y_{i}$ are the dimensionless equilibrium constants and mass fractions of species $i$. Once the stream flow rates and compositions were calculated, the subsequent purification of propylene and propane by distillation were modeled 
using ASPEN Plus to determine the energy inputs needed to produce $99.5 \%$ propylene and to recover the solvent from both extract and raffinate streams for recycle back into the SMB system. A schematic of this system is shown in Figure 27 and it consists of a 4-bed SMB unit, 2 distillation units for purifying the propylene and propane, and two heat exchangers for heat recovery from the hot desorbent recycle streams. The SMB unit operates $\sim 50^{\circ} \mathrm{C}$ and $200 \mathrm{psig}$ pressure (where we have collected Pulse Test Data). The distillation units operate at lower temperature $\left(\sim 37^{\circ} \mathrm{C}\right)$ and 200 psig, which is close to the operating conditions of a conventional C3 splitter.

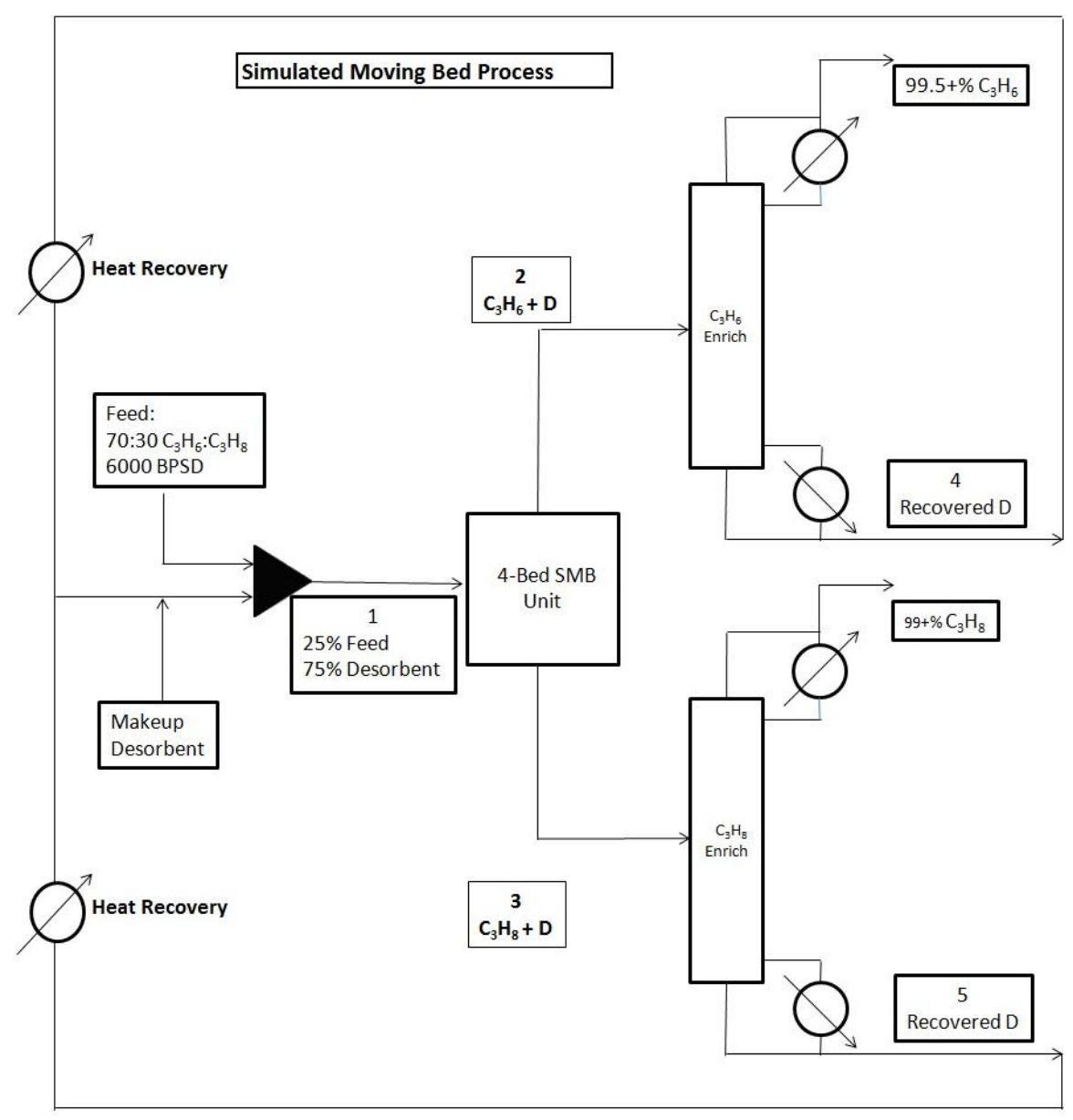

Figure 27. Schematic of a hypothetical integrated 4-bed SMB unit for processing 6000 BPSD C3 stream

For a system governed by the stoichiometric adsorption isotherm (Equation 11) with desorbent present in the feed, the following procedure for determining the optimal values of the flow ratio's $m_{2}$ and $m_{3}$ is presented. For this system of a desorbent with stronger adsorption than either component to be separated the general relation $\mathrm{K}_{\mathrm{C} 3 \mathrm{H} 8}<\mathrm{K}_{\mathrm{C} 3 \mathrm{H} 6}<\mathrm{K}_{\mathrm{D}}$ holds true. The flow ratios of 
sections 1 and 4 are independent of the values of $m_{2}$ and $m_{3}$ and are only bounded by the constraints

$\frac{K_{C 3 H 6}}{K_{D}}<m_{1}<+\infty$

$0<m_{4}<\frac{K_{C 3 H 8}}{K_{D}}$

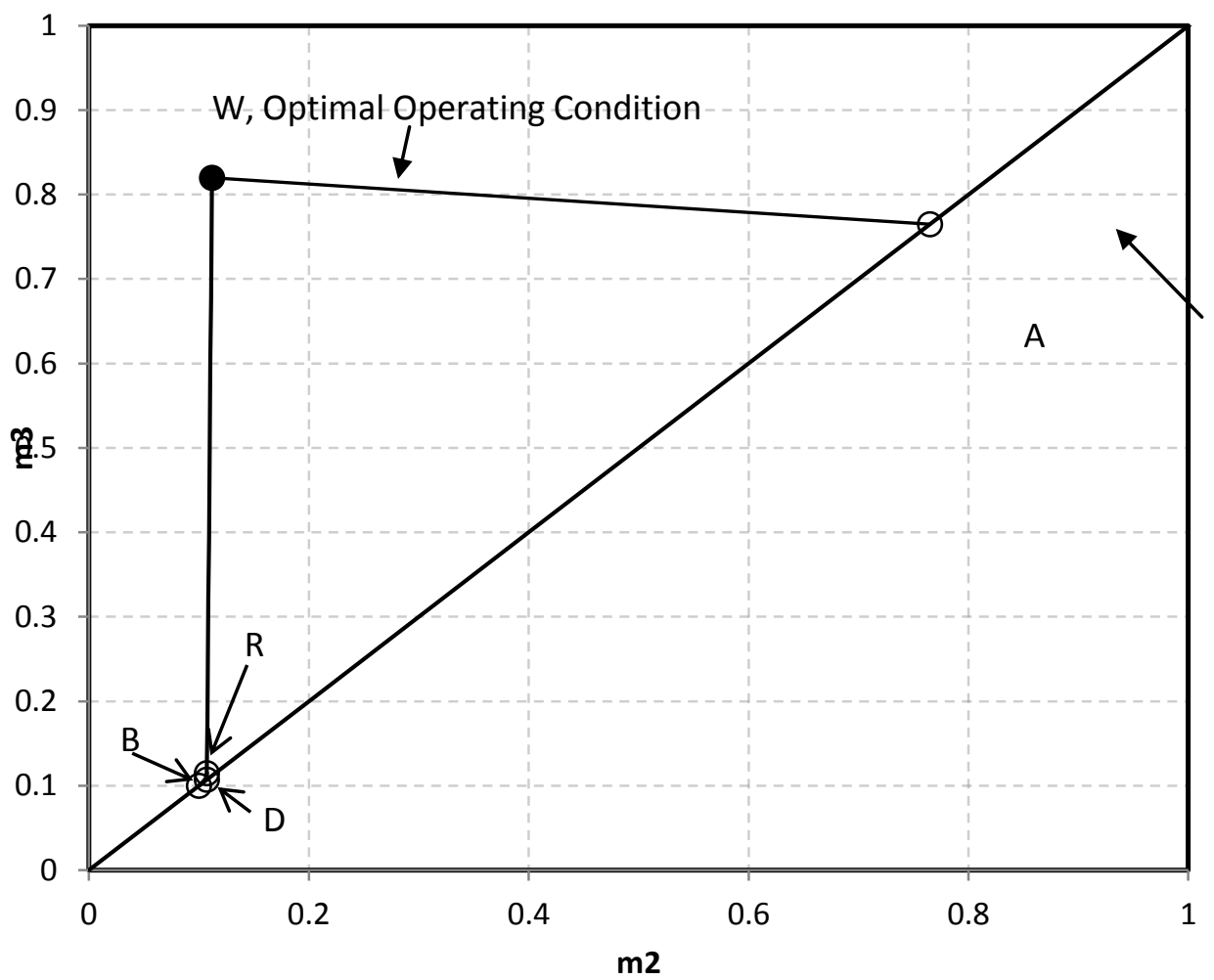

Figure 28. Region of complete separation in the $\left(\mathrm{m}_{2}, \mathrm{~m}_{3}\right)$ plane, $\mathrm{K}_{A}=1.5, \mathrm{y}_{\mathrm{A}}{ }^{\mathrm{F}}=0.175, \mathrm{~K}_{\mathrm{B}}=0.2$, $\mathrm{y}_{B}{ }^{\mathrm{F}}=0.075, \mathrm{~K}_{\mathrm{D}}=2.0, \mathrm{y}_{\mathrm{D}}{ }^{\mathrm{F}}=0.75$

Conservative restraints for the case of a strong desorbent have been identified as $m_{1}>1$. The construction of the separation region is based on certain mathematical projections that have been described in detail in the literature and will not be discussed here.[25, 26] Figure 28 shows the construction of the separation plot for the Rived $\mathrm{NaX}$ using the pulse test data at $50^{\circ} \mathrm{C}$ described in the previous experimental section. For complete separation, $m_{3}>m_{2}$ so a lower bound of the region is the line $m_{3}=m_{2}$. Several other bounds to the region appear on the plot and are depicted by the points, $A, B, R, D$, and $W$. The point at $W$ indicates where optimum separation performance is achieved, but any $\left(\mathrm{m}_{2}, \mathrm{~m}_{3}\right)$ pair lying within the boundary of Figure 28 will lead to complete separation of propane and propylene. The values of these points are based from the measured equilibrium constants and the feed fractions of each component. Two 
parameters, $\Omega_{\mathrm{G}}$ and $\Omega_{\mathrm{H}}$, are first defined as the real, positive roots of the following quadratic equation:

$$
\begin{aligned}
& \delta_{F} \Omega^{2}-\left[K_{A} y_{A}^{F}\left(K_{B}+K_{D}\right)+K_{B} y_{B}^{F}\left(K_{A}+K_{D}\right)+K_{D} y_{D}^{F}\left(K_{A}+K_{B}\right)\right] \Omega+K_{A} K_{B} K_{D}=0 \\
& \delta=K_{A} y_{A}^{F}+K_{B} y_{B}^{F}+K_{D} y_{D}^{F} \\
& 15
\end{aligned}
$$

where the subscripts $A=C_{3} H_{6}, B=C_{3} H_{8}$, and $D=$ desorbent. $y_{i}{ }^{F}$ is the concentration of each species in the feed, and for the roots $\Omega_{G}>\Omega_{H}>0$.

The points on the plot are given as follows:

Point A: $\left(\frac{K_{A}}{K_{D}}, \frac{K_{A}}{K_{D}}\right)$

Point B: $\left(\frac{K_{B}}{K_{D}}, \frac{K_{B}}{K_{D}}\right)$

Point R:

$$
\left(\frac{\Omega_{H}\left[\Omega_{G}\left(K_{A}-K_{B}\right)-\Omega_{H}\left(K_{A}-\Omega_{G}\right)\right]}{K_{A} K_{D}\left(\Omega_{G}-K_{B}\right)}, \frac{\Omega_{H}^{2}}{K_{B} K_{D}}\right)
$$

Point W: $\left(\frac{\Omega_{H}\left[\Omega_{G}\left(K_{A}-K_{B}\right)-K_{A}\left(K_{A}-\Omega_{G}\right)\right]}{K_{A} K_{D}\left(\Omega_{G}-K_{B}\right)}, \frac{\Omega_{H} K_{A}}{K_{B} K_{D}}\right)$

The points on the plot are then connected by the following relations to finish construction of the $\left(m_{2}, m_{3}\right)$ separation region:

Straight Line WD:

$$
m_{3}=\frac{\frac{\Omega_{G} \Omega_{H}\left(K_{A}-K_{B}\right)}{K_{D}}-K_{A}\left(\Omega_{G}-K_{B}\right) m_{2}}{K_{B}\left(K_{A}-\Omega_{G}\right)}
$$

Straight Line WA: $m_{3}=\frac{K_{A}\left(K_{A}-K_{B}\right)-K_{A}\left(K_{D}-K_{B}\right) y_{B}^{F} m_{2}}{K_{D}\left(K_{A}-K_{B}\right)-K_{A}\left(K_{D}-K_{B}\right)}$

Curve RB: $m_{2}=m_{3}-\frac{\left(\sqrt{K_{B}}-\sqrt{K_{D} m_{3}}\right)^{2}}{y_{B}^{F}\left(K_{D}-K_{B}\right)}$

Straight Line AB: $\quad m_{2}=m_{3}$ 
Using the experimental $\mathrm{K}$ values, the optimal operating conditions, $\left(\mathrm{m}_{2}, \mathrm{~m}_{3}\right)$ was determined to be $(0.11,0.82)$.

Table 9 lists the calculated flow ratios, mass flow rates of feed, raffinate, desorbent, and extract streams, and corresponding purities (mass basis) of the raffinate and extract streams for these optimal operating conditions. The feed rate is based on a 6000 BPSD feed of 70:30 mixture of propylene: propane, diluted in desorbent: $\mathrm{C}_{3}$ ratio of $3: 1$.

Table 9. Calculations for a hypothetical SMB process: Subscripts $F=F e e d, R=$ Raffinate, $D=$ Desorbent, $\mathrm{E}=$ Extract

\begin{tabular}{|c|c|c|c|c|c|c|c|}
\hline \multicolumn{2}{|c|}{$\begin{array}{c}\text { EQ constants \& Feed } \\
\text { concentrations }\end{array}$} & \multicolumn{2}{|c|}{ Flow Ratios } & \multicolumn{2}{|c|}{$\begin{array}{c}\text { Calculated mass flow rates } 6000 \\
\text { BPSD C } 3 \text { mixture }(\mathrm{kg} / \mathrm{min})\end{array}$} & \multicolumn{2}{|c|}{$\begin{array}{c}\text { Raffinate/Extract } \\
\text { Purities } \\
\end{array}$} \\
\hline $\mathrm{K}_{\mathrm{A}}$ & 1.53 & $\mathrm{~m}_{1}$ & 1.10 & $\mathrm{G}_{\mathrm{F}}$ & 1282 & $\mathrm{y}_{\mathrm{B}}{ }^{\mathrm{R}}$ & $y_{D}{ }^{R}$ \\
\hline$K_{B}$ & 0.2 & $\mathrm{~m}_{2}$ & 0.11 & $G_{R}$ & 1321 & 0.073 & 0.927 \\
\hline$K_{D}$ & 2 & $m_{3}$ & 0.82 & $\mathrm{G}_{\mathrm{D}}$ & 1828 & $y_{A}{ }^{E}$ & $y_{D}{ }^{E}$ \\
\hline $\mathrm{y}_{\mathrm{A}}{ }^{\mathrm{F}}$ & 0.175 & $\mathrm{~m}_{4}$ & 0.09 & $\mathrm{G}_{\mathrm{E}}$ & 1788 & 0.125 & 0.875 \\
\hline $\mathrm{y}_{\mathrm{B}}{ }^{\mathrm{F}}$ & 0.075 & & & & & & \\
\hline$y_{0}{ }^{F}$ & 0.75 & & & & & & \\
\hline
\end{tabular}

Once the flow rates and purities of the extract and raffinate streams were calculated, ASPEN Plus process modeling software was used to determine energy inputs (Reboiler and condenser duties along with sizing) of the two subsequent distillations. The feed was assumed to be at $37^{\circ} \mathrm{C}$ and 200 psig. Target purities for the propylene and propane were both set at $99.5 \%$. Equilibrium stage calculations were used in ASPEN's RadFrac distillation unit. The PengRobinson equation of state was used as it determines molecular interactions for hydrocarbons well. The column pressure drop was calculated by the model, and Murphee tray efficiencies of $70 \%$ were used. The number of equilibrium stages was set to a near optimum level to try to keep the column reflux ratio below 2 , and the tallest column (Raffinate separation) was $22 \mathrm{EQ}$ stages tall. The feed stage introduction point was manipulated until the minimum energy requirements were found. The energy duties for the reboilers and condenser units were recorded as $\mathrm{BTU} / \mathrm{lb} \mathrm{C}_{3} \mathrm{H}_{6}$ product. For the condenser duty, cooling water was assumed to be available with a $8.3^{\circ} \mathrm{C} \Delta \mathrm{T}$, and from the calculated duties, the total gallons per minute of cooling water necessary per $\mathrm{lb} \mathrm{C}_{3} \mathrm{H}_{6}$ was calculated. Once calculated, the necessary power requirements to pump the SMB feed, desorbent, extract, raffinate, and cooling water streams were calculated using a pump efficiency of $70 \%$. The cost of electricity for these pumps was assumed to be $\$ 0.09$ per kWhr, and an electricity cost per ton of $\mathrm{C}_{3} \mathrm{H}_{6}$ product was calculated. $\mathrm{CO}_{2}$ emissions were calculated for supplying the electricity to the pumps by assuming that refinery still gas could be used to generate power, with a carbon intensity of $1.135 \mathrm{lb} \mathrm{CO}_{2}$ generated per kWhr of electricity produced. These rough numbers were obtained from general numbers for power generation found on the Energy Information Administration's web site.[30]

The bottoms products from both distillation units are to be recycled back to the SMB unit as seen in Figure 26 , but are very hot $\left(T>150^{\circ} \mathrm{C}\right)$. ASPEN was also used to recover heat from 
these streams using phase-specific heat transfer coefficients. The amount of heat recovered from these streams was subtracted from the calculated reboiler duties to give a net BTU/lb $\mathrm{C}_{3} \mathrm{H}_{6}$ for the process. To supply this heat, it was assumed that refinery still gas would be used as fuel with a lower heating value of $20,267 \mathrm{BTU} / \mathrm{lb}$ still gas. The price of still gas, which is similar in heat content to natural gas, was assumed to be the market cost of natural gas obtained from the Energy Information Administration's web site and was \$3.76/MM BTU. The carbon emissions from firing the reboilers was calculated by using a carbon intensity of natural gas of $117 \mathrm{lbs} \mathrm{CO}_{2}$ /MM BTU.

Several other cases were also investigated such as feeding the SMB unit a less diluted stream of C3 feed ( $35 \% \mathrm{C}_{3}$ feed vs. $25 \% \mathrm{C}_{3}$ feed) and the use of desorbents other than hexane. The less diluted feed to the SMB unit resulted in higher purities of the extract and raffinate streams due to less desorbent present in the system and less energy demand for the subsequent purification of propylene and propane. Using the same calculated compositions for both $25 \%$ and $35 \%$ feed, other $\mathrm{C}_{3}$-desorbent separations were modeled using pentane and iso-pentane as the desorbent. The same calculations described above were performed for all these cases, and also at an elevated pressure of 265 psig. The same duties calculated for the extract and raffinate columns were compared with the numbers from a conventional $\mathrm{C}_{3}$ splitter operating at 265 psig and was done by an outside source. Table 10 shows the cases studied using various desorbents. As can be seen from the tables the overall reduction in cost of supplemental energy required for the separation can be reduced by $60-80 \%$ depending on the conditions chosen, the desorbent selected, and proper heat integration of the process. An additional value that has not been quantified is the reduction in $\mathrm{CO}_{2}$ emissions by the SMB process. The reduced energy requirements directly result in reduced $\mathrm{CO}_{2}$ emissions, and as can be seen from the table, for a single separation system in a single year, 30,000-35,000 tons of $\mathrm{CO}_{2}$ can be avoided each year by the $\mathrm{SMB}$ process compared to the conventional $\mathrm{C}_{3}$ splitter. Assuming there is a price associated with carbon emissions of $\$ 40 /$ ton, this carbon emission reduction results in avoided penalties of $\$ 1.2-1.4$ million per year.

A comparison of the energy savings of Rived and UnRived adsorbents does not give a fair analysis due to the nature of the calculation performed. The main advantages of the Riving process are (for $\mathrm{NaX}$ zeolite) much enhanced kinetics at the sacrifice of some equilibrium adsorption capacity. For $\mathrm{NaY}$ zeolite, we observe enhanced kinetics with only a very slight decrease of the equilibrium adsorption capacity. The calculations performed here assumed that local equilibrium prevails, therefore eliminating the effects of kinetics. The kinetic advantage of the Rived zeolites cannot be realized by this calculation alone. However, it can be stated that the enhanced kinetics of the Rived zeolites makes the assumption of local equilibrium much more likely for the Rived adsorbents compared to the UnRived adsorbents. The enhanced kinetics will also make the SMB process much more efficient by better utilization of adsorbent inventory, and will lead to reduced size of adsorber beds. Another advantage of the Rived adsorbents was assessed by using the Ergun equation [31] in which the pressure drop per unit length through a packed column is given by: 
Table 10. Comparison of energy savings of SMB process using hexane (top), pentane (middle), and iso-pentane (bottom) as desorbent. Last column are corresponding numbers for conventional $\mathrm{C}_{3}$ splitter

\begin{tabular}{|c|c|c|c|c|c|}
\hline Energy Duty & $\begin{array}{c}\text { SMB system, } \\
25 \% \text { feed, } \\
\text { hexane, } 200 \\
\text { psig Rived NaX }\end{array}$ & \begin{tabular}{|c|} 
SMB system, \\
$35 \%$ feed, \\
hexane, 200 \\
psig Rived NaX
\end{tabular} & \begin{tabular}{|c|} 
SMB system, \\
$25 \%$ feed, \\
hexane, 265 psig \\
Rived $\mathrm{NaX}$
\end{tabular} \mid & \begin{tabular}{|c|} 
SMB system, \\
$35 \%$ feed, \\
hexane, 265 psig \\
Rived NaX
\end{tabular} \mid C & $\begin{array}{c}\text { Conventional C3 } \\
\text { splitter }\end{array}$ \\
\hline \multicolumn{6}{|c|}{ Reboiler Duties } \\
\hline net heat supply needed (BTU//b $\mathrm{C}_{3} \mathrm{H}_{6}$ ) & 483 & 425 & 493 & 453 & 2790 \\
\hline Energy savings & $82.7 \%$ & $84.8 \%$ & $82.3 \%$ & $83.8 \%$ & \\
\hline Additional Cost to fire reboilers (\$/ton) & 3.63 & 3.19 & 3.71 & 3.41 & 21.0 \\
\hline Reboiler $\mathrm{CO}_{2}$ emisssons per ton $\mathrm{C}_{3} \mathrm{H}_{6}$ (lb/ton) & 113 & 99 & 115 & 106 & 653 \\
\hline \multicolumn{6}{|c|}{ Condenser Duties } \\
\hline Total Condenser Heat Duty $\left(\mathrm{BTU} / \mathrm{Ib} \mathrm{C}_{3} \mathrm{H}_{6}\right)$ & 166 & 164 & 167 & 184 & 2774 \\
\hline Total cooling water consumption (gal//b $\mathrm{C}_{3} \mathrm{H}_{6}$ ) & 1.3 & 1.3 & 1.3 & 1.5 & 22.27 \\
\hline Total Solvent makeup $\left(\mathrm{Ib} / \mathrm{lb} \mathrm{C}_{3} \mathrm{H}_{6}\right)$ & 7.1E-03 & $5.0 \mathrm{E}-03$ & 7.1E-03 & $5.0 \mathrm{E}-03$ & -- \\
\hline $\begin{array}{l}\text { Pump Electricty Cost }\left(\$ / \text { ton } \mathrm{C}_{3} \mathrm{H}_{6}\right) \text { Includes pumping } \\
\text { feed, extract, Raffinate, Desorbent Streams \& } \\
\text { Circulating Cooling } \mathrm{H}_{2} \mathrm{O} \text { for condensers }\end{array}$ & 2.11 & 1.54 & 2.76 & 2.01 & 2.41 \\
\hline $\mathrm{CO}_{2}$ emissions from pump powering ( $\mathrm{lb} \mathrm{CO} 2 /$ ton $\mathrm{C}_{3} \mathrm{H}_{6}$ ) & 27 & 19 & 35 & 25 & 30 \\
\hline Total $\mathrm{CO}_{2}$ emissions ( $\mathrm{Ib} \mathrm{CO}_{2}$ /ton $\mathrm{C}_{3} \mathrm{H}_{6}$ ) & 140 & 119 & 150 & 132 & 684 \\
\hline Avoided $\mathrm{CO} 2$ emissions in one year ( tons) & 33905 & 35204 & 33246 & 34412 & -- \\
\hline net utility cost per ton of $\mathrm{C}_{3} \mathrm{H}_{6}$ & 5.74 & 4.73 & 6.47 & 5.42 & 23.41 \\
\hline Utility cost reduction per ton of $\mathrm{C}_{3} \mathrm{H}_{6}$ & $75.5 \%$ & $79.8 \%$ & $72.4 \%$ & $76.8 \%$ & - \\
\hline Energy Duty & \begin{tabular}{c|} 
SMB system, \\
$25 \%$ feed, \\
pentane, 200 \\
psig Rived $\mathrm{NaX}$
\end{tabular} & $\begin{array}{c}\text { SMB system, } 35 \% \\
\text { feed, pentane, } \\
200 \text { psig Rived NaX }\end{array}$ & $\begin{array}{c}\text { SMB system, } 25 \% \\
\text { feed, pentane, } 265 \\
\text { psig Rived NaX } \\
\end{array}$ & \begin{tabular}{|c|} 
SMB system, $35 \%$ \\
feed, pentane, 265 \\
psig Rived NaX \\
\end{tabular} & \begin{tabular}{c|c} 
Conventional \\
C3 splitter
\end{tabular} \\
\hline \multicolumn{6}{|c|}{ Reboiler Duties } \\
\hline net heat supply needed $\left(\mathrm{BTU} / \mathrm{lb} \mathrm{C}_{3} \mathrm{H}_{6}\right)$ & 598 & 520 & 664 & 583 & 2790 \\
\hline Energy savings & $78.6 \%$ & $81.4 \%$ & $76.2 \%$ & $79.1 \%$ & \\
\hline Additional Cost to fire reboilers (\$/ton) & 4.49 & 3.91 & 4.99 & 4.38 & 21.0 \\
\hline Reboiler $\mathrm{CO}_{2}$ emisssons per ton $\mathrm{C}_{3} \mathrm{H}_{6}$ (lb/ton) & 140 & 122 & 155 & 136 & 653 \\
\hline \multicolumn{6}{|c|}{ Condenser Duties } \\
\hline Total Condenser Heat Duty $\left(\mathrm{BTU} / \mathrm{Ib} \mathrm{C}_{3} \mathrm{H}_{6}\right)$ & 281 & 261 & 338 & 314 & 2774 \\
\hline Total cooling water consumption (gal//b $\mathrm{C}_{3} \mathrm{H}_{6}$ ) & 2.2 & 2.1 & 2.7 & 2.5 & 22.27 \\
\hline Total Solvent makeup $\left(\mathrm{Ib} / \mathrm{lb}_{3} \mathrm{H}_{6}\right)$ & $7.1 \mathrm{E}-03$ & $7.1 \mathrm{E}-03$ & 7.1E-03 & $7.1 \mathrm{E}-03$ & -- \\
\hline $\begin{array}{c}\text { Pump Electricty } \operatorname{cost}\left(\$ / \text { ton } \mathrm{C}_{3} \mathrm{H}_{6}\right) \text { Includes pumping } \\
\text { feed, extract, Raffinate, Desorbent Streams \& Circulating } \\
\text { Cooling } \mathrm{H}_{2} \mathrm{O} \text { for condensers }\end{array}$ & \begin{tabular}{l|l}
2.30 & -100 \\
\end{tabular} & 1.68 & 3.03 & 2.21 & 2.41 \\
\hline $\mathrm{CO}_{2}$ emissions from pump powering ( $\left(\mathrm{b} \mathrm{CO} 2 /\right.$ ton $\mathrm{C}_{3} \mathrm{H}_{6}$ ) & 29.1 & 21.2 & 38.2 & 27.8 & 30.4 \\
\hline Total $\mathrm{CO}_{2}$ emissions $\left(\mathrm{lb} \mathrm{CO} /\right.$ ton $\left.\mathrm{C}_{3} \mathrm{H}_{6}\right)$ & 169 & 143 & 194 & 164 & 684 \\
\hline Avoided $\mathrm{CO} 2$ emissions in one year ( tons) & 32077 & 33701 & 30544 & 32375 & - \\
\hline net utility cost per ton of $\mathrm{C}_{3} \mathrm{H}_{6}$ & 6.79 & 5.59 & 8.02 & 6.59 & 23.41 \\
\hline Utility cost reduction per ton of $\mathrm{C}_{3} \mathrm{H}_{6}$ & $71.0 \%$ & $76.1 \%$ & $65.7 \%$ & $71.8 \%$ & -- \\
\hline
\end{tabular}




\begin{tabular}{|c|c|c|c|c|c|}
\hline Energy Duty & $\begin{array}{l}\text { SMB system, } \\
25 \% \text { feed, } \\
\text { IsoPentane, } \\
200 \text { psig Rived } \\
\text { NaX }\end{array}$ & $\begin{array}{l}\text { SMB system, } \\
35 \% \text { feed, } \\
\text { IsoPentane, } 200 \\
\text { psig Rived } \mathrm{NaX}\end{array}$ & $\begin{array}{c}\text { SMB system, } 25 \% \\
\text { feed, } \\
\text { IsoPentane, } 265 \\
\text { psig Rived NaX }\end{array}$ & $\begin{array}{l}\text { SMB system, } \\
35 \% \text { feed, } \\
\text { IsoPentane, } 265 \\
\text { psig Rived NaX }\end{array}$ & $\begin{array}{c}\text { Conventional C3 } \\
\text { splitter }\end{array}$ \\
\hline \multicolumn{6}{|c|}{ Reboiler Duties } \\
\hline net heat supply needed $\left(\mathrm{BTU} / \mathrm{Ib} \mathrm{C}_{3} \mathrm{H}_{6}\right)$ & 693 & 607 & 803 & 746 & 2790 \\
\hline Energy savings & $75.2 \%$ & $78.2 \%$ & $71.2 \%$ & $73.3 \%$ & \\
\hline Additional Cost to fire reboilers (\$/ton) & 5.21 & 4.56 & 6.04 & 5.61 & 21.0 \\
\hline Reboiler $\mathrm{CO}_{2}$ emisssons per ton $\mathrm{C}_{3} \mathrm{H}_{6}$ (lb/ton) & 162 & 142 & 188 & 175 & 653 \\
\hline \multicolumn{6}{|c|}{ Condenser Duties } \\
\hline Total Condenser Heat Duty (BTU//b C $\mathrm{H}_{6}$ ) & 376 & 347 & 476 & 477 & 2774 \\
\hline Total cooling water consumption (gal// $\mathrm{b} \mathrm{C}_{3} \mathrm{H}_{6}$ ) & 3.0 & 2.8 & 3.8 & 3.8 & 22.27 \\
\hline Total Solvent makeup $\left(\mathrm{lb} / \mathrm{Ib} \mathrm{C}_{3} \mathrm{H}_{6}\right)$ & 7.1E-03 & 7.1E-03 & 7.1E-03 & 7.1E-03 & -- \\
\hline $\begin{array}{l}\text { Pump Electricty Cost }\left(\$ / \text { ton } \mathrm{C}_{3} \mathrm{H}_{6}\right) \text { Includes pumping } \\
\text { feed, extract, Raffinate, Desorbent Streams \& } \\
\text { Circulating Cooling } \mathrm{H}_{2} \mathrm{O} \text { for condensers }\end{array}$ & 2.36 & 1.75 & 2.98 & 2.34 & 2.41 \\
\hline $\mathrm{CO}_{2}$ emissions from pump powering ( $\mathrm{lb} \mathrm{CO} 2 /$ ton $\mathrm{C}_{3} \mathrm{H}_{6}$ ) & 29.8 & 22.1 & 37.6 & 29.5 & 30.4 \\
\hline Total $\mathrm{CO}_{2}$ emissions $\left(\mathrm{Ib} \mathrm{CO}_{2} /\right.$ ton $\left.\mathrm{C}_{3} \mathrm{H}_{6}\right)$ & 192 & 164 & 226 & 204 & 684 \\
\hline Avoided $\mathrm{CO} 2$ emissions in one year ( tons) & 30642 & 32382 & 28554 & 29886 & -- \\
\hline net utility cost per ton of $\mathrm{C}_{3} \mathrm{H}_{6}$ & 7.57 & 6.31 & 9.02 & 7.95 & 23.41 \\
\hline Utility cost reduction per ton of $\mathrm{C}_{3} \mathrm{H}_{6}$ & $67.7 \%$ & $73.0 \%$ & $61.5 \%$ & $66.0 \%$ & \\
\hline
\end{tabular}

$$
\frac{\Delta P}{L}=\frac{150 V_{s} \mu(1-\varepsilon)^{2}}{D_{p}^{2} \varepsilon^{3}}+\frac{1.75 \rho V_{s}^{2}(1-\varepsilon)}{D_{p} \varepsilon^{3}}
$$

where $V_{s}$ is the fluid superficial velocity $(\mathrm{m} / \mathrm{s}), \mu$ is the fluid dynamic viscosity $(\mathrm{Pa} \mathrm{s}), D_{p}$ is the adsorbent particle size $(\mathrm{m}), \varepsilon$ is the column void fraction, and $\rho$ is the fluid density $\left(\mathrm{kg} / \mathrm{m}^{3}\right)$. Using the Glueckauf [32] approximation in which the overall mass transport rate, $\left.\mathrm{k}^{-1} \mathrm{~s}^{-1}\right)$, is related to the diffusivity by

$k=\frac{\Omega D}{D_{p}^{2}}$

where $\Omega$ is a constant, generally 15 . It can be calculated that to achieve the same mass transfer values observed on Rived $\mathrm{NaX}$ by using UnRived $\mathrm{NaX}$, the particle size would need to be reduced by $\sim 40 \%$. Using the Ergun Equation, it can be calculated that holding all other numbers constant, this could nearly double the column pressure drop to achieve the same transport rates. Also, the increased porosity of the Rived adsorbents will allow for the use of smaller particles while still achieving the same pressure drop. This decrease of particle size will further enhance the mass transport.

In summary, a hypothetical SMB propane/propylene separation system was approximated as a True Countercurrent adsorption process using equilibrium theory to determine the steady state

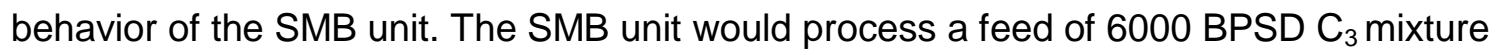
containing $70 \%$ propylene and $30 \%$ propane, which was further diluted in desorbent to a feed 
fraction of 0.25 . This calculation requires the relative equilibrium constants and feed compositions of propylene, propane, and desorbent (hexane, used in the experiments) to predict the complete separation of propane/propylene and the resulting purities of the SMB raffinate and extract streams. The equilibrium constant of the desorbent was assumed to be a value larger than that of either propane or propylene as it was not directly measured. The raffinate (containing propane and desorbent) and extract (containing propylene and desorbent) are subsequently separated in distillation units to obtain the pure products. ASPEN was used to model these separation units along with a heat recovery scheme, and the calculated energy duties were compared with the energy requirements of a conventional $\mathrm{C}_{3}$ splitter. The energy consumption of the SMB process also included the necessary additional pumping power required for all the additional fluid streams involved in the SMB process. The energy calculation was performed for cases using hexane, pentane, and iso-pentane as the desorbent. Two different pressures (200 and $265 \mathrm{psig}$ ) and two different feed concentrations to the SMB unit (25\% and $35 \%$ ) were also investigated for each different desorbent.

The results showed that the energy requirements of the propylene/propane separation can be reduced by $60-80 \%$ depending upon the choice of desorbent, operating conditions, and implementation of a proper heat recovery system. The utility cost savings were quantified in terms of amount of fuel burned and amount of electrical energy needed for fluid pumping. An additional benefit is that this reduction of energy usage directly relates to reduced $\mathrm{CO}_{2}$ emissions by the process. Future regulations may result in a cost penalty on $\mathrm{CO}_{2}$ emissions, and the SMB process would alleviate some of that burden.

The comparison of Rived and UnRived zeolites for $\mathrm{C}_{3}$ separation by an equilibrium based calculation does not give a true comparison of the advantages of the Rived zeolite as the enhanced transport through the Rived materials cannot be realized. It can be said that the equilibrium assumption is more likely to be true for the Rived material compared to the UnRived materials. The enhanced transport will lead to smaller adsorbent beds and more efficient utilization of adsorbent inventory. Smaller particles of Rived adsorbents can be used to further increase transport while maintaining a constant pressure drop due to the increased porosity of the Rived materials. It has been shown that use of an adsorption process for $\mathrm{C}_{3}$ separations has the potential to drastically reduce the energy consumption of production of polymer grade propylene. 


\section{Conclusions:}

1. The mesoporous zeolite $Y$ technology was successfully extended to $X$ and $A$ zeolites that are more relevant to adsorbent applications.

2. The zeolites (mesoporous and conventional) were formed into adsorbent particles and the particles maintain enhanced mesoporosity and external surface area.

3. Pulse testing established that the enhanced mesoporosity inside the mesoporous zeolite based adsorbents leads to much increased ( $>100 \%$ increase) overall mass transport rate for propane and propylene.

4. Energy saving calculation shows that for a hypothetical SMB propane/propylene separation plant using the mesoporous $\mathrm{NaX}$ zeolite based asorbents that process 6000 BPSD refinery grade propylene consumes $60-80 \%$ less energy, depending on the operation conditions, than a hypothetical C3 splitter operating at the same capacity. The energy saving also translates to a reduction of $30,000-35,000$ tons of $\mathrm{CO}_{2}$ emission per year. 


\section{Patents/Publications:}

Patent applications are current in preparation for filing.

\section{References:}

1) "Propylene Uses and Market Data." ICIS Chemical Business. April 2010. Web. 10 Oct. 2011. http://icis.com/v2/chemicals/9076455/propylene/uses.html

2) Grande, C.A., Rodrigues, A.E., "Propane/Propylene Separation by Pressure Swing Adsorption Using Zeolite 4A," Ind. Eng. Chem. Res., 2005, 44, pp. 8815-8829.

3) Rege, S.U., Yang, R.T., "Propane/Propylene Separation by Pressure Swing Adsorption: Sorbent Comparison and Multiplicity of Cyclic Steady States," Chem. Eng. Sci., 2002, 57, pp. 1139-1149.

4) Da Silva, F.A., Rodrigues, A.E., "Vacuum Swing Adsorption for Propylene/Propane Separation with 4A Zeolite Pellets," Ind. Eng. Chem. Res., 2001, 40, pp. 5758-5774.

5) Da Silva, F.A., Rodrigues, A.E., "Propylene/Propane Separation by VSA Using Commercial 13X Zeolite Pellets," AIChE J., 2001, 47, pp. 341-357.

6) Padin, J., Rege, S.U., Yang, R.T., Cheng, L.S., "Molecular Sieve Sorbents for Kinetic Separation of Propane/Propylene," Chem. Eng. Sci., 2000, 55, pp. 4525-4535.

7) Gomes, P.S., Lamia, N., Rodrigues, A.E., "Design of a Gas Phase Simulated Moving Bed for Propane/Propylene Separation," Chem. Eng. Sci., 2009, 64, pp. 1336-1357.

8) Da Silva, F.A., Rodrigues, A.E., "Adsorption Equilibria and Kinetics for Propylene and Propane over 13X and 4A Zeolite Pellets," Ind. Eng. Chem. Res., 1999, 38, pp. 2051-2057.

9) J. Y. Ying, J. García-Martínez, US Patent Application Publication No. US 2005/0239634 A1. Filed on Apr. 23, 2004.

10) J. García-Martínez, M. Johnson, US Patent Application 20080138274, 2008.

11) J. García-Martínez, M. Johnson, US Patent Application 20100021321, 2010.

12) L. Dight, J. García-Martínez, J. Valla, M. Johnson, US Patent Application 20100190632, 2010.

13) J. Garcia-Martinez, E. Senderov, B. Speronello, US Patent Application 61/473,588, filed on April 8, 2011.

14) deRosset, A. J., Neuzil, R. W., Korus, D. J. “Liquid Column Chromatography as Predictive Tool for Continuous Countercurrent Adsorptive Separations," 1976, 15(2), pp261-266.

15) Hinshaw, J.V., "Pinning Down Tailing Peaks," Sept.1 2009, Web. August 2011 http://chromatographonline.com.

16) Perry, R.H.; Green, D.W. (1997). Perry's Chemical Engineers' Handbook (7th Edition)... McGraw-Hill. Chapter 16.

17) Schneider, P., Smith, J.M., "Adsorption Rate Constants from Chromatography," AIChE J., 1968, 14, pp. 762-771.

18) Van Deemter, J.J., Zuiderweg, F.J., Klinkenberg, A., "Longitudinal Diffusion and Resistance to Mass Transfer as Causes of Nonideality in Chromatography," Chem. Eng. Sci., 1956, 5, pp. 271-289. 
19) Ruthven, D.M., "Fundamentals of Adsorption Equilibrium and Kinetics in Microporous Solids," Mol. Sieves, 2008, 7, pp. 1-43.

20) Sircar, S., Rao, M.B., "Heat of Adsorption of Pure Gas and Multicomponent Gas Mixtures on Microporous Adsorbents," Surfaces of Nanoparticles and Porous Materials; Eds. J.A. Schwarz, C.I. Contescu, Marcel Dekker, Inc.,: New York, 1999, Chapter 19, pp. 501-528.

21) Da Silva, F.A., Rodrigues, A.E., "Adsorption Equilibria and Kinetics for Propylene and Propane over 13X and 4A Zeolite Pellets," Ind. Eng. Chem. Res., 1999, 38, pp 2051-2057.

22) Loughlin, K.F., Hasanain, M.A., Abdul-Rehman, H.B., "Quaternary, Ternary, Binary, and Pure Component Sorption on Zeolites. 2. Light Alkanes on Linde 5A and 13X Zeolites at Moderate to High Pressures," Ind. Eng. Chem. Res., 1990, 29, 1535.

23) Sircar, S. "Recent Developments in Macroscopic Measurement of Multicomponent Gas Adsorption Equilibria, Kinetics, and Heats," Ind. Eng. Chem. Res., 2007, 46, pp. 2917-2927.

24) Ruthven, D.M., Ching, C.B., "Counter-Current and Simulated Counter-Current Adsorption Separation Processes," Chem. Eng. Sci., 1989, 44, pp. 1011-1038.

25) Storti, G., Mazzotti, M., Morbidelli, M., Carra, S., "Robust Design of Binary Countercurrent Adsorption Separation Processes," AIChE J., 1993, 39, pp. 471-492.

26) Mazzotti, M., Storti, G., Morbidelli, M., "Robust Design of Countercurrent Adsorption Separation Processes: 4 Desorbent in the Feed," AIChE J., 1997, 43, pp. 64-72.

27) Chiang, A., Equilibrium Theory for Simulated Moving Bed Adsorption Processes," 1998, 44, pp. 2431-2441.

28) Storti, G., Masi, M, Carra, S., "Optimal Design of Multicomponent Countercurrent Adsorption Separation Processes Involving Nonlinear Equilibria," Chem Eng Sci, 1989, 44, pp 13291345.

29) Mazzotti, M., "Equilibrium Theory Based Design of Simulated Moving Bed Processes for a Generalized Langmuir Isotherm," J. Chromatography A, 2006, 1126, pp. 311-322.

30) Data obtained from http://eia.gov.

31) Ergun, S., Chem Eng. Progress, 1952, 48.

32) Glueckauf, E., "Theory of Chromatography 10: Formula for Diffusion into Spheres and their Application in Chromatography," Trans. Faraday Soc., 1955, 51, pp. 1540-1551. 


\section{Appendix:}

Front-end energy consumption simulation by Adsortech, Inc., NJ

1. Study procedure

(i) Develop a design basis to benchmark a typical $\mathrm{C} 3 / \mathrm{C} 3=$ splitter column in a Refinery or Petrochemical complex. The design basis defines typical feed flowrate, pressure, temperature and composition.

(ii) Use the above design basis to simulate a conventional $\mathrm{C} 3 / \mathrm{C} 3=$ column using a commercial process simulator and prior experience designing such a system.

(iii) Make assumptions about the performance of the Propane-Propylene Adsorption system and use the process simulator to design the desorbent/propane and desorbent/propylene distillation columns.

(iv) Compare the energy consumption of the conventional system from step 2 with newly designed separation system in step 3.

(v) Tabulate the assumptions and create objectives to be determined experimentally by research team creating the molecular sieve material.

Key assumptions made for the study

(i) The $\mathrm{C} 3 / \mathrm{C} 3=$ separation system is fed a mixture of 70:30 (wt. basis) of Propylene and Propane at 265 psig and $97 \mathrm{deg} F$. The flow rate of this stream is 6000 bpsd (50000 bpsd FCC unit).

(ii) The product propylene must have polymer grade purity of $99.5 \% \mathrm{wt}$. basis.

(iii) The $\mathrm{C} 3 / \mathrm{C} 3=$ adsorption system splits the feed stream with a $100 \%$ recovery of propane and propylene components in Raffinate and Extract streams respectively.

(iv) The desorbent liquid used in the adsorbent is recycled from both the Raffinate and Extract distillation columns and along with some make up desorbent is fed into $\mathrm{C} 3 / \mathrm{C} 3=$ adsorption system in a feed to volume ratio of 2:1 (Desorbent : Feed).

(v) A small amount of desorbent used in the process is lost with Propane and Propylene product streams from Raffinate and Extract distillation units.

(vi) The desorbent used for the study is 1-Hexene.

(vii) The desorbent is split in the same weight ratio with the propane and propylene stream as present in the feed downstream of the Adsorption system. (i.e. $70 \%$ wt of desorbent mixing with propylene to form Extract stream and balance with propane stream to form Raffinate). 
(viii) Low pressure (LP) and medium pressure (MP) steam are available from Reboiler duty at 65 psig and 210 psig, with 30 deg $F$ superheat.

(ix) The cooling water is used in the distillation towers with 15 deg $F$ temperature swing. (Supply at $77 \mathrm{deg} F$ and Return at $92 \mathrm{deg}$ F.)

(x) Pumping energy of various streams in the above processes consumes some energy and has been neglected in this study.

(xi) In addition to the above, reasonable pressure losses, exchanger temperature approaches, thermodynamic model choices etc were also made in the study but are not listed separately.

2. Tabulated summary results of the study simulations

Table 1: Major utility consumptions per pound of propylene product

\begin{tabular}{|l|l|l|l|l|}
\hline $\begin{array}{l}\text { Process } \\
\text { scheme }\end{array}$ & $\begin{array}{l}\text { Reboiler Duty } \\
\text { Btu/lb of C3= } \\
\text { product }\end{array}$ & $\begin{array}{l}\text { Condenser } \\
\text { Duty Btu/lb of } \\
\text { C3= product }\end{array}$ & $\begin{array}{l}\text { Steam usage } \\
\text { Ib/lb of C3= } \\
\text { product }\end{array}$ & $\begin{array}{l}\text { Cooling water } \\
\text { US gal/lb of C3= } \\
\text { product }\end{array}$ \\
\hline $\begin{array}{l}\text { Conventional } \\
\text { C3/C3= } \\
\text { distillation } \\
\text { process }\end{array}$ & 2790 & 2774 & 2.98 & 22.27 \\
(LP Steam) \\
$\begin{array}{l}\text { Idealized } \\
\text { Adsorption } \\
\text { separation } \\
\text { process }\end{array}$
\end{tabular}

Table 2: Energy saving projected to entire FCC feed stream in US (DOE database)

\begin{tabular}{|l|l|l|l|}
\hline Year & $\begin{array}{l}\text { FCC feed Stream } \\
\text { average (Thousand } \\
\text { Barrel per day) }\end{array}$ & $\begin{array}{l}\text { Reboiler Energy } \\
\text { saving Billion } \\
\text { Btu/year @ 8500 } \\
\text { stream hours per } \\
\text { year }\end{array}$ & $\begin{array}{l}\text { CO }_{2} \text { Emissions } \\
\text { equivalent } \\
\text { Burning of barrels of } \\
\text { oil per day }\end{array}$ \\
\hline 2007 & 5250 & 60145 & 19160 \\
\hline 2008 & 4983 & 57087 & 18186 \\
\hline 2009 & 4957 & 56788 & 18091 \\
\hline
\end{tabular}

Source: http://tonto.eia.doe.gov/dnav/pet/hist/LeafHandler.ashx? $n=P E T \& s=M C R C C U S 2 \& f=A$ 
Table 3: Major Equipment sizes for 6000 bpsd C3/C3=separation duty

\begin{tabular}{|c|c|c|c|c|}
\hline $\begin{array}{l}\text { Process } \\
\text { scheme }\end{array}$ & Column sizes & $\begin{array}{l}\text { Duty for major } \\
\text { exchangers } \\
\text { (includes } \\
\text { design } \\
\text { margins) } \\
\text { MMBtu/hr }\end{array}$ & $\begin{array}{l}\text { Cooling water } \\
\text { and steam } \\
\text { consumptions }\end{array}$ & $\begin{array}{l}\text { Rough order of } \\
\text { magnitude cost } \\
\text { Million USD }\end{array}$ \\
\hline $\begin{array}{l}\text { Conventional } \\
\text { C3/C3= } \\
\text { distillation } \\
\text { process }\end{array}$ & $\begin{array}{l}16 \text { ' diameter X } \\
300 \mathrm{ft} \text { tall, } 220 \\
\text { trays } \\
\text { Double column } \\
\text { system }\end{array}$ & 220 & $\begin{array}{l}48 \text { tph LP Steam } \\
11850 \mathrm{gpm} \mathrm{CW}\end{array}$ & $55-65$ \\
\hline $\begin{array}{l}\text { Idealized } \\
\text { C3/C3= } \\
\text { Adsorption } \\
\text { separation } \\
\text { process }\end{array}$ & $\begin{array}{l}\text { 4' diameter } X 30 \\
\mathrm{ft} \text { tall }(16 \text { trays })+ \\
6 \text { ' diameter } \times 30 \\
\mathrm{ft} \text { tall ( } 16 \text { trays) }\end{array}$ & 40 & $\begin{array}{l}13 \text { tph MP } \\
\text { Steam } \\
2900 \text { gpm CW }\end{array}$ & $\begin{array}{l}10-15 \\
\text { (Excluding } \\
\text { Adsorption } \\
\text { system) }\end{array}$ \\
\hline
\end{tabular}


3. Process schematics

(1) CONVENTIONAL C3/C3= DISTILLATION COLUMN

PROPAHE PROPYLEHE SPLITTER SEPARATIOH SCHEME

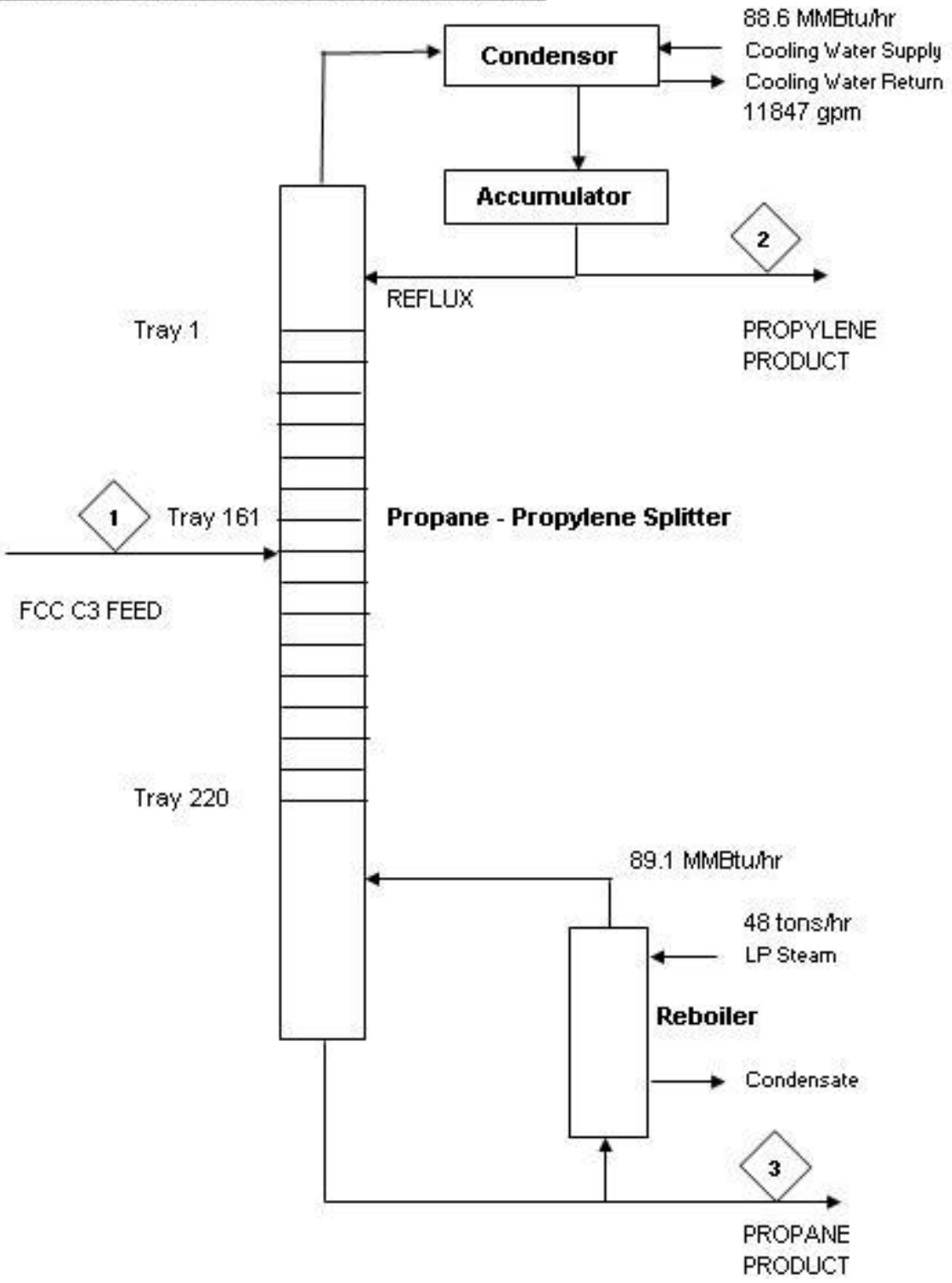


(2) ADSORPTION BASED C3/C3= SEPARATION PROCESS

\section{PFD 1: ADSORPTION SYSTEM}

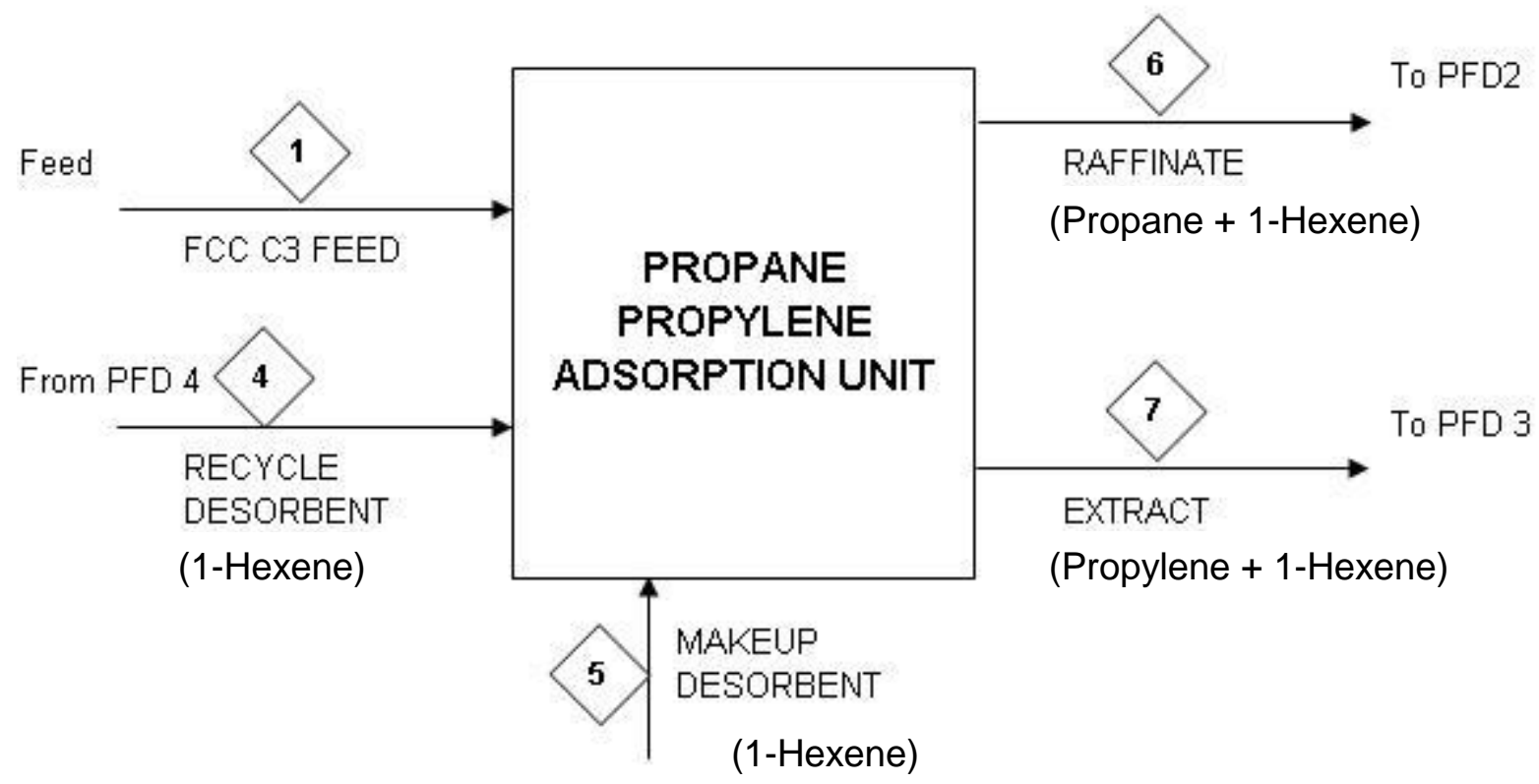

\section{PFD 2: RAFFINATE COLUMN}

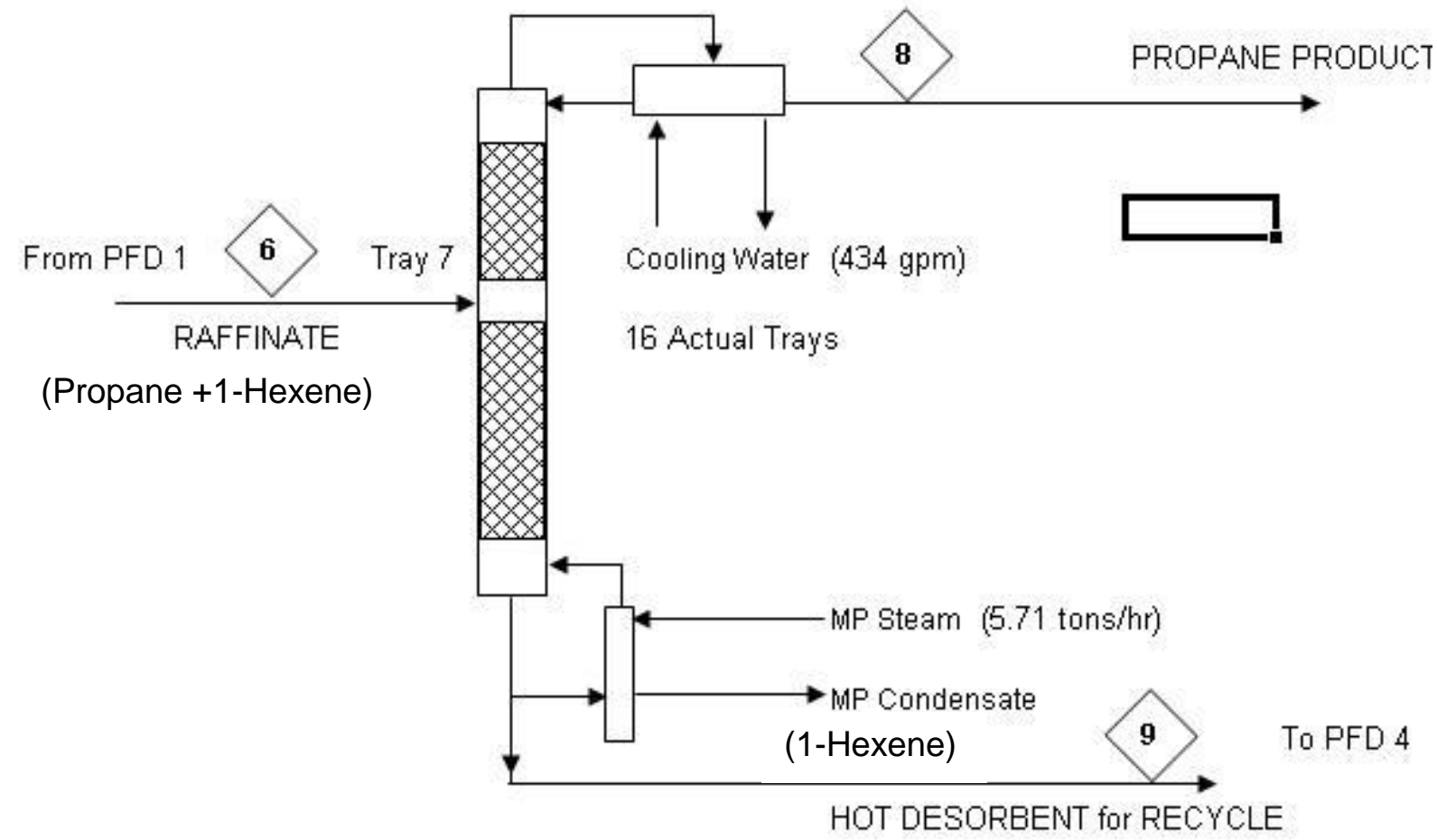




\section{PFD 3: EXTRACT COLUMN}

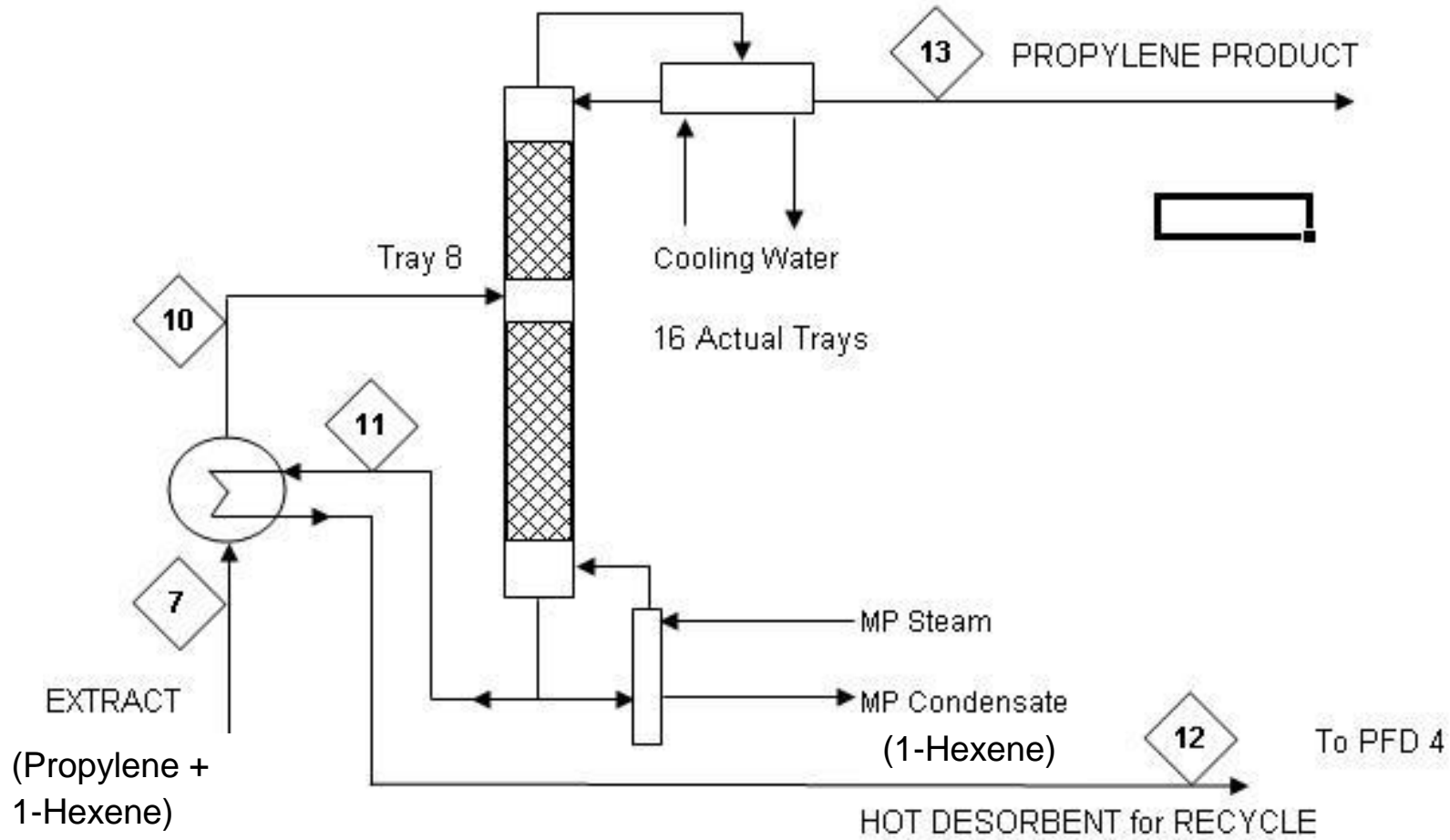

PFD 4: DESORBENT COOLING \& RECYCLE PUMP

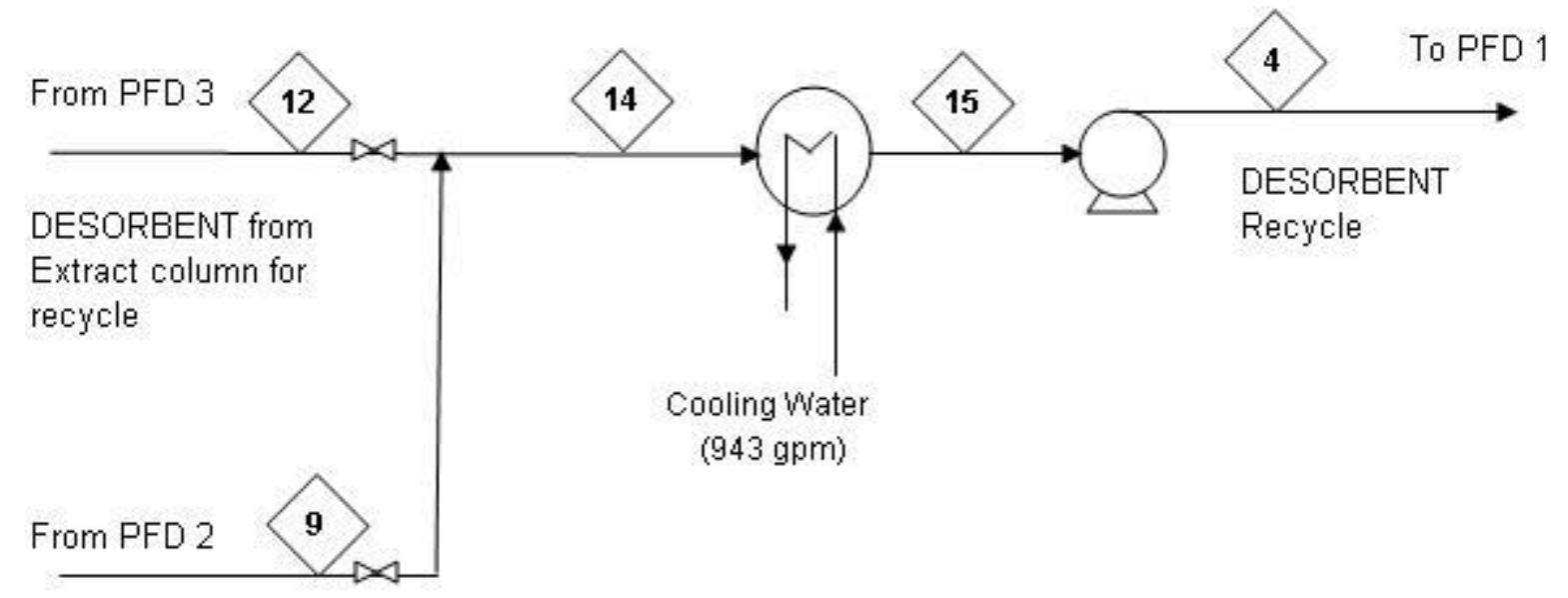

HOT DESORBENT from Raffinate column for recycle 
4. Suggested experimental work for getting a better estimate of process design and energy estimates

(i) The optimum desorbent type needs to be determined. The study suggests that in order to use lower temperature in the Raffinate and Extract columns it may be advisable to use a lower boiling point molecule or mixture of molecules. Such as C5 or C5 in mixture with c6.

(ii) The actual ratio of adsorbent carryover to the Raffinate and Extract columns needs to be determined. This ratio has been assumed to be in the same proportion as the ratio of $\mathrm{C} 3$ and $\mathrm{C} 3=$ in the feed.

(iii) The assumption that $100 \%$ propane and propylene are recovered in the adsorption process is ideal. The actual carryover needs to be estimated or experimentally determined.

(iv) Based on the input from the experiments with data for diffusion and other adsorption parameters a better design estimate and process cycle for the adsorption system needs to be determined. This cycle and design can give a better cost estimate and the energy estimate for the process.

(v) The simulation done is very preliminary and the process to distill Raffinate and Extract can be further optimized with significant energy savings if studied in more detail. 